\title{
Anatomical pathways involved in generating and sensing rhythmic whisker movements
}

\author{
Laurens W. J. Bosman ${ }^{1,2}$, Arthur R. Houweling ${ }^{1}$, Cullen B. Owens ${ }^{1}$, Nouk Tanke ${ }^{1}$, Olesya T. Shevchouk ${ }^{1}$, \\ Negah Rahmati ${ }^{1}$, Wouter H. T. Teunissen ${ }^{1}$, Chiheng Ju ${ }^{1}$, Wei Gong ${ }^{1}$, Sebastiaan K. E. Koekkoek ${ }^{1}$ and \\ Chris I. De Zeeuw ${ }^{1,2 *}$
}

Department of Neuroscience, Erasmus MC, Rotterdam, Netherlands

${ }^{2}$ Netherlands Institute for Neuroscience, Royal Academy of Arts and Sciences, Amsterdam, Netherlands

\section{Edited by:}

Agnes Gruart, University Pablo de

Olavide Seville, Spain

Reviewed by:

Michael Brecht, Humboldt University

Berlin, Germany

Josè M. Delgado-García, University

Pablo de Olavide Seville, Spain

*Correspondence:

Chris I. De Zeeuw, Department of Neuroscience, Erasmus MC, PO Box 2040, 3000 CA Rotterdam,

Netherlands.

e-mail: c.dezeeuw@erasmusmc.nl
The rodent whisker system is widely used as a model system for investigating sensorimotor integration, neural mechanisms of complex cognitive tasks, neural development, and robotics. The whisker pathways to the barrel cortex have received considerable attention. However, many subcortical structures are paramount to the whisker system. They contribute to important processes, like filtering out salient features, integration with other senses, and adaptation of the whisker system to the general behavioral state of the animal. We present here an overview of the brain regions and their connections involved in the whisker system. We do not only describe the anatomy and functional roles of the cerebral cortex, but also those of subcortical structures like the striatum, superior colliculus, cerebellum, pontomedullary reticular formation, zona incerta, and anterior pretectal nucleus as well as those of level setting systems like the cholinergic, histaminergic, serotonergic, and noradrenergic pathways. We conclude by discussing how these brain regions may affect each other and how they together may control the precise timing of whisker movements and coordinate whisker perception.

Keywords: vibrissa, follicle-sinus complex, barrel cortex, basal ganglia, cerebellum, sensorimotor integration, rhythmic movements, anatomy

\section{INTRODUCTION}

Rodents have highly mobile whiskers, with which they can rapidly locate and discriminate objects in their environment. The rodent whisker system has become a popular model system for brain development, experience-dependent plasticity, perceptual learning, repetitive, timed motor responses, sensorimotor integration, and robotics. Of the many brain regions involved in the whisker system, the trigeminal brainstem, thalamus and primary somatosensory cortex (S1), and to a lesser extent the whisker motor cortex (wM1), have attracted most attention (for reviews see Kleinfeld et al., 1999; Deschênes et al., 2005; Brecht, 2007; Petersen, 2007; Alloway, 2008; Diamond et al., 2008). Other brain regions and the structures of the whisker pad itself have received less attention. Here we aim to integrate the current knowledge on subcortical structures into the well-known whisker pathways, thus presenting an overview of the most important structures of the whisker system and their interconnections as a whole. In addition, we discuss how these structures may cooperate to generate and sense whisker movements.

Tactile hairs are specialized hairs that, due to the presence of sensitive mechanoreceptors at their follicles, provide accurate somatosensory input. Tactile hairs which grow from a follicle-sinus complex (FSC) are called "vibrissae" or "whiskers." Almost all mammals, except humans and egg-laying mammals (monotremes), have vibrissae (Chernova, 2006; Muchlinski, 2010). Vibrissae can grow from all body parts, but are mainly located on the face (Sarko et al., 2011). Most likely, all vibrissae can be moved, but there is a large variability in movement mechanics. Some vibrissae, like the genal vibrissae in the hamster, lack musculature and are moved solely by vascular and connective tissue dynamics (Wineski, 1985). Other vibrissae can be moved by muscles involved in the erection of hairs (m. arrector pili; Hyvärinen et al., 2009), while mystacial vibrissae can be moved by a group of specialized muscles (Brecht et al., 1997; Haidarliu et al., 2010; Sarko et al., 2011). In some species, including shrews (Munz et al., 2010) and rodents such as rats, mice, gerbils, hamsters, chinchillas, and porcupines (Woolsey et al., 1975), the mystacial vibrissae can move fast and rhythmically (Figure 1A). This behavior is called "whisking," and in accordance we reserve the term "whiskers" here for those vibrissae that can be whisked. Whisking behavior is absent in most species, including well-studied species like rabbits, cats, and seals (Woolsey et al., 1975; Dehnhardt and Kaminski, 1995). The main function of vibrissae is to complement or replace nearvision (Welker, 1964; Gogan et al., 1981; Ahl, 1986). In addition, marine mammals use their vibrissae for long-distance sensing. For instance, a seal may "feel" prey fish at more than $180 \mathrm{~m}$ distance (Dehnhardt et al., 2001). Vibrissae also help to locate, identify, and capture prey (Anjum et al., 2006; Munz et al., 2010; Favaro et al., 2011). In addition, vibrissae inform about body posture, especially in water (Ahl, 1982), and play a central role in social behavior (Miller, 1975; Blanchard et al., 1977).

Well-timed, rhythmic whisker movements are instrumental in exploring the environment (Carvell and Simons, 1990; Grant et al., 2009; Hartmann, 2011). When doing so, rats make large whisker 
movements at a relatively low frequency $(5-15 \mathrm{~Hz})$. Once their interest has been caught, they can thrust their whiskers forward and make smaller movements at higher frequencies $(15-25 \mathrm{~Hz})$ to identify objects and textures (Carvell and Simons, 1995; Harvey et al., 2001; Berg and Kleinfeld, 2003a). Small variations in surface texture may halt the whisker tip for a short while, after which it slips past the fine obstruction (Figure 1B; Neimark et al., 2003; Ritt et al., 2008; Wolfe et al., 2008). Such “slip-stick" movements can trigger stereotypical neuronal responses allowing the animal to sense subtle features of surfaces (Figure 1C; Jadhav et al., 2009). The combination of rhythmic movements and precisely timed sensory input thus greatly increases the acuity of whisker input.

\section{WHISKERS}

\section{THE WHISKER PAD}

The organization of the whiskers on the mystacial pad varies greatly between different species, but is relatively similar between rats and mice (Woolsey et al., 1975; Brecht et al., 1997). Rats and mice have five rows of whiskers. The upper two rows (AB) have four whiskers each, while the lower three rows (C-E) each contain about seven whiskers. In addition, there are four

A
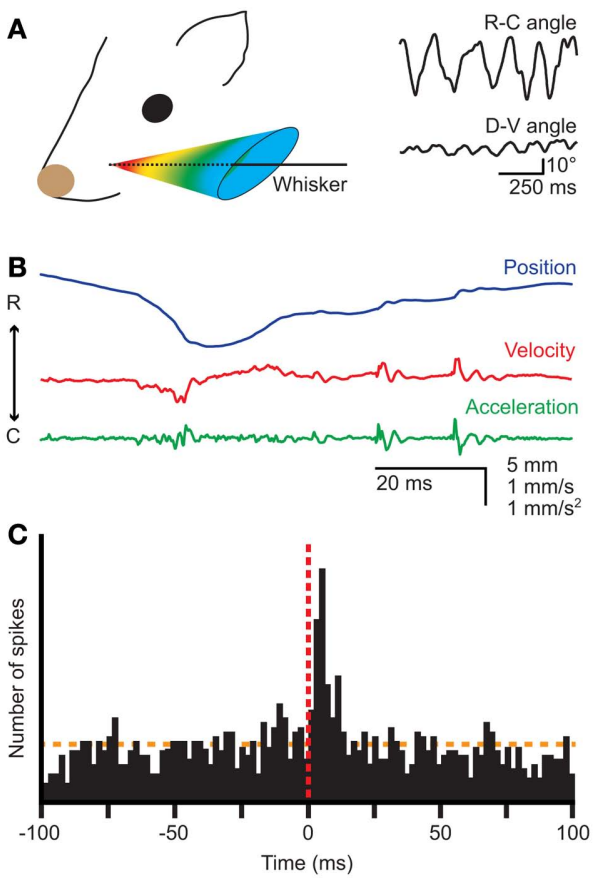

FIGURE 1 |Whisker movements. (A) Whiskers move rhythmically back-and-forth during exploratory whisking in the rat. The deflection along the rostro-caudal axis is much larger than that on the dorso-ventral axis. The left panel is a schematic drawing of the space in which a whisker can be moved, based on Bermejo et al. (2002). The right panels are reproduced with permission from Hill et al. (2008). (B) Position, velocity, and acceleration of a rat D3 whisker during one whisking cycle on P150 sandpaper. Irregularities in the sandpaper surface cause "slip-stick" movements. Reproduced with permission from Wolfe et al. (2008). (C) Slips can trigger neuronal responses in rat wS1, as shown by a peri-stimulus time histogram of the spike times of a single neuron aligned on the first slips of whisker movements. Reproduced with permission from Jadhav et al. (2009). particularly large whiskers ("straddlers"), labeled $\alpha-\delta$, at the caudal edge of the mystacial pad (Figure 2A). The muscles of the mystacial pad are divided into extrinsic and intrinsic muscles, all of which are innervated by specific branches of the facial nerve (Figure 2A; Dörfl, 1985). The intrinsic muscles are completely situated within the mystacial pad, while the extrinsic muscles have their origins outside the mystacial region (Dörfl, 1982; Jin et al., 2004; Haidarliu et al., 2010). During a normal, exploratory whisking cycle, the whiskers first protract and then retract. Whisker protraction is initiated by contraction of the medial inferior and medial superior parts of the extrinsic muscle m. nasolabialis profundus and completed by contraction of the intrinsic capsular muscles. Subsequent whisker retraction is under control of two extrinsic muscles, the $\mathrm{m}$. nasolabialis and the $\mathrm{m}$. maxillolabialis (Figures 2A,B; Berg and Kleinfeld, 2003a; Hill et al., 2008; Simony et al., 2010). Whisker retraction during foveal whisking is a relatively passive process, involving virtually no muscle activity; during foveal whisking the vibrissae are thrust forward and palpate objects with low-amplitude movements at high frequency (Berg and Kleinfeld, 2003a). Rodents can also move the whole mystacial pad. Pad movements may contribute to the normal whisking cycle (Bermejo et al., 2005), but can also involve rotation or resizing of the whisker pad to optimize object contact (Haidarliu et al., 2010; Towal et al., 2011). For instance, contraction of $\mathrm{m}$. nasolabialis superficialis moves the $\mathrm{A}$ and $\mathrm{B}$ rows dorsally, and contraction of $\mathrm{m}$. buccinatorius pars orbicularis oris moves the C-E rows ventrally, thereby adjusting the mystacial field size (Haidarliu et al., 2010). Although the general structure of the mystacial pad is similar in mice (Dörfl, 1982), hamsters (Wineski, 1985), and rats (Haidarliu et al., 2010), minor differences between species do occur, mainly in the organization of the $\mathrm{m}$. nasolabialis profundus (cf Haidarliu et al., 2010).

\section{FOLLICLE-SINUS COMPLEXES}

Vibrissae differ from other (pelagic) hairs in that each of their (epidermal) follicles is surrounded by a (dermal) blood sinus, which in most species is composed of a distal ring sinus and a proximal cavernous sinus (Figures 2B,C; Szymonowicz, 1895; Ebara et al., 2002; Kim et al., 2011). It has been suggested that animals can modulate the dynamic range of the vibrissal mechanoreceptors by changing the blood pressure in the blood sinus (Vincent, 1913; Nilsson, 1969; Gottschaldt et al., 1973). In addition, the size of the FSC seems to be adapted for the behavior and environment of the animals. In general, the largest FSCs are found in marine mammals, intermediate FSCs in semi-aquatic species, like otters and water rats, and the smallest FSCs in purely terrestrial mammals (Dehnhardt et al., 1999; Hyvärinen et al., 2009). Larger FSCs make the vibrissal movements more resistant to water, which has a much higher density than air, and allows better thermal insulation of mechanoreceptors to cold or warm water (Dehnhardt et al., 1998, 1999). The larger size of the FSCs of marine mammals is due to the presence of a second, external cavernous sinus (Figure 2C; Sarko et al., 2007; Hyvärinen et al., 2009). In species where the vibrissal system is relatively unimportant, such as marsupials and primates, the FSCs lack a ring sinus (Van Horn, 1970; Hollis and Lyne, 1974; Marotte et al., 1992). Thus, the adaptations in the FSC-anatomy are in line with specific behavioral requirements. 

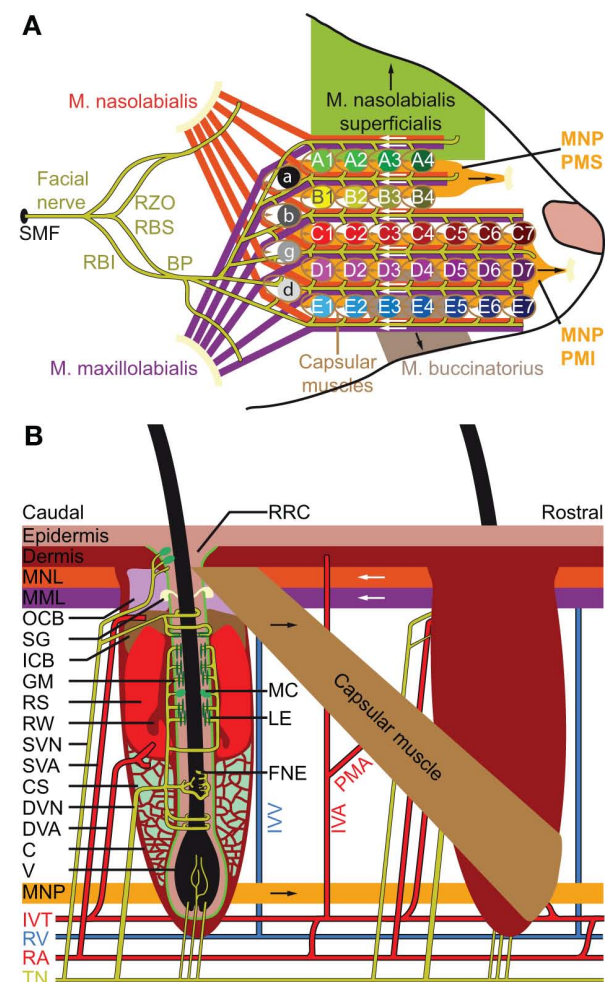

C Wallaby Monkey Rat Water rat Sea cow Seal

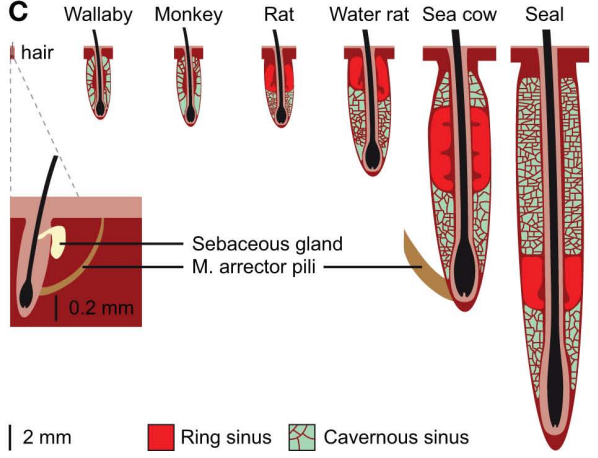

FIGURE 2 | Location and structure of the whiskers. (A) The whiskers are organized in rows on the mystacial pad. Mice and rats have five rows of whiskers, as well as four "straddlers" caudal to these rows. Each whisker is associated with an intrinsic capsular muscle [see also (B)]. Extrinsic muscles connect to multiple whiskers. The $\mathrm{m}$. nasolabialis profundis (MNP) consists of two parts, the mediosuperior (PMS) and the medioinferior (PMI) parts, both of which are involved in whisker protraction. The $\mathrm{m}$. nasolabialis and $\mathrm{m}$. maxillolabialis are involved in whisker retraction. The other extrinsic whiskers, including the $\mathrm{m}$. nasolabialis superficialis and the $\mathrm{m}$. buccinatorius, are involved in resizing the entire mystacial pad. The mystacial muscles are almost exclusively innervated by the facial nerve, which leaves the skull via the stylomastoid foramen (SMF). After leaving the SMF, the facial nerve splits up in two streams. The lower stream consists of the rami buccolabialis superior (RBS) and inferior (RBI), which anastomose in the buccal plexus (BP). From the BP all extrinsic and intrinsic whisker muscles are innervated, with the exception of $\mathrm{m}$. nasolabialis, which is innervated by the upper stream, which includes the ramus zygomatico-orbitalis (RZO). (B) Schematic drawing of the follicle-sinus complex (FSC) of the rat. The vibrissa (V) lies within a follicle that is derived from the epidermis and that is surrounded by the glassy membrane (GM). Around the follicle is a blood sinus derived from the dermis, and which is

\section{FIGURE 2 | Continued}

composed of two sinuses: the cavernous sinus (CS), which has numerous collagenous trabeculae, and the ring sinus (RS), which is an open structure. At the bottom of the ring sinus, there is an asymmetric structure of connective tissue: the ringwulst (RW). At the distal end of the ring sinus, the inner conical body (ICB) links the follicle strongly to the capsule (C). Distal to the ICB is the outer conical body (OCB) that contains the sebaceous gland (SG). Intrinsic capsular muscles connect pairs of FSCs. Extrinsic muscles are located just below the skin (m. nasolabialis, MNL and $m$. maxillolabialis, MML), or at the lower end of the FSC (m. nasolabialis profundus, MNP). The arrows indicate whether contraction of the muscle causes pro- or retraction of the vibrissae. The vibrissae are surrounded by three different types of mechanoreceptors: Merkel cells (MC), lanceolate endings (LE), and free nerve endings (FNE). Mechanoreceptors in the upper part of the FSC are innervated by superficial vibrissal nerves (SVN) and those in the lower part by the deep vibrissal nerve (DVN). In addition, there are some small-caliber fibers at the bottom. The sensory fibers come together with fibers from other parts of the face to form the infraorbital branch of the trigeminal nerve (TN). Blood supply to the FSCs is organized via row arteries (RA) located between the whisker rows, with superficial vibrissal arteries (SVA) supplying the upper parts and deep vibrissal arteries (DVA) the lower parts of the FSCs. The DVA does not directly branch from a RA, but from the anastomozing intervibrissal trunks (IVT). In between the FSCs are intervibrissal arteries (IVA) that supply the skin and hair follicles. The capsular muscles receive their blood from arterioles (PMA) branching from the IVA and directly from the IVT. Venal drainage is organized by intervibrissal veins (IVV) that empty in row veins (RV). (C) Schematic drawings of the follicle of a typical mammalian body hair (left) and of the structure of the blood sinuses of FSCs in different species. A hair follicle lacks a blood sinus and can be moved by contraction of the $\mathrm{m}$. arrector pili. In marsupials and primates, the blood sinus is composed of a single compartment (the cavernous sinus), as illustrated for the tammar wallaby (Macropus eugenii; Marotte et al., 1992) and the rhesus monkey Nan Horn, 1970). Most species, however, have two sinuses: the ring sinus and the cavernous sinus, as illustrated for the rat (Rattus sp.; Ebara et al., 2002) and the Australian water rat (Hydromys chrysogaster; Dehnhardt et al., 1999). Pinnipeds have tricompartite blood sinuses, including an outer cavernous sinus, as illustrated for a sea cow, the Florida manatee (Trichechus manatus latirostris; Reep et al., 2001), and the ringed seal (Phoca hispida; Hyvärinen et al., 2009). Non-whisking species can generally move their vibrissae using $\mathrm{m}$. arrector pili muscles, as indicated for the FSC of the sea cow.

Cavernous sinuses contain trabeculae of connective tissue, with the spaces in between filled with blood and nerve fibers (Rice, 1993; Hyvärinen et al., 2009; Kim et al., 2011). The ring sinus is an open structure, lacking trabeculae. At the bottom of the ring sinus, most species have an asymmetric, collagenous appendix: the ringwulst. Most likely, the rigid ringwulst transmits vibrations to the soft ring sinus with which it is associated (Stephens et al., 1973), while the ring sinus probably acts to dampen these vibrations (Yohro, 1977). This would imply that the anatomy of the blood sinus, including that of the ringwulst, determines the sensitivity range, which can be fine-tuned by modulating the pressure of the blood sinus. In conclusion, specific adaptations to environmental conditions and behavioral requirements, may have led to variations in the anatomy of the FSC. Such diversity can also be observed between FSCs at various body regions of a single animal. In the Florida manatee, for instance, the facial FSCs are substantially larger and more complex than those at other body regions (Sarko et al., 2007), consistent with the prominent role of facial vibrissae during feeding (Reep et al., 2001). 


\section{TRANSDUCTION OF SENSORY INPUT TRIGEMINAL NERVE \\ Mechanoreceptors}

Vibrissal vibrations are detected by several types of mechanoreceptors with different functional properties. Each FSC is innervated by several small superficial vibrissal nerves (SVN), a single, large deep vibrissal nerve (DVN) containing 100-200 fibers (Rice et al., 1986), as well as a number of unmyelinated fibers at the base of the FSC (Figure 2B). The SVN and the DVN contain mainly A $\beta$ and A $\delta$ fibers. Thickly myelinated $A \beta$ fibers have Merkel cell endings, which are slowly adapting (SA) mechanoreceptors, or lanceolate endings, which are rapidly adapting (RA). Hence, Merkel cell endings will primarily signal ongoing movements, while lanceolate endings will predominantly detect unexpected movements (Gottschaldt et al., 1973; Halata et al., 2010; Lumpkin et al., 2010). Merkel cells are located within the epidermis at two regions: at the rete ridge collar and at the level of the ring sinus (Ebara et al., 2002). Remarkably, in the mystacial FSCs of rats, the Merkel cells at the rete ridge collar are almost exclusively found at the caudal site of the FSC, implying that they predominantly transmit backward deflections (Fundin et al., 1994; Ebara et al., 2002). Circumferentially oriented lanceolate endings are mainly located at the level of the inner conical body, while longitudinally oriented lanceolate endings are mostly restricted to the level of the ring sinus (Ebara et al., 2002). The thinly myelinated A $\delta$ fibers supply a highly heterogeneous group of other endings, including spindlelike, club-like, reticular, spiny, and encapsulated endings. These endings are dispersed through the epidermal sheet of the FSC, but enriched at the level of the cavernous sinus (Ebara et al., 2002; Sarko et al., 2007). The specific functions of these mechanoreceptors are presently unclear. At the base of the FSC are unmyelinated C fibers (Ebara et al., 2002). Since C fibers predominantly conduct nociceptive stimuli, they could signal pulling of the vibrissae.

\section{Trigeminal ganglion}

The cell bodies of the trigeminal nerve fibers are located either in the trigeminal ganglion or in the mesencephalic nucleus (see Trigeminal Mesencephalic Nucleus). As a rule, each neuron in the trigeminal ganglion receives input only from a single vibrissa (Kerr and Lysak, 1964; Zucker and Welker, 1969; Lichtenstein et al., 1990). However, neurons receiving input from very small vibrissae may be connected to two or three individual vibrissae (Kerr and Lysak, 1964). In addition, very large deflections of a single vibrissa can cause deformation of the skin, and in that way also activate mechanoreceptors of adjacent FSCs (Simons, 1985). The receptive fields of the trigeminal ganglion are loosely arranged in a somatotopic fashion, with the caudal part of the face projecting to the dorsal part of the ganglion, and the rostral part of the face to the ventral part of the ganglion. The whisker projections follow this general pattern (Erzurumlu and Killackey, 1983; Leiser and Moxon, 2006). Originally, it was reported that dorsal vibrissae are represented medially and ventral vibrissae laterally within the trigeminal ganglion (Zucker and Welker, 1969), but Leiser and Moxon (2006) could not reproduce this medio-lateral patterning.

During rest, when the vibrissae are neither moving nor being touched, the neurons of the trigeminal ganglion are silent (Gibson and Welker, 1983; Lichtenstein et al., 1990; Leiser and Moxon,
2007). Based on their response pattern to vibrissal movement, the majority of trigeminal ganglion neurons are classified as SA, while the others are RA (Fitzgerald, 1940; Kerr and Lysak, 1964; Lichtenstein et al., 1990; Leiser and Moxon, 2007). During whisking in air, SA neurons fire about three times as often as RA neurons (Leiser and Moxon, 2007). Upon touching an object, both SA and RA neurons increase their firing rate. Both types of neurons reach similar firing rates upon whisker touching (Jones et al., 2004; Leiser and Moxon, 2007). Overall, trigeminal ganglion neurons have a broad range of activation thresholds that vary mainly in amplitude and speed, but also in direction of whisker movement (Arabzadeh et al., 2005; Leiser and Moxon, 2007; Khatri et al., 2009; Gerdjikov et al., 2010). Most trigeminal ganglion neurons receive whisker sensory input via the DVN rather than the SVN, but the information content of both types of fibers seems to be very similar (Waite and Jacquin, 1992).

\section{Trigeminal mesencephalic nucleus}

A subset of trigeminal nerve fibers does not have their somata in the trigeminal ganglion, but in the trigeminal mesencephalic nucleus $(\mathrm{MeV})$. Thus, $\mathrm{MeV}$ houses primary sensory neurons within the CNS, which makes it a unique structure. MeV neurons mainly innervate muscle spindles in the masticatory and extraocular muscles and are thus involved in proprioception. In addition, several other types of receptors in the dental, oral, and peri-oral domain are innervated by $\mathrm{MeV}$ neurons (Lazarov, 2002). Although whisker muscles lack spindles, $\mathrm{MeV}$ contains neurons that innervate the mystacial pad and that respond to spontaneous whisker movements (Mameli et al., 2010). MeV projects to, among others, the dorsomedial part of the principal trigeminal nucleus, the pontomedullary reticular formation (RF), and the superior colliculus (SC; Matesz, 1981; Ndiaye et al., 2000).

\section{SENSORY TRIGEMINAL NUCLEI}

The sensory trigeminal nuclei form the main entrance to the brain for whisker input. The principal trigeminal nucleus (PrV) lies anterior to the spinal trigeminal nucleus $(\mathrm{SpV})$, which consists of an oral (SpVo), an interpolar (SpVi), and a caudal part (SpVc; Figure 3A). Afferent fibers of the trigeminal root bifurcate to form a rostral branch ascending to $\operatorname{PrV}$ and a caudal branch descending to SpV (Hayashi, 1980). Of the individual fibers, some target only PrV or SpV, while others bifurcate and innervate both. Afferents to SpV can terminate in all three subregions (Hayashi, 1980). All compartments, except SpVo and the rostral part of SpVi, have barrelettes, discrete groups of neurons that receive input from the same vibrissa and that can be visualized by cytochrome oxidase staining (Figure 3B; Belford and Killackey, 1979; Ma, 1991; Li et al., 1994; Erzurumlu et al., 2010). Neurons in the barrelettes are relatively small and their dendritic trees are confined within the borders of the barrelette (Veinante and Deschênes, 1999). Roughly one-third of the neurons dedicated to whisker input are located between the barrelettes. These interbarrelette cells have widespread dendritic trees and receive input from multiple vibrissae, mainly located within a single row on the mystacial pad (Veinante and Deschênes, 1999). The barrelettes are organized according to an inverted somatotopy, with dorsal whiskers having a ventral representation and rostral whiskers a medial one (Ma, 1991; Erzurumlu 


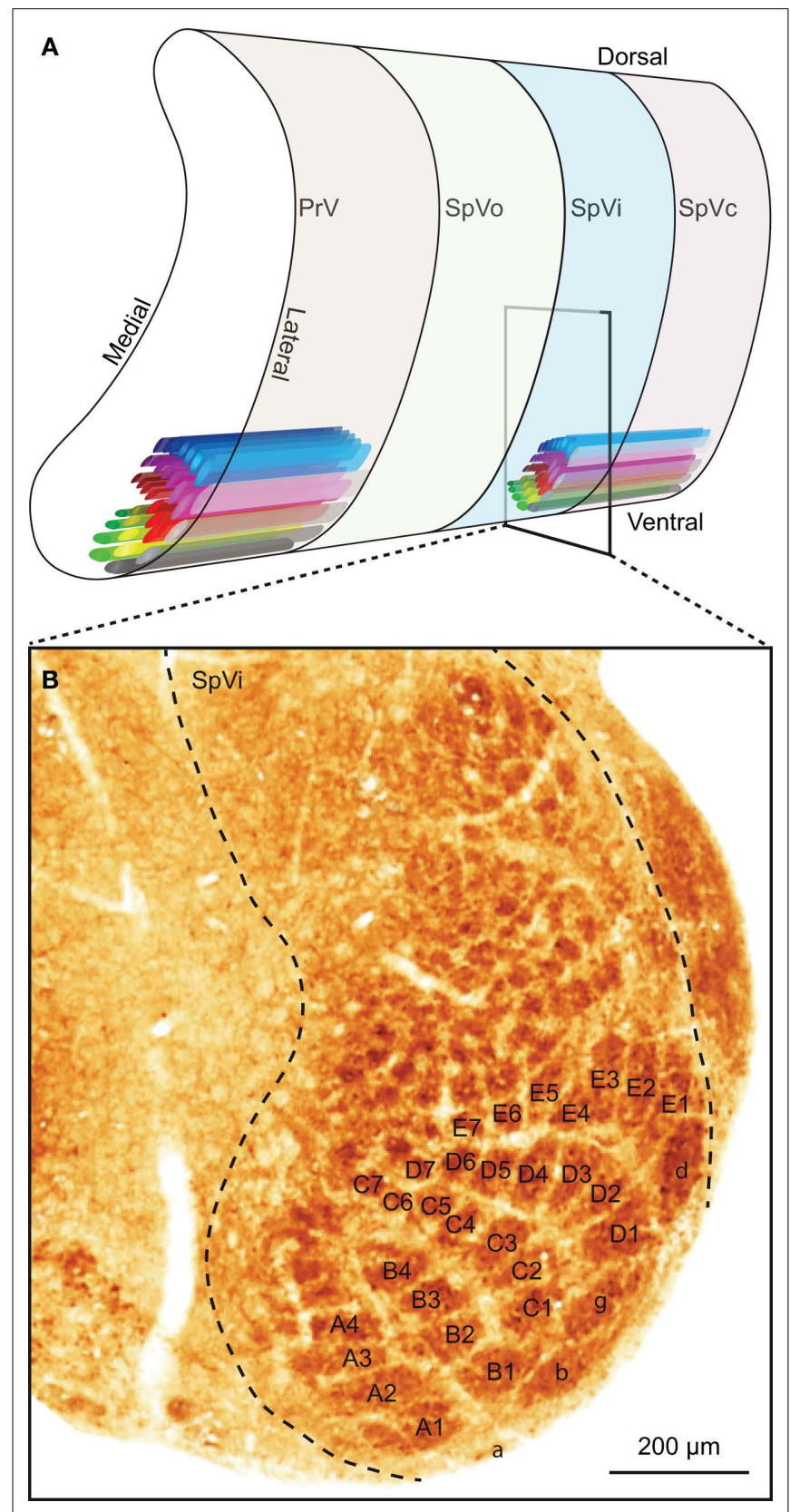

FIGURE 3 |The trigeminal nuclei. (A) The sensory trigeminal nuclei consist of two nuclei, oriented along the antero-posterior axis. The principal nucleus (PrV) is located at the anterior end and the spinal nucleus (SpV) at the posterior site. The SpV can be subdivided into an oral (SpVo), interpolar $(\mathrm{SpVi})$, and caudal part (SpVc). The facial vibrissae project to the ventral part of the trigeminal nuclei. In PrV, SpVc, and the caudal part of SpVi, each vibrissa has its own projection field: a barrelette. The orientation of the barrelettes of the facial macro-vibrissae is indicated schematically. (B) Coronal section of a neonatal mouse brain, showing the location of the barrelettes of the facial macro-vibrissae in the ventral part of SpVi. Following cytochrome oxidase staining, barrelettes appear as dark patches. Note the inverted somatotopy: dorsal vibrissae project to ventral barrelettes. The smaller patches dorsal to the barrelettes of the E-row are the receptive fields of the facial micro-vibrissae. The photomicrograph was kindly provided by Dr. R. S. Erzurumlu. et al., 2010). In addition to the large barrelettes representing the whiskers, smaller barrelettes can be seen that mainly represent the facial micro-vibrissae (Figure 3B). We will restrict ourselves to the description of the neuronal circuitry of the whiskers, rather than that of the other vibrissae.

In $\mathrm{PrV}$, output neurons can be found both within and between barrelettes (Veinante and Deschênes, 1999). In SpVi, however, single-whisker neurons project mainly within the trigeminal nuclei, while multi-whisker neurons project to other brain regions (Woolston et al., 1983; Jacquin et al., 1989a,b). The small singlewhisker neurons of $\mathrm{SpVi}$ are part of an extensive, inter-trigeminal network. GABAergic and glycinergic neurons of $\mathrm{SpVc}$ project to $\mathrm{SpVi}$, and GABAergic and glycinergic neurons of $\mathrm{SpVi}$ project to PrV (Furuta et al., 2008). In addition, glutamatergic interneurons of SpVc project to both SpVi and PrV (Furuta et al., 2008). In this way, $\mathrm{SpV}$ can modulate the sensitivity of PrV to whisker inputs (Timofeeva et al., 2005; Furuta et al., 2008; Lee et al., 2008a). This $\mathrm{SpV}$-mediated modulation of PrV in turn is subject to modulation by the somatosensory cortex (Furuta et al., 2010). This allows for central control of the whisker sensitivity. Most likely, this pathway is being used during active whisking, when the whisker-induced output of $\operatorname{PrV}$ is suppressed (Lee et al., 2008a). Since there is no strong, direct pathway from wM1 to $\mathrm{SpV}$, this effect is most likely mediated by the whisker area of $\mathrm{S} 1$ (wS1). Thus, activity in wM1 activates wS1, which in turn activates the inhibitory projection from SpVi to PrV, reducing the output of PrV (Lee et al., 2008a). This could help the trigeminal nuclei to filter out irrelevant inputs, which may be particularly prominent during movement. Another way to reduce irrelevant input is selective adaptation. PrV responses triggered by weak sensory inputs rapidly desensitize, but are relatively unaffected by repeated strong inputs (Ganmor et al., 2010). Finally, the activity of the sensory trigeminal nuclei can be modulated by several inputs that mainly reflect the general state of alertness, including a cholinergic projection from the pedunculopontine tegmental nuclei (PPTg; Timofeeva et al., 2005; Beak et al., 2010), a serotonergic projection from the raphe nuclei (Lee et al., 2008c) and a noradrenergic projection from the locus coeruleus (Moore and Bloom, 1979). Taken together, the level of detail of the sensory information forwarded to the rest of the brain by the trigeminal nuclei depends on the behavioral state of the animal.

Apart from the contralateral projections to the thalamus described in detail below, there are also contralateral projections from the trigeminal nuclei to the pontine nuclei (see The Pontine Nucleus and the Nucleus Reticularis Tegmenti Pontis), the inferior olive (IO; see Cerebellum and Inferior Olive), the SC (see Superior Colliculus), and the zona incerta (ZI; see Zona Incerta). In addition, there are predominantly ipsilateral connections to the cerebellum (see Cerebellum and Inferior Olive), the pontomedullary RF (see Pontomedullary Reticular Formation), and the lateral facial nucleus. The trigemino-facial connections originate from all four subnuclei, but mainly from SpVc (Erzurumlu and Killackey, 1979; Pinganaud et al., 1999; Hattox et al., 2002). Since the lateral facial nucleus houses whisker motor neurons (Klein and Rhoades, 1985; Herfst and Brecht, 2008), this connection forms a direct feedback loop (Nguyen and Kleinfeld, 2005). It has been suggested that $\mathrm{SpV}$ also receives motor input from $\mathrm{wS} 1$, 
the information of which might be forwarded to the lateral facial nucleus via the direct connection (Matyas et al., 2010).

\section{THALAMUS AND TRIGEMINO-THALAMO-CORTICAL PATHWAYS}

The thalamus is the main gateway to the cerebral cortex. It is composed of several nuclei, two of which are critically involved in the transmission of whisker stimuli to $\mathrm{wS} 1$ : the ventral posterior medial nucleus (VPM) and the medial posterior nucleus (Pom). There are at least six pathways conveying whisker input from the trigeminal nuclei to the cerebral cortex (Figure 4E). To some extent, these pathways convey different aspects of whisker sensation (Yu et al., 2006). The pathways that make synapses in VPM convey whisker input with short latencies, while those via Pom have considerably longer latencies. VPM receives both singleand multiple-whisker input, Pom only multi-whisker input. An anatomical difference between VPM and Pom is that VPM, in contrast to Pom, contains barreloids, analogous to the barrelettes in the trigeminal nuclei, and the barrels in wS1. The barreloids are prominent in the dorsomedial part of VPM (VPMdm), but fade away toward the ventrolateral part (VPMvl; Van der Loos, 1976; Land et al., 1995; Haidarliu and Ahissar, 2001). As a consequence, VPMdm processes mainly single-whisker input and
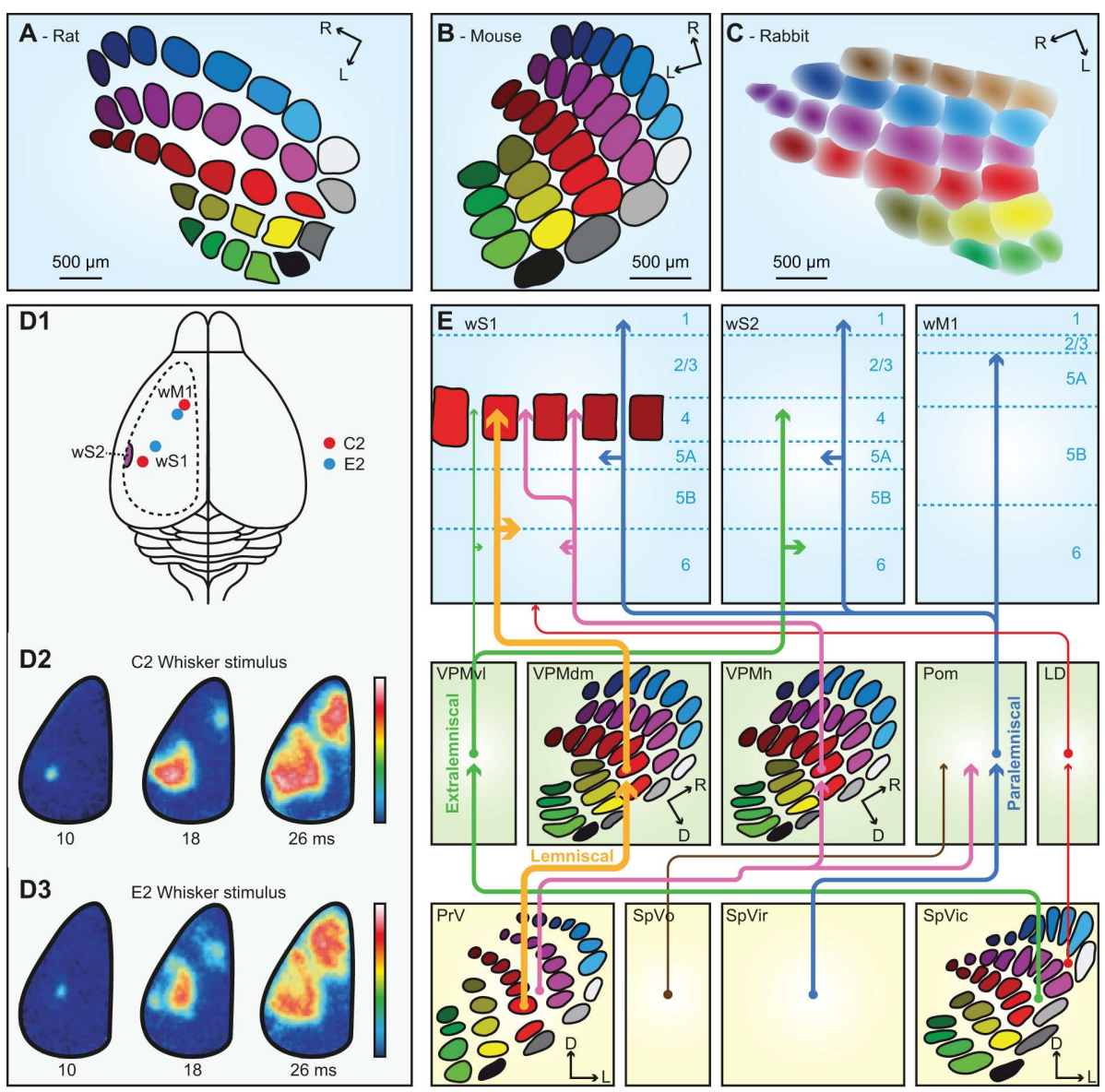

FIGURE 4 |The trigemino-thalamo-cortical pathways. Schematic drawing of the organization of the barrels in layer 4 of a tangential slice of an adult rat (A), mouse (B), and rabbit (C). Note that the septa are prominent in rats but very small in mice. In adult rabbits, barrels are absent. Instead, the somatotopic representation of the vibrissae is more gradual. (D1) Schematic drawing of a rat brain. The dotted line indicates the recording area for the panels (D2,D3). The red dots indicate the representations of the C2 whisker, and the blue dots those of the E2 whisker in wS1 and wM1. wS2 is partially visible on the extreme left of the recording area. (D2) Voltage-sensitive dye images in urethane-anesthetized mice showing that stimulation of the contralateral C2 whisker initially evokes a very local signal in the C2 barrel of wS1. Consecutively, the signal spreads over the rest of wS1, and also to wM1, and to a lesser extent also to wS2. The time points indicate the time since the onset of whisker deflection, the scale bar the fluorescent signal (blue = weak, white = high). (D3) Idem, but for the E2 whisker. Note that the early responses to the $\mathrm{C} 2$ and $\mathrm{E} 2$ whiskers are at different locations, but this difference is less obvious during later phases of the response. Panel $D$ is reproduced with permission from Aronoff et al. (2010). (E) Schematic representation of the trigemino-thalamo-cortical pathways discussed in the main text. The arrowheads indicate the termination areas of the axons. Note that (in the cerebral cortex) the postsynaptic cells may have their somata in other layers. The line thickness indicates the relative importance of the pathways. The barreloids in VPM are indicated in an oblique coronal slice, the barrelettes of the trigeminal nuclei in coronal slices. $D=$ dorsal; $L$, lateral; LD, laterodorsal nucleus of the thalamus; Pom, medial posterior nucleus of the thalamus; PrV, primary trigeminal nucleus; R, rostral; SpVic, caudal part of spinal trigeminal nucleus pars interpolaris; SpVio, oral part of SpVi; SpVo, spinal trigeminal nucleus pars oralis; VPMdm, dorsomedial part of the ventroposterior medial nucleus of the thalamus; VPMh, "head" area of VPM; VPMVl, ventrolateral part of VPM; wM1, whisker motor cortex; wS1, whisker part of primary sensorimotor cortex; wS2, whisker part of secondary sensorimotor cortex 
VPMvl multi-whisker input. Within a barreloid, the neurons are ordered according to their angular preference (Timofeeva et al., 2003).

Of all trigemino-thalamo-cortical pathways, the lemniscal pathway is the only one that predominantly conveys single-whisker input. This disynaptic pathway links the barrelettes of PrV to the barrels of wS1 via the barreloids of VPMdm (Erzurumlu et al., 1980; Williams et al., 1994; Veinante and Deschênes, 1999). The main targets are the barrels of layer 4 in wS1, but there are also terminals in layers 5/6 of wS1 (Killackey, 1973; Koralek et al., 1988; Chmielowska et al., 1989; Lu and Lin, 1993; Bureau et al., 2006; Petreanu et al., 2009; Meyer et al., 2010a). The thalamic relay cells in the barreloids of VPMdm respond with precisely timed single action potentials to deflections of a single principle whisker at short latencies (4-8 ms; Ito, 1988; Simons and Carvell, 1989; Armstrong-James and Callahan, 1991; Diamond et al., 1992b; Brecht and Sakmann, 2002b).

A second pathway synapsing in VPM is the extralemniscal pathway. In contrast to the lemniscal pathway, the extralemniscal pathway passes through VPMvl, where the barreloids are not as distinct as in VPMdm. The input of the extralemniscal pathway originates from the multi-whisker, interbarrelette cells of the caudal part of SpVi, and the output is targeted to layers 4 and 6 of wS2, as well as the septal columns of wS1 (Pierret et al., 2000).

The third pathway, the paralemniscal pathway, arises from the multi-whisker cells in the rostral part of SpVi (Erzurumlu and Killackey, 1980; Peschanski, 1984; Williams et al., 1994; Veinante et al., 2000a), contacts relay cells in Pom and targets wS1, wS2, and wM1. Pom axons terminate mainly throughout layers $5 \mathrm{a}$ and 1 of $\mathrm{wS} 1$ as well as in layer 4 of the septa (Koralek et al., 1988; Chmielowska et al., 1989; Lu and Lin, 1993; Bureau et al., 2006; Petreanu et al., 2009; Wimmer et al., 2010), where they also provide synaptic input to pyramidal neurons in layers 3 and 5a (Bureau et al., 2006; Petreanu et al., 2009; Meyer et al., 2010a). In addition, Pom terminals are found in wS2 and wM1 (Carvell and Simons, 1987). From Pom, there are also projections to the striatum (Alloway et al., 2006), the perirhinal cortex and the insular cortex (Deschênes et al., 1998). Responses of relay cells in Pom to single-whisker deflections differ from those in VPM: in Pom, the receptive fields are larger, the latencies longer and more variable and the activity is under control of a strong cortical feedback (Diamond et al., 1992b; Ahissar et al., 2000). The variable and relatively long response latencies (19-27 ms) of Pom cells are likely caused by inhibitory inputs from ZI gating peripheral inputs to Pom (Trageser and Keller, 2004).

In addition, there are at least three other trigemino-thalamocortical pathways. All of these convey multi-whisker information. The first arises from the interbarrelette cells of PrV, projects to Pom and to multi-whisker relay cells in the "heads" of the barreloids at the dorsomedial margin of VPM (VPMh; Veinante and Deschênes, 1999; Urbain and Deschênes, 2007b). The head barreloid cells send axons to the septal columns of wS1 (Furuta et al., 2009). A second multi-whisker pathway involves projections from $\mathrm{SpVi}$ to the thalamic laterodorsal nucleus (LD), which projects mainly to the cingulate and retrosplenial cortex, and only sparsely to wS1 (Bezdudnaya and Keller, 2008). And finally, there is a relatively sparse and poorly characterized pathway originating from multiwhisker neurons in SpVo and projecting to caudal thalamic regions including the most posterior parts of VPM and Pom (Jacquin and Rhoades, 1990; Veinante et al., 2000a). These thalamic regions receive inputs from different sensory modalities and project to the perirhinal cortex, striatum, and amygdala (Groenewegen and Witter, 2004).

Apart from being the relay station between the trigeminal nuclei and the cerebral cortex, the thalamus also contains intra-thalamic projections. As such the reticular nucleus (RT) is involved in several negative feedback loops that modulate the flow of information through trigemino-thalamo-cortical pathways discussed above. RT forms a sheet of GABAergic neurons surrounding the thalamus and it contains a somatotopic body map with a large representation of the whiskers (Shosaku et al., 1984; Guillery and Harting, 2003; Pinault, 2004). Axons of VPM and Pom cells give off collaterals in RT (Crabtree et al., 1998; Lam and Sherman, 2011), while RT in turn provides strong inhibitory input to VPM and Pom (Pinault et al., 1995; Cox et al., 1997; Brecht and Sakmann, 2002b). The VPM-projections from RT cells are whisker-specific: they target the barreloid of their own principle whisker (Desilets-Roy et al., 2002). Since RT neurons adapt stronger to repeated, high-frequency stimulation than VPM neurons, strong whisker stimulation can lead to disinhibition of VPM neurons (Hartings et al., 2003; Ganmor et al., 2010). Furthermore, VPM cells can influence activity in Pom through intra-thalamic pathways involving RT (Crabtree et al., 1998). Additional indirect inhibitory feedback loops to Pom involve ZI (see Other Structures Projecting to the Facial Nucleus), which receives both peripheral and cortico-thalamic input and provides a significant portion of GABAergic synaptic terminals in Pom (Barthó et al., 2002; Bokor et al., 2005).

\section{PRIMARY SOMATOSENSORY CORTEX (S1)}

The whisker part of S1 (wS1) is of crucial importance for perception and processing of whisker input. For instance, $\mathrm{wS} 1$ is required for whisker-based object localization (O'Connor et al., 2010a), gap-crossing (Hutson and Masterton, 1986), and aperture width discrimination (Krupa et al., 2001). Direct stimulation of wS1 in rabbits can substitute for peripheral vibrissa stimulation (LealCampanario et al., 2006). This suggests that wS1 can form sensory percepts, but does not differentiate between peripheral and central stimulation (see also Huber et al., 2008). Recent evidence indicates that wS1 also has a previously unanticipated role in motor control of whisker retraction (Matyas et al., 2010).

As all cortical areas, wS1 is composed of layers. Layer 4 is the main input layer, and in mice it is organized in patches ("barrels") of neurons primarily receiving input from a single whisker (Figure 4B; Woolsey and Van der Loos, 1970). Within a mouse barrel, most neurons are found at the borders, leaving the barrel center relatively empty. In rats, a similar organization is found (Figure 4A), but the barrel diameters are larger $(\sim 400 \mu \mathrm{m})$ than in mice $(\sim 280 \mu \mathrm{m})$, and the cells are equally distributed within the barrels (Welker and Woolsey, 1974). In mice, a single barrel column contains, distributed over all layers, $\sim 6,500$ neurons $(\mathrm{C} 2$ barrel; Lefort et al., 2009), while the rat C2 barrel contains $\sim 19,000$ neurons (Meyer et al., 2010b). The barrels are strictly organized in a somatotopic pattern (Welker, 1971). In between the barrels are the septa, which mainly receive multi-whisker input (Brumberg 
et al., 1999; Furuta et al., 2009). The septa are larger in rats than in mice (Welker, 1971; Woolsey et al., 1975). Within the class of mammals, rats and mice are quite exceptional in having barrels in $\mathrm{wS} 1$. Barrels are only present in some rodents, as well as a few other species (Woolsey et al., 1975; Rice, 1985). In adult rabbits, for instance, barrels cannot be identified. Yet, also rabbits probably have a somatotopic representation of their vibrissae in S1, but the borders between the whisker receptive fields are fuzzier than in animals with barrels (Figure 4C; Woolsey et al., 1975; McMullen et al., 1994).

Throughout wS1, sensory-evoked responses are sparse and near-simultaneous, but the response probabilities are layer- and cell type-specific (Brecht and Sakmann, 2002a; Brecht et al., 2003; Manns et al., 2004; De Kock et al., 2007). In the barrel columns, spiking responses in excitatory neurons across all layers are largely restricted to deflections of the principle whisker, except for thicktufted layer 5 pyramidal neurons (Welker, 1971; Simons, 1978; Manns et al., 2004; De Kock et al., 2007). Subthreshold synaptic responses, however, can also be triggered by the movement of several whiskers surrounding the principle whisker (Brecht and Sakmann, 2002a). Sensory-evoked responses in layer 4 cells are brief due to the recruitment of powerful thalamo-cortical feedforward inhibition (Swadlow, 2002; Gabernet et al., 2005; Sun et al., 2006; Cruikshank et al., 2007). Angular tuning domains have been observed within layers 4 (Bruno et al., 2003) and 2/3 in adult rats (Andermann and Moore, 2006; Kremer et al., 2011). During free whisking, neurons across all layers respond to active touch (Curtis and Kleinfeld, 2009; O'Connor et al., 2010b; Crochet et al., 2011) and to slip-stick motion events (Figure 1C; Jadhav et al., 2009). Sensory-evoked activity patterns in wS1 correlate well with psychophysical performance in whisker-dependent tactile discrimination tasks (Krupa et al., 2004; von Heimendahl et al., 2007; Stüttgen and Schwarz, 2008; O'Connor et al., 2010b). The activity of wS1 neurons encodes the spatial location of the whiskers over time (Fee et al., 1997; Crochet and Petersen, 2006; De Kock and Sakmann, 2009). This is also true for GABAergic interneurons (Gentet et al., 2010). Such a reference signal is required for decoding horizontal object position (Diamond et al., 2008), for example by neurons in wS1 for which phase in the whisk cycle gates the response to touch (Curtis and Kleinfeld, 2009).

In comparison to responses in the barrel columns, those in the septal columns are less whisker-specific. The barrel and septal columns have been proposed to represent two partially segregated circuits that process different aspects of whisker movements (Kim and Ebner, 1999; Shepherd and Svoboda, 2005; Alloway, 2008). However, the segregation between barrels and septa, while prominent in rats, is not so clear in other species, like mice which have only very thin septa (cf Bureau et al., 2006).

The microcircuit of $\mathrm{wS} 1$ has been extensively characterized, yielding increasingly detailed connectivity schemes (Lübke and Feldmeyer, 2007; Schubert et al., 2007; Lefort et al., 2009; Petreanu et al., 2009). Layer 4 barrel neurons, which are the main recipients of the lemniscal pathway, project to all layers within their own barrel column, but most prominently to other layer 4 cells as well as layer 2/3 pyramidal cells (Kim and Ebner, 1999; Lübke et al., 2000; Petersen and Sakmann, 2000; Schubert et al., 2001; Feldmeyer et al., 2002, 2005; Shepherd and Svoboda, 2005; Lefort et al.,
2009). Layer $2 / 3$ pyramidal cells project both within their own barrel column as well as over long distances across barrel columns (Lübke and Feldmeyer, 2007). They contact cells within all layers except layer 4 , with a particularly strong connection to other layer $2 / 3$ pyramidal neurons and to thick-tufted layer $5 \mathrm{~b}$ pyramidal cells (Reyes and Sakmann, 1999; Schubert et al., 2001; Lefort et al., 2009; Petreanu et al., 2009). Layer 5a neurons, which are the main recipients of the paralemniscal pathway, project strongly within their own barrel column to other pyramidal cells across layer 5 (Lefort et al., 2009), and to layer 2 cells distributed across multiple columns and preferentially located above the septa (in rats, but not in mice; Shepherd and Svoboda, 2005; Bureau et al., 2006). Layer 2 neurons receive additional inputs from layer 3 neurons located above barrels (Bureau et al., 2006), providing one of several possible points of convergence for the lemniscal and paralemniscal pathways (Lübke and Feldmeyer, 2007). Inhibitory input to excitatory neurons is derived from cells within the same cortical layer as well as from cells from other cortical layers (Helmstaedter et al., 2009; Kätzel et al., 2011). In addition to the aforementioned intracolumnar connections within $\mathrm{wS} 1$, intracortical projections extend throughout much of wS1 and its dysgranular zone (Chapin et al., 1987; Hoeflinger et al., 1995; Kim and Ebner, 1999; Aronoff et al., 2010).

The whisker area of S1 forms reciprocal connections with several other cortical areas, including the whisker part of the secondary somatosensory cortex (wS2), wM1, insular cortex, and perirhinal cortex (White and DeAmicis, 1977; Welker et al., 1988; Fabri and Burton, 1991; Cauller et al., 1998; Aronoff et al., 2010). The contralateral $\mathrm{wS} 1$ is targeted via callosal projections (Larsen et al., 2007; Petreanu et al., 2007). Axonal projections to wS2 originate from the infragranular and supragranular layers of $\mathrm{wS} 1$ and arborize across all layers in wS2 (Welker et al., 1988; Fabri and Burton, 1991; Cauller et al., 1998; Chakrabarti and Alloway, 2006; Aronoff et al., 2010). The wS1 to wM1 projection is somatotopically arranged such that a column in wS1 connects to a column of the same whisker in wM1 (Izraeli and Porter, 1995; Hoffer et al., 2003; Ferezou et al., 2007). Layer 2/3 pyramidal cells of wS1 densely innervate layers $5 / 6$ of wM1, while those of layers $5 / 6$ preferentially innervate layers 1 and $2 / 3$ in wM1 (Porter and White, 1983; Miyashita et al., 1994; Aronoff et al., 2010). The majority of connections to wM1 arises from neurons located in septal columns (Crandall et al., 1986; Alloway et al., 2004; Chakrabarti et al., 2008). The reciprocal projection, from wM1 to wS1, innervates mainly layers 5/6 and 1 (Cauller et al., 1998; Veinante and Deschênes, 2003; Matyas et al., 2010).

Cortico-thalamic projections originate in layer 5/6 and target relay cells in VPM and Pom, as well as GABAergic neurons in RT (Hoogland et al., 1987; Welker et al., 1988; Chmielowska et al., 1989; Bourassa et al., 1995; Deschênes et al., 1998; Veinante et al., 2000b; Killackey and Sherman, 2003). The projections to VPM originate from layer 6 a pyramidal neurons (located below both the barrels and the septa) and target the barreloid of the corresponding principal whisker as well as those of several whiskers located within the same arc (Hoogland et al., 1987; Bourassa et al., 1995). VPMvl, which is the thalamic relay station for the extralemniscal pathway, receives cortical input from layer 6 pyramidal cells, both from wS1 and from wS2 (Bokor et al., 2008). The heads of 
the barreloids in VPM, which participate in a multi-whisker lemniscal pathway, receive collaterals from layer $6 \mathrm{~b}$ pyramidal cells projecting to Pom (Bourassa et al., 1995; Deschênes et al., 1998). The relay cells of Pom also receive input from layer 6a pyramidal cells (located below the septa) and layer 5b tall-tufted pyramidal cells (located below both the barrels and the septa), whose axons form large and powerful synapses that can drive Pom neurons (Hoogland et al., 1991; Killackey and Sherman, 2003; Larsen et al., 2007; Groh et al., 2008). These relay cells project to wS2, forming a cortico-thalamo-cortical pathway (Theyel et al., 2010). Layer 5b neurons also project to ZI (Bourassa et al., 1995; Mitrofanis and Mikuletic, 1999; Veinante et al., 2000b; Barthó et al., 2007), which is involved in state-dependent suppression of whisker sensory responses in Pom (see Zona Incerta). RT cells are innervated by collaterals of cortico-thalamic axons from layer 6 cells, but not layer 5 cells (Bourassa et al., 1995), which strongly activate RT cells and evoke disynaptic inhibition in thalamo-cortical relay cells (Cruikshank et al., 2010; Lam and Sherman, 2010). Other projections of wS1 include projections from layer 5a pyramidal cells to the striatum (see Basal Ganglia) and from layer 5b pyramidal cells to the anterior pretectal (APT) nucleus (Aronoff et al., 2010), SC (see Superior Colliculus), the red nucleus (see Anterior Pretectal Nucleus), the pontine nuclei (see The Pontine Nucleus and the Nucleus Reticularis Tegmenti Pontis), and the sensory trigeminal nuclei (see Sensory Trigeminal Nuclei).

\section{SECONDARY SOMATOSENSORY CORTEX (S2)}

S2 contains a highly organized somatotopic representation of the whiskers (wS2) that occupies around $14 \%$ of the total area of S2 and that is located in the parietal cortex, lateral to wS1 (Carvell and Simons, 1986; Koralek et al., 1990; Fabri and Burton, 1991; Hoffer et al., 2003; Benison et al., 2007). The whisker receptive fields in wS2 are larger than in wS1; wS2 neurons generally respond equally well to several adjacent whiskers (Welker and Sinha, 1972; Carvell and Simons, 1986; Kwegyir-Afful and Keller, 2004). Responses in wS2 to single-whisker deflections are weaker than those in wS1, but they display stronger direction selectivity, while the onset latencies are comparable (Kwegyir-Afful and Keller, 2004). The local connections within wS2 are similar to those within wS1. However, in contrast to $\mathrm{wS} 1$, the projections from layer $2 / 3$ to layer 5 are stronger than those from layer 4 to layer 3 (Hooks et al., 2011). Furthermore, the reciprocal connections between layers 5 and 6 , which are weak in wS1, are more pronounced in wS2 (Hooks et al., 2011). Whisker input reaches wS2 via the extralemniscal pathway through VPMvl (Pierret et al., 2000; Bokor et al., 2008), but also via Pom (Carvell and Simons, 1987; Spreafico et al., 1987; Alloway et al., 2000; Theyel et al., 2010) and from both the barrel and septal columns of wS1 (Kim and Ebner, 1999; Chakrabarti and Alloway, 2006). The connections between wS1 and wS2 are reciprocal (Carvell and Simons, 1987; Aronoff et al., 2010). In addition, there are reciprocal connections between wS2 and wM1 (Porter and White, 1983; Miyashita et al., 1994). There are also projections to the striatum (see Basal Ganglia), the pontine nuclei (see The Pontine Nucleus and the Nucleus Reticularis Tegmenti Pontis), and to several thalamic nuclei, including VPM, Pom, and RT (Liao et al., 2010). wS2 also receives cholinergic input from the nucleus basalis magnocellularis (Deurveilher and Semba, 2011).

\section{WHISKER MOTOR CONTROL}

Rhythmic whisker movements increase the acuity of the whisker system (Szwed et al., 2003; Knutsen et al., 2006). Whisker movements are generated in the facial nucleus, whose activity is affected by a large number of brain regions. It has been proposed that higher-order areas can initiate movement, but that the rhythmicity of the whiskers is caused by a brainstem central pattern generator (CPG; see Serotonin).

\section{FACIAL NUCLEUS}

The motor neurons of both the intrinsic and the extrinsic muscles of the whisker pad are located in the lateral facial nucleus (Ashwell, 1982; Klein and Rhoades, 1985; Herfst and Brecht, 2008). Of the lateral facial nucleus neurons that evoke whisker movements, about $80 \%$ induce the protraction of a single whisker and about $20 \%$ the retraction of multiple whiskers (Herfst and Brecht, 2008). Each intrinsic capsular muscle has about 25-50 motoneurons in the lateral facial nucleus (Klein and Rhoades, 1985). The motor commands are forwarded to the whisker muscles via the facial nerve (Figure 2A; Dörfl, 1985; Haidarliu et al., 2010). In addition, there is sparse innervation of the extrinsic muscles by the hypoglossal nucleus via the infraorbital branch of the trigeminal nerve (Mameli et al., 2008).

Single motor neurons in the lateral facial nucleus evoke fast, short, and stereotypic whisker movements, whereas single neurons in wM1 evoke slow, small, and long-lasting rhythmic movements (Brecht et al., 2004b; Herfst and Brecht, 2008). This discrepancy makes it unlikely that wM1 directly commands activity of the lateral facial nucleus, despite the possible existence of a sparse monosynaptic projection from wM1 to the contralateral lateral facial nucleus (Grinevich et al., 2005). Instead, wM1 may induce rhythmic whisker movements via oligosynaptic pathways to the lateral facial nucleus. Remarkably, rhythmic whisker movements persist in the absence of wM1 (Welker, 1964; Semba and Komisaruk, 1984; Gao et al., 2003). Hence, it has been proposed that wM1 projects to a CPG in the brainstem, possibly the dorsal raphe nucleus, that in turn activates the lateral facial nucleus (Hattox et al., 2003; see Serotonin). In addition, the lateral facial nucleus receives input from several other subcortical structures, all of which are directly or indirectly innervated by wM1. These afferent regions include the ipsilateral sensory trigeminal nuclei (Nguyen and Kleinfeld, 2005), the ipsilateral pontomedullary RF (ZerariMailly et al., 2001), and the contralateral SC (Miyashita and Mori, 1995; Hattox et al., 2002). In addition, the lateral facial nucleus is targeted by cholinergic, histaminergic, and noradrenergic connections, which may set the overall activity level of the whisker movements (see Arousal, Alertness, and Attention). Altogether, there is a strong convergence of inputs at the level of the lateral facial nucleus, allowing the integration of whisker movements and other forms of behavior.

\section{CEREBRAL CORTEX Primary motor cortex (M1)}

The primary motor cortex (M1) is a large area in the frontal cortex involved in movement. M1 has an agranular appearance, low stimulation thresholds for evoking movements, and a topographic and complete representation of the body muscles 
(Gioanni and Lamarche, 1985; Brecht et al., 2004a). M1 can be divided into the agranular medial field (AGm), the agranular lateral field (AGl), and the cingulate area (Cg1). The topographic representation of whiskers is almost exclusively located in AGm (Brecht et al., 2004a). Sensory input from the whiskers to whisker M1 (wM1) comes predominantly via wS1 (Armstrong-James and Fox, 1987), but also directly from Pom (Deschênes et al., 1998). The latencies to whisker stimulation are 10-20 ms longer in wM1 than in wS1 (Figure 4D; Ferezou et al., 2007). Microstimulation of wM1 can generate whisker motion that strongly resembles natural exploratory whisking (Berg and Kleinfeld, 2003b; Brecht et al., 2004b; Haiss and Schwarz, 2005; Matyas et al., 2010). During a training paradigm, mice can learn to protract their whiskers following an auditory conditioned stimulus (CS; Troncoso et al., 2004). Such associative learning probably involves synaptic plasticity of layer 5 pyramidal cells in wM1 (Troncoso et al., 2007). This suggests that whisker movements are subject to change following long-term synaptic plasticity in wM1. Although complete ablation of wM1 does not abolish whisking, it does disrupt whisking kinematics, coordination, and temporal organization such as whisking synchrony (Gao et al., 2003). There are several indirect routes from $\mathrm{wM} 1$ to the lateral facial nucleus, for example via SC (see Superior Colliculus) or the pontomedullary RF (see Pontomedullary Reticular Formation) and wS1 (see Somatosensory Cortex as a Premotor Area). In addition, wM1 is involved in several feedback loops, including reciprocal connections with wS1 (Aronoff et al., 2010), thalamus (Cicirata et al., 1986; Colechio and Alloway, 2009), and loops involving the basal ganglia (see Basal Ganglia), the cerebellum (see The Cerebellar System), and the claustrum (see Bilateral Coordination of Whisker Movements). Finally, wM1 projects to the deep mesencephalic nucleus, the periaqueductal gray, and the red nucleus (Alloway et al., 2010). This network of inputs and outputs enables wM1 to adjust whisker movements both to sensory input and to the general behavior.

The output of wM1 is not uniform. Layer 5 pyramidal cells project to cells around the facial nucleus while those of layer 6 project to the thalamus. Evidence for strong myelinization and an expanded layer 5 in AGm points to the possible contribution to high speed whisking (Brecht et al., 2004b). Layer 5 output may correspond with timing of individual whisking movements and may be able to reset these rhythms, while layer 6 output may correspond with grouping of multiple whisking movement bursts where action potential frequency determines movement direction and amplitude (Brecht et al., 2004b).

\section{Somatosensory cortex as a premotor area}

Microstimulation of wM1 can induce both whisker protraction and retraction depending on the location of stimulation in wM1 (Gioanni and Lamarche, 1985; Haiss and Schwarz, 2005; Matyas et al., 2010). A recent study found that stimulation of wS1 induces whisker retraction at shorter latencies than wM1 stimulation. In fact, the wM1-induced whisker retraction can be mediated by synaptic activation in wS1 (Matyas et al., 2010). Contrary to stimulation of $\mathrm{wM} 1$, stimulation of $\mathrm{wS} 1$ does not evoke whisker protraction (Matyas et al., 2010). In the same study, the authors suggest that $\mathrm{wS} 1$ exerts its effect on whisker movement by a disynaptic pathway via $\mathrm{SpV}$ to the facial nucleus. Thus, wM1 and wS1 could together form an additional source of rhythmic whisker movements, alongside the putative brainstem pattern generators (see Serotonin). Such an organization is in line with the idea that wM1 specifies motor programs rather than simple muscle activity (Brecht et al., 2004b).

\section{BASAL GANGLIA}

The first somatosensory feedback system to be discussed involves the basal ganglia, which are important for a wide variety of (sensori-)motor functions. In the oculomotor system, the basal ganglia have been associated with orienting saccadic eye movements based on reward expectancy (Hikosaka et al., 2006). A similar function for the whisker system could very well be possible. The basal ganglia are a heterogeneous group of brain regions, whose main components are the striatum, the globus pallidus (GP), the substantia nigra (SN), and the subthalamic nucleus (STN). The GP consists of two parts: an external (GPe) and an internal part (GPi). In rodents, GPi is commonly referred to as the entopeduncular nucleus (EPN; Nambu, 2007). SN is composed of a pars compacta $(\mathrm{SNc})$ and a pars reticulata $(\mathrm{SNr})$. In general, the information from the cerebral cortex enters the striatum, is forwarded to other parts of the basal ganglia and the output to the thalamus and SC is eventually generated by EPN and $\mathrm{SNr}$ (Figure 5A).

The striatum, or "neostriatum," is a single area in rodents, but in higher mammals it is composed of two nuclei: the caudate and the putamen (Tepper et al., 2007). Based on function and connectivity, the striatum can be divided into a dorsolateral and a ventromedial part (Voorn et al., 2004). The striatum is involved in the acquisition of habits, goal-directed behaviors and in the motivation to perform. The whisker receptive fields of the dorsolateral striatum are organized in a loosely somatotopic manner: dorsal whiskers project laterally and caudal whiskers project dorsally (Figure 5B; Alloway et al., 1999; Wright et al., 1999). There is much overlap between the projection areas of whiskers from a single row, but hardly any from whiskers in different rows. There is also a weaker whisker representation in the ventromedial striatum (Alloway et al., 1999; Wright et al., 1999). The cortico-striatal projections are predominantly ipsilateral and originate from layer 5 pyramidal cells in both barrels and septa (Alloway et al., 2006). Thus, cortico-striatal projections serve to integrate rather than segregate input from different whiskers. In addition, the striatum receives input from wS2, wM1, and other cortical areas, including motor, cognitive, and other sensory areas (Wright et al., 2001; Alloway et al., 2006; Tepper et al., 2007). Hence, the striatum can integrate the whiskers and general behavior.

Apart from the extensive input from the cerebral cortex, the striatum also receives direct input from the thalamus. The thalamo-striatal connections originate mainly in the intralaminar nuclei of the thalamus (Smith et al., 2004; Tepper et al., 2007) and in Pom (Alloway et al., 2006). During whisker stimulation at low frequencies, the responses of the medium-spiny neurons in the dorsolateral striatum are approximately $5 \mathrm{~ms}$ later than in wS1 (Mowery et al., 2011; Pidoux et al., 2011; Syed et al., 2011). However, during repeated whisker stimulation at $5-8 \mathrm{~Hz}$, striatal responses actually preceded those in wS1 (Mowery et al., 2011). In addition, the striatal responses showed less adaptation to repeated 


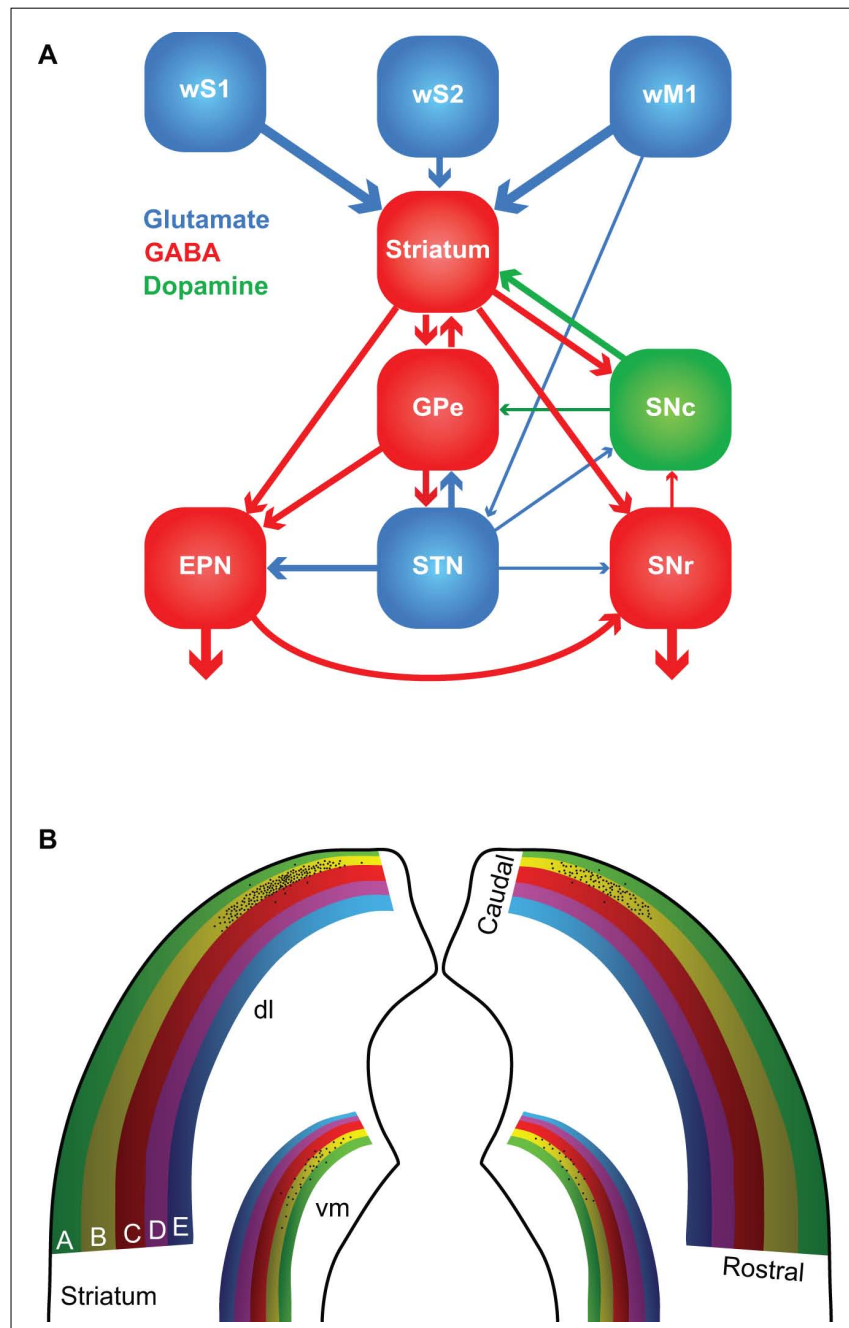

FIGURE 5 |The basal ganglia. (A) The major connections between the components of the basal ganglia. Most of the input comes from the cerebral cortex (in this case: wS1, wS2, and wM1), and is directed to the striatum. GABAergic medium-spiny neurons of the striatum project to the external part of the globus pallidus (GPe), the entopeduncular nucleus (EPN), and the reticular ( $\mathrm{SNr}$ ) and compact (SNc) parts of the substantia nigra. SNc provides dopaminergic input to the striatum, and the subthalamic nucleus (STN) glutamatergic input to GPe, EPN, and SNr. The main output of the basal ganglia is directed to the thalamus, via GPe and $\mathrm{SNr}$, and the superior colliculus, via SNr. The line thickness indicates the relative importance for the whisker system. (B) Whisker responses in the dorsolateral (dl) striatum follow a loose somatotopy, which is mainly organized according to whisker rows. The black dots indicate schematically the projections of the layer 5 pyramidal cells in the B2 barrel of left wS1. The projection is mainly, but not exclusively, ipsilateral, and largely within the " $B$ row" area in the striatum. There is considerable overlap, however, with the projection areas of other B row whiskers. "Rostral" and "caudal" refer to the positions of the whiskers on the mystacial pad. A smaller and less characterized projection area is also present in the ventromedial (vm) striatum.

whisker stimulation as responses in wS1 (Mowery et al., 2011). The latter findings support an important role for the direct thalamostriatal pathway, in addition to the well-established thalamocortico-striatal route. The thalamo-striatal pathway conveying whisker information originates mainly in Pom (Alloway et al., 2006). Relay cells in Pom are inhibited during rest and become disinhibited during periods of activity (see Zona Incerta and Anterior Pretectal Nucleus). Although the disinhibition of Pom has been predominantly linked to active whisking (Bokor et al., 2005; Lavallée et al., 2005; Urbain and Deschênes, 2007a), it might also be evoked by repeated, passive whisker input. Other inputs to the striatum come from the amygdala (Kelley et al., 1982; Popescu et al., 2009), the dorsal raphe nuclei (Di Matteo et al., 2008), GP and SN (Tepper et al., 2007). The main output of the striatum is composed of GABAergic projections to GP and SN.

The GABAergic output of the striatum is the dominant input to $\mathrm{SNc}$, but $\mathrm{SNc}$ also receives GABAergic input from $\mathrm{SNr}$ and glutamatergic input from the amygdala, and to a lesser extent also from STN (Kita and Kitai, 1987; Gonzales and Chesselet, 1990; Misgeld, 2004). SNc also receives histaminergic input from the tuberomammillary nuclei (Lee et al., 2008b). SNc forms dopaminergic connections to the striatum and is implicated in the reward system (Hikosaka et al., 2006; Redgrave et al., 2008). Its degeneration is an important cause of the motor problems associated with Parkinson's disease (Gibb and Lees, 1988; Esposito et al., 2007). $\mathrm{SNr}$ receives GABAergic input from the striatum and, to a lesser extent also glutamatergic input from STN and the cerebral cortex (Kita and Kitai, 1987; Naito and Kita, 1994; Tepper et al., 2007). $\mathrm{SNr}$ sends GABAergic projections to the ventromedial thalamus and the SC (Beckstead et al., 1979; Di Chiara et al., 1979; Grofova et al., 1982). Activation of the nociceptin/orphanin FQ (N/OFQ) receptors in $\mathrm{SNr}$ modulates whisker motor output (Marti et al., 2009).

The external globus pallidus receives GABAergic input from the striatum and glutamatergic input from STN. Sparse innervation comes from the cerebral cortex, the intralaminar nuclei of the thalamus, SNc, the dorsal raphe nuclei, and PPTg (Kita, 2007). The main output areas of GPe are EPN, STN, and the striatum (Kita, 2007). EPN receives GABAergic input from GPe and the striatum, and glutamatergic input from STN (Nambu, 2007). In turn, EPN projects to the ventrolateral thalamic nucleus (VL; Nambu, 2007). To our knowledge, no systematic study of the role of GP in the rodent whisker system has been undertaken. However, GP neurons in cats show responses to vibrissal stimulation, whereby the response depends on the direction of vibrissal movement (Schneider et al., 1982).

The lateral half of STN shows responses to contralateral whisker stimulation. Interestingly, each neuron that responds to contralateral whisker stimulation, also responds to somatosensory stimulation of another area, e.g., forepaw or ipsilateral whisker stimulation (Hammond et al., 1978). This is in line with the putative role of the basal ganglia in bringing different behavioral aspects together. STN receives input from the cerebral cortex, predominantly $\mathrm{wM} 1$, and GPe, and projects to GPe, EPN, and SNr (Kita and Kitai, 1987; Joel and Weiner, 1997).

\section{SUPERIOR COLLICULUS}

The second sensorimotor feedback system involves SC, which is also known as the "tectum." The upper layers of SC process sensory information, the intermediate layers sensorimotor information, and the lower layers motor information. SC receives sensory input 
via direct connections from all four parts of the sensory trigeminal nuclei (Steindler, 1985; Cohen et al., 2008), and provides a direct output to the facial nucleus. However, the SC neurons that receive trigeminal input are not the same as those that innervate the facial nucleus (Hemelt and Keller, 2008). Hence, SC does not function as a simple, "reflexive" relay station between the trigeminal nuclei and the facial nucleus. Similarly, the input to SC from wM1 is also not directly relayed to the facial nucleus, since microstimulation of wM1 and SC show qualitatively and quantitatively different whisker responses (Hemelt and Keller, 2008). Instead, the main function of SC for the whisker system may be closely related to its best known function, which is to control saccadic eye movements and direct the gaze direction toward an interesting visual cue (Boehnke and Munoz, 2008; Gandhi and Katnani, 2011). SC can direct all mobile senses toward an object of interest. Microstimulation at a single spot in the intermediate or deep layers of SC can induce coherent movements of the eyes, the auricles, and the whiskers together (McHaffie and Stein, 1982). While microstimulation within wM1 induces rhythmic whisker movements (Brecht et al., 2004b; Matyas et al., 2010), microstimulation in SC causes sustained whisker protraction (Hemelt and Keller, 2008), which is in accordance with its putative function in the direction of the whiskers. In addition, SC also responds to whisker input. Passive touch (air puff) as well as whisking in air and active touch (surface contact during whisking) evoked SC neuronal responses which were subject to strong adaptation. Passive and active touch evoked stronger responses than whisking in air. As a consequence, whisking in air at $10 \mathrm{~Hz}$ hardly evokes any response in SC, but active touch does (Bezdudnaya and CastroAlamancos, 2011). SC responses can have different latencies. Fast responses $(<10 \mathrm{~ms}$ ) are probably due to the direct trigemino-tectal input and slow responses are likely mediated by wS1 (Bezdudnaya and Castro-Alamancos, 2011).

The superior colliculus receives strong input from ipsilateral wM1 (Miyashita et al., 1994; Alloway et al., 2010), wS1 (Wise and Jones, 1977; Cohen et al., 2008; Aronoff et al., 2010) and the cerebellar nuclei, mainly the dentate and interpositus nucleus, and to a lesser extent also from the fastigial nucleus (May, 2006). Other inputs come, as mentioned before, from the trigeminal nuclei (Steindler, 1985; Cohen et al., 2008), and also from ZI, which supplies both glutamatergic and GABAergic efferents (Beitz, 1989; Kim et al., 1992), from SNr (Beckstead et al., 1979; Kaneda et al., 2008) as well as from the visual cortex (Boehnke and Munoz, 2008). There is also input from the thalamus, but this seems to relate more to the visual than to the whisker system (Cosenza and Moore, 1984; Taylor and Lieberman, 1987). SC projects to the lateral facial nucleus. This connection is mainly ipsilateral, but there are distinct patches of neurons within SC that project to the contralateral lateral facial nucleus (Hemelt and Keller, 2008). SC also projects to the contralateral nucleus reticularis tegmenti pontis (NRTP; Westby et al., 1993; May, 2006), which provides mossy fiber input to the cerebellar cortex and cerebellar nuclei (Mihailoff, 1993). There is also a projection from SC to the contralateral medial accessory olive (MAO; Huerta et al., 1983; May, 2006), which is a source of climbing fibers to the cerebellar cortex. Thus, there are two disynaptic pathways from SC to the cerebellar cortex, which projects back to SC via the cerebellar nuclei.

\section{THE CEREBELLAR SYSTEM}

The third somatosensory feedback system is that of the cerebellum, which receives most of its mossy fiber afferents from the pons and all its climbing fiber afferents from IO (Figure 6).

\section{The pontine nucleus and the nucleus reticularis tegmenti pontis}

The pontine nucleus (or "basal pons") forms the main gateway to the cerebellum for efferents from the cerebral cortex. The main input to the pontine nucleus comes from layer 5 neurons

\section{A}

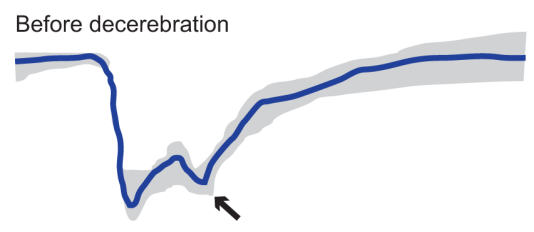

After decerebration
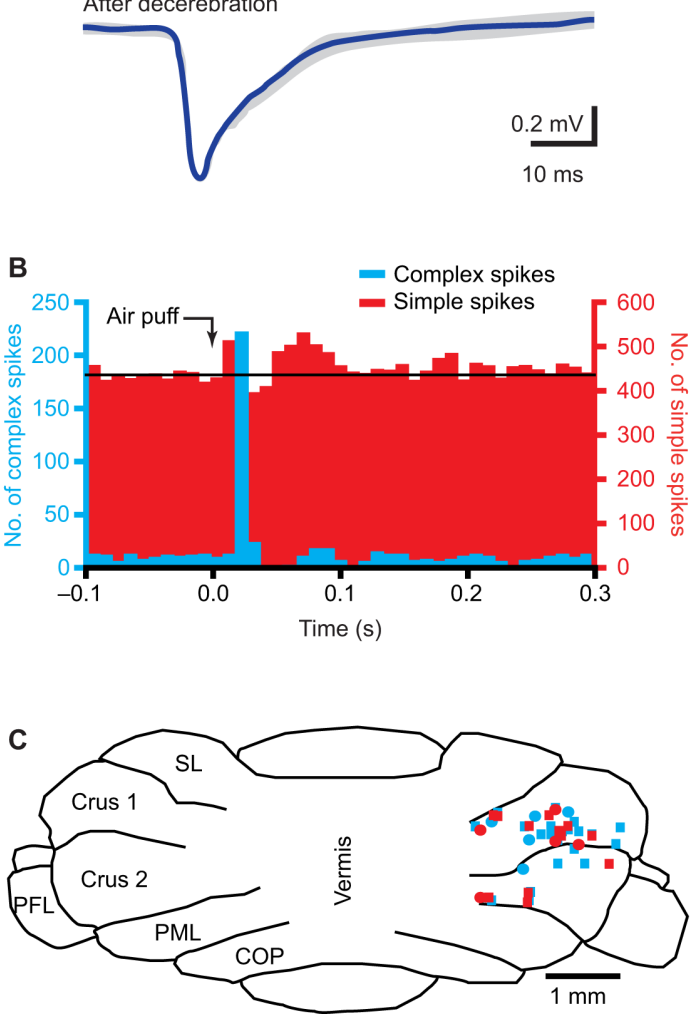

FIGURE 6 |The cerebellum. (A) Tactile stimulation of the upper lip evokes a bi-phasic response in the cerebellar cortex, as measured with field potential recordings in the granule cell layer in crus 2 of adult rats. Complete midcollicular decerebration abolished the late phase response, indicating that the late phase response (arrow) is induced by the cerebral cortex, while the early phase is not. Schematic drawing based on Morisette and Bower (1996). (B) Peri-stimulus time histograms of complex spike (blue) and simple spike (red) responses to ipsilateral air puff stimulation of the whiskers in a Purkinje cell in crus 1 of an awake mouse. The complex spike response is uni-phasic, while clear early and late phase simple spike responses can be observed. Reproduced with permission from Bosman et al. (2010). (C) Cross section of the cerebellar cortex, showing the locations where Purkinje cell responses to ipsilateral stimulation of whisker from the $C$ row were observed in crus 1 and crus 2. COP, copula pyramidis; PFL, paraflocculus; PML, paramedian lobule; SL, simple lobule. Modified with permission from Bosman et al. (2010). 
throughout the entire ipsilateral cerebral cortex, and the efferents all go to the cerebellum (Legg et al., 1989; Brodal and Bjaalie, 1992). Cerebral cortical inputs are mapped multiply and in different combinations to the pontine nucleus (Schwarz and Möck, 2001; Leergaard et al., 2004, 2006). In general, cortico-pontine projections from different cortical regions do not overlap. This seems to hold true also for the barrels of ${ }_{\mathrm{w}} \mathrm{S} 1$, implying that the pontine nucleus may receive single-whisker input (Schwarz and Möck, 2001). Nevertheless, the whisker-related parts of wS1, wS2, and wM1, sometimes project to adjacent, or even partially overlapping regions (Leergaard et al., 2004). Thus, the somatotopy in the pontine nucleus is somewhat intermediate between the continuous somatotopy of the cerebral cortex and the fractured somatotopy of the cerebellum.

The pontine nucleus sends bilateral (but mainly contralateral) mossy fiber connections to the cerebellar cortex, which give off collaterals to the cerebellar nuclei (Eller and Chan-Palay, 1976; Parenti et al., 2002; Leergaard et al., 2006). The cerebellar cortex also projects to the cerebellar nuclei. This feedback loop is completed by afferents from the cerebellar nuclei back to the pontine nucleus (De Zeeuw et al., 2011; Ruigrok, 2011). In addition to the input from the cerebral cortex, which is the dominant input, and of the cerebellar nuclei, the pontine nucleus also receives inputs from dozens of other brain regions (Mihailoff et al., 1989). The functional relevance of these other inputs is not very clear, and their specific functions for the whisker system are currently unknown. The inputs that could be of importance for the whisker system include projections from the sensory trigeminal nuclei (mainly SpVi; Swenson et al., 1984; Mihailoff et al., 1989), SC (Burne et al., 1981; Mihailoff et al., 1989), ZI (Ricardo, 1981; Mihailoff, 1995), the dorsal raphe nuclei (Mihailoff et al., 1989), PPTg (Mihailoff et al., 1989), and the tuberomammillary nuclei (Pillot et al., 2002). Recently, a direct connection from STN to the pontine nuclei has been described in cebus monkeys (Bostan et al., 2010). This could underlie a direct coupling between the basal ganglia and the cerebellar system.

Immediately dorsal of the pontine nucleus is the NRTP. The main input to NRTP comes from the cerebellar nuclei (Torigoe et al., 1986b; Brodal and Bjaalie, 1992). Other inputs come from SC and the pontomedullary RF (Torigoe et al., 1986b). NRTP also receives input from layer 5 pyramidal cells of the cerebral cortex, mainly bilaterally from the cingulate cortex and to a lesser extent also ipsilaterally from motor areas (Brodal, 1980; Torigoe et al., 1986a). NRTP projects, amongst others, ipsilaterally to the cerebellar cortex and the cerebellar nuclei (Mihailoff, 1993; Parenti et al., 2002) and bilaterally to the lateral facial nucleus (IsokawaAkesson and Komisaruk, 1987; Hattox et al., 2002). Hence, NRTP may be a relay station between the cerebellar nuclei and the lateral facial nucleus, but whether it has a role in the whisker system is not clear yet.

\section{Cerebellum and inferior olive}

The cerebellum has a central role in sensorimotor integration and motor learning (Ito, 2000; De Zeeuw and Yeo, 2005; Krakauer and Shadmehr, 2006). It receives sensory input from the whiskers (Figure 6B; Axelrad and Crepel, 1977; Brown and Bower, 2001; Loewenstein et al., 2005; Bosman et al., 2010; Chu et al., 2011) and its activity can affect whisker movements (Esakov and Pronichev, 2001; Lang et al., 2006). The cerebellar cortex has two afferent pathways, the climbing fiber and mossy fiber/parallel fiber pathway, that converge on the cerebellar Purkinje cells, which form the sole efferent projection to the cerebellar and vestibular nuclei (De Zeeuw et al., 2011).

Each adult Purkinje cell is innervated by a single climbing fiber only, with the climbing fiber-to-Purkinje cell synapse being extraordinarily strong (Eccles et al., 1964; Bosman et al., 2008; Davie et al., 2008). Thus, climbing fiber activity reliably evokes postsynaptic spikes, which are, due to their complex waveforms, called “complex spikes” (Davie et al., 2008; De Zeeuw et al., 2011). Climbing fibers originate exclusively from the contralateral IO. IO comprises three main nuclei, all of which receive input from SpV, but not from PrV (Molinari et al., 1996; Yatim et al., 1996). Trigemino-olivary connections originate from all three compartments of $\mathrm{SpV}$ and target mainly the contralateral rostromedial part of the dorsal accessory olive (DAO) and the adjacent dorsal leaf of the principal olive (PO), and to a lesser extent the ventral leaf of the PO and the caudal part of the MAO (Huerta et al., 1983; Molinari et al., 1996; Yatim et al., 1996). Ipsilateral trigemino-olivary projections mirror the contralateral ones, but are relatively sparse (Molinari et al., 1996; Yatim et al., 1996). Altogether, most IO neurons react to somatosensory input (Gellman et al., 1985; Gibson et al., 2004). IO also receives input from many other regions. These include direct and indirect spinal projections (Miskolczy, 1931; Swenson and Castro, 1983), as well as projections from SC (Akaike, 1992), ZI (Brown et al., 1977), the raphe nuclei (Brown et al., 1977), and the ipsilateral cerebral cortex, both from somatosensory and motor areas (Swenson et al., 1989). As a consequence, Purkinje cells fire complex spikes in response to stimulation of wM1 (Lang, 2002; Lang et al., 2006).

The subnuclei of IO project to specific parasagittal zones of the cerebellar cortex (Voogd and Glickstein, 1998; Apps and Hawkes, 2009). The IO area with the strongest trigeminal input, the rostromedial DAO and dorsal PO, projects to the C3 and D zones, while the other areas project mainly to the A zones (Yatim et al., 1996; Apps and Hawkes, 2009). Indeed, most Purkinje cells showing complex spike responses to whisker stimulation were found in the $\mathrm{C} 3$ and D zones in lobule crus 1, and to a lesser extent also in crus 2 (Figure 6C; Bosman et al., 2010). Climbing fiber responses have also been found in the A zones of lobule VII (Thomson et al., 1989). In lobule IX, mossy fiber whisker responses have been reported, but climbing fiber responses were not evaluated (Joseph et al., 1978).

Climbing fiber input to the cerebellar cortex does not follow a somatotopic organization on single-whisker level. For most Purkinje cells, the receptive field of the climbing fiber input is restricted to a single whisker, where nearby Purkinje cells may receive inputs from totally unrelated whiskers (Axelrad and Crepel, 1977; Bosman et al., 2010). In the rare cases where a Purkinje cell received input from multiple whiskers, these whiskers were located within the same row (Bosman et al., 2010). Complex spike responses to whisker stimulation are relatively sparse, encoding typically about $10 \%$ of the stimuli in responsive Purkinje cells, show a large jitter in the latencies and depend on the direction of whisker movement (Thomson et al., 1989; Bosman et al., 2010). 
Mossy fibers terminate at the cerebellar granule cells, whose axons form the parallel fibers, that run transversely over a long distance, innervating numerous Purkinje cells on their way, but with each parallel fiber-to-Purkinje cell synapse being only very weak (De Zeeuw et al., 2011). There are two main mossy fiber routes via which whisker sensory information reaches the cerebellar cortex. First, there is a direct mossy fiber projection from the trigeminal nuclei to the cerebellar cortex. The trigemino-cerebellar mossy fibers originate from ipsilateral PrV, SpVo, and SpVi, and to a lesser extent from SpVc (Yatim et al., 1996). This direct pathway can evoke Purkinje cell simple spike responses with a short latency. The second main mossy fiber input originates in the pontine nucleus, which in turn is activated by wS1. This cerebrocerebellar pathway evokes Purkinje cell simple spike responses with a long latency. Lesioning of the cerebral cortex abolishes the longlatency response, while leaving the short-latency responses in tact (Figure 6A; Kennedy et al., 1966; Morisette and Bower, 1996). There is also a direct, trigemino-pontine connection from $\mathrm{SpVi}$, but its relevance for the whisker system is not clear (Swenson et al., 1984; Mihailoff et al., 1989).

Whisker input can also inhibit Purkinje cell simple spike firing, with the inhibitory response having a longer latency than the excitatory response (Figure 6B; Bosman et al., 2010; Chu et al., 2011). This reflects most likely the feedforward inhibition by molecular layer interneurons within the cerebellar cortex (Chu et al., 2011; De Zeeuw et al., 2011). The complex spike and simple spike responses of an individual Purkinje cell are largely uncorrelated, both at the level of the receptive field and on the level of individual trials (Bosman et al., 2010). Simple spikes receptive fields usually involve multiple whiskers, without any obvious somatotopic ordering. And, also in contrast to complex spike responses, simple spike responses are not affected by the direction of whisker stimulation (Bosman et al., 2010). Mossy fiber-mediated whisker input seems to be strongest in crus 1, strong in crus 2 and lobules VII and IX in the vermis, and sparse in the simplex and paramedian lobules (Joseph et al., 1978; Shambes et al., 1978; Thomson et al., 1989; Bosman et al., 2010).

Thus, large parts of the cerebellar cortex receive whisker input. The output of the GABAergic Purkinje cells in the whiskersensitive regions is fully directed to the cerebellar nuclei. From there, the cerebellar output to the whisker system mainly follows three pathways: (i) to IO, where it closes the olivo-cortico-nuclear feedback loop (Voogd and Glickstein, 1998; De Zeeuw et al., 2011); (ii) to the VL nucleus of the thalamus (Aumann et al., 1994) to provide feedback to the cerebral cortex (Aumann et al., 1994), and possibly also to the basal ganglia (Hoshi et al., 2005); and (iii) to regions that directly project to the lateral facial nucleus, such as SC (Westby et al., 1993) and NRTP (Torigoe et al., 1986b). So these latter routes may allow the cerebellum to directly affect motor output.

Both the striatum and the pontine nuclei receive input from the cerebral cortex. Interestingly, the cortico-pontine pathway has a stronger convergence of inputs from related regions in wS1 and wS2 than the cortico-striatal pathway (Leergaard et al., 2004). This could imply that the cerebellar system is especially suited for the processing of sensory data. Recent findings in primates link the cerebellar system and the basal ganglia via reciprocal disynaptic pathways. The dentate nucleus projects via the thalamus to the striatum (Hoshi et al., 2005) and STN projects via the pontine nuclei to the cerebellar cortex (Bostan et al., 2010).

\section{VENTROLATERAL NUCLEUS OF THE THALAMUS}

Both the basal ganglia and the cerebellum have an ascending projection to wM1 via the ventrolateral nucleus (VL) of the thalamus. VL incorporates input from EPN (Nambu, 2007), the cerebellar nuclei (Aumann et al., 1994), and wM1 (Miyashita et al., 1994; Alloway et al., 2008). VL itself has a somatotopic representation, including a separate area related to the whiskers (Tlamsa and Brumberg, 2010). Thus, VL is a crucial part of the central motor control system.

\section{OTHER STRUCTURES PROJECTING TO THE FACIAL NUCLEUS Pontomedullary reticular formation}

The pontomedullary RF is a premotor area, whose activation can cause widespread movements (Quessy and Freedman, 2004; Stapley and Drew, 2009). Within RF, several distinct regions can be discriminated. Of these, the dorsal medullary reticular field and the parvocellular reticular nucleus receive strong input from $\mathrm{SpVi}$ and $\mathrm{SpV} c$, while the gigantocellular reticular nucleus receives moderate input from SpVo (Zerari-Mailly et al., 2001). Relatively weak inputs from $\mathrm{SpV}$ to the other parts of RF can also be found, as well as a few connections between PrV and RF (Zerari-Mailly et al., 2001). The dorsal reticular nucleus (DRN) is probably a pain modulating area (Villanueva et al., 1988; Bouhassira et al., 1992). DRN forms, as other parts of RF, strong bilateral connections to the facial nucleus (Hattox et al., 2002; Leite-Almeida et al., 2006). Indeed, mice move their whiskers, as well as other parts of the face, in response to pain (Langford et al., 2010). In addition, DRN projects to dozens of other brain structures, including other parts of RF, the ipsilateral amygdala, periaqueductal gray, red nucleus, and $\mathrm{SpV}$, as well as the contralateral IO, SC, ZI, and several nuclei of the thalamus, including Pom and to a lesser extent VPM (LeiteAlmeida et al., 2006). Apart from a role in pain transmission, RF is also involved in "normal" whisker movements. RF neurons receiving trigeminal input project to the lateral facial and hypoglossal nuclei (Dauvergne et al., 2001). In addition, RF receives direct input from wM1, and RF stimulation causes whisker retraction (Matyas et al., 2010). RF also receives cholinergic input from the pedunculopontine tegmental nuclei (Jones, 1990) and noradrenergic input from the locus coeruleus (Jones, 1991), indicating that RF activity is strongly modulated by the general state of alertness.

\section{Zona incerta}

The zona incerta can be functionally divided into rostral (ZIr), dorsal (ZId), ventral (ZIv), and caudal (ZIc) sectors (Kim et al., 1992; Ma et al., 1992; Nicolelis et al., 1992, 1995b) and contributes to the whisker paralemniscal somatosensory pathway (Urbain and Deschênes, 2007a). It has been said to have connections with almost every center in the neuraxis (Mitrofanis, 2005). Multiple whisker receptive fields have been found in both ZId and ZIv. A somatotopic map was found to be partial in ZId and complete in ZIv. The ZId somatotopic map was characterized by large facial receptive fields including the whiskers (Nicolelis et al., 1992; Simpson et al., 2008). Direct whisker input reaches ZI mainly from both 
PrV and SpVi (Lin et al., 1990; Kolmac et al., 1998; Lavallée et al., 2005), but also via wS1 (Lin et al., 1990; Aronoff et al., 2010). Most likely, the main impact of ZI on the whisker system is by its GABAergic output to Pom. The thalamus can be divided into first order and higher-order nuclei where the latter can be defined by different coding strategies, receptive field properties and cortical layer 5 input (Diamond et al., 1992a; Ojima, 1994; Ahissar et al., 2000). ZI forms GABAergic projections that terminate on such higher-order thalamic nuclei (Barthó et al., 2002). During rest, ZIv inhibits whisker sensory transmission via Pom (Lavallée et al., 2005). However, wM1 input to the motor subsector of ZI can induce GABAergic interneurons that inhibit the whisker sensory subsector of ZI, which in turn disinhibits the relay cells of Pom, providing a mechanism of lateral inhibition in ZI (Urbain and Deschênes, 2007b). Thus, during active whisker movements, $\mathrm{wM} 1$ activity releases the inhibition on sensory gating in Pom. This implies that Pom transmits more details on whisker input during active movement than during periods of rest. Apart from wM1, also cholinergic input from PPTg and the laterodorsal tegmental nucleus (LDTg) can reduce the inhibitory output of ZIv to Pom (Trageser et al., 2006). Since the cholinergic input to ZI is highest during active states (Trageser et al., 2006), this is a possible second form of gating of the whisker input to wS1 under control of ZI. ZI forms also GABAergic projections to the intermediate and deep layers of SC, that in turn project back to ZI (Roger and Cadusseau, 1985; May, 2006). In addition, ZId has glutamatergic projections to the basal ganglia (Heise and Mitrofanis, 2004).

\section{Anterior pretectal nucleus}

Like ZI, the APT nucleus provides strong GABAergic inhibition in Pom. The morphology of the projections to Pom from ZI and APT are similar, forming multiple synapses on the thick dendrites of relay cells, and different from RT projections that form single synapses on the thin, distal dendrites of relay cells (Bokor et al., 2005; Wanaverbecq et al., 2008). Input from APT strongly suppresses whisker responses in Pom (Murray et al., 2010). In view of the heterogeneity in firing patterns of APT neurons observed in vivo, it has been suggested that APT, like ZI, controls the thalamo-cortical output in a state-dependent manner (Bokor et al., 2005). ZI and APT are reciprocally connected. There is a strong projection of both GABAergic and non-GABAergic APT neurons to ZIv, from where the thalamic projections originate (May et al., 1997). The reciprocal connection from ZIv to APT is relatively sparse (May et al., 1997; Giber et al., 2008). Thus, ZI and APT may cooperate in controlling the flow of information from Pom to the cerebral cortex in a state-dependent manner.

Apart from ZI and Pom, APT also targets a large number of brain regions. The functional relevance of these other outputs for the whisker system is still unclear, but potentially relevant target areas are SC, the pontomedullary RF, the pontine nucleus, red nucleus, and (dorsal) IO (Cadusseau and Roger, 1991; Terenzi et al., 1995; Zagon et al., 1995). In turn, APT receives strong input from amongst others wS1, SC, the deep mesencephalic nucleus, and PPTg, as well as sparse input from the locus coeruleus and the periaqueductal gray (Foster et al., 1989; Cadusseau and Roger, 1991).

\section{Red nucleus}

The red nucleus is closely associated with limb movements (Massion, 1988; Muir and Whishaw, 2000) and is composed of two parts. The magnocellular part receives input from the cerebral cortex, including wS1 and wM1 (Alloway et al., 2010), as well as from the cerebellar interposed nucleus (Teune et al., 2000), and sends its output to the contralateral limbs via the rubrospinal tract (ten Donkelaar, 1988; Paul and Gould, 2010). The parvocellular part receives its input from the cerebellar dentate nucleus (Teune et al., 2000) and sends its output to the contralateral facial nucleus (Hattox et al., 2002). Thus, from an anatomical point of view, the red nucleus is strongly implicated in the whisker system. However, electrical stimulation of the red nucleus did not evoke whisker movements in a consistent way (Isokawa-Akesson and Komisaruk, 1987).

\section{Pontine respiratory group}

The parabrachial complex and the Kölliker-Fuse nucleus, both part of the pontine respiratory group, provide strong, ipsilateral projections to the lateral facial nucleus (Isokawa-Akesson and Komisaruk, 1987; Hattox et al., 2002). The pontine respiratory group projects to several areas of the medullar respiratory group, and may therefore affect the respiratory rhythm (Smith et al., 2009). Thus, the connection between the pontine respiratory group and the lateral facial nucleus may facilitate the synchronization of sniffing and whisking. Such coupling is prominent during exploratory whisking (Welker, 1964).

\section{Ambiguus nucleus}

The ambiguus nucleus has a dense projection to the ipsilateral lateral facial nucleus (Isokawa-Akesson and Komisaruk, 1987; Hattox et al., 2002). Electrical stimulation of the ambiguus nucleus could evoke ipsilateral, rhythmic whisker movements with a remarkably low stimulation threshold (Isokawa-Akesson and Komisaruk, 1987). Since the ambiguus nucleus is mainly involved in respiration (Delgado-García et al., 1983) and swallowing (Broussard and Altschuler, 2000), it could serve to synchronize whisker movements to respiration and swallowing.

\section{Other brain regions}

This list of brain regions is incomplete since we lack sufficient knowledge of other brain regions which might be involved in the whisker system. Potentially important areas include the deep mesencephalic nucleus and the periaqueductal gray. The deep mesencephalic nucleus receives a strong, ipsilateral input from $\mathrm{wM} 1$, and forms dense projections to the lateral facial nucleus (Hattox et al., 2002; Alloway et al., 2010). Yet, its function for the whisker system is not clear. The periaqueductal gray is, amongst others, important for pain transmission and integrating defensive behavior (Behbehani, 1995; Graeff, 2004). Stimulating the periaqueductal gray results in whisker twitches (Verberne and Struyker Boudier, 1991). The periaqueductal gray receives serotonergic input from the dorsal raphe nucleus (Graeff, 2004), strong input from ipsilateral wM1 (Alloway et al., 2010), and forms relatively sparse, bilateral connections to the lateral facial nucleus (Hattox et al., 2002). For further connections of the periaqueductal gray, see Vianna and Brandão (2003). 


\section{BILATERAL COORDINATION OF WHISKER MOVEMENTS}

In the absence of object contact and head movements, whisker movements on both sides of the head tend to be symmetric. However, during active exploration, in particular involving head movements, whisker movements are often asymmetric (Towal and Hartmann, 2006, 2008; Mitchinson et al., 2007). This implies that both hemispheres are interconnected, but can be decoupled if the actual behavior requires to do so. In line with this, many, if not most, of the connections discussed in this review are actually bilateral, although the strengths of the ipsi- and contralateral projections are often quite different (see also Alloway et al., 2010). Putative candidates for the modification of interhemispheric connections, especially involving wM1, are the feedback loops with the thalamus, the basal ganglia, and the claustrum (Alloway et al., 2008, 2009, 2010). Particularly the claustrum has been proposed to facilitate interhemispheric communication of wM1 (Alloway et al., 2009; Smith and Alloway, 2010). wM1 targets the claustrum mainly contralaterally, and the claustrum projects mainly ipsilaterally to wM1. These projections are highly specific: the cortico-claustrocortical projections connect the same whisker fields in wM1 of both hemispheres (Smith and Alloway, 2010).

\section{AROUSAL, ALERTNESS, AND ATTENTION}

Whisker movements and the processing of whisker input depend on the general state of alertness. For instance, stimulation of wM1 leads to larger whisker movements in aroused rather than in awake, but sessile rats (Berg et al., 2005). Furthermore, whisker stimuli evoke smaller responses in $\mathrm{wS} 1$ showing less spreading during whisking than during rest (Ferezou et al., 2007). The neural systems that control the general state of alertness affect many brain regions and are not specific for the whisker system. We discuss here those systems of which clear effects on the whisker system have been documented or can be expected based on anatomical connections.

\section{ACETYLCHOLINE}

Central cholinergic projections, mainly originating from the basal forebrain and the tegmentum, affect the whisker system at different levels (Woolf, 1991; Dani and Bertrand, 2007). Roughly, the basal forebrain targets $\mathrm{wS} 1$ and $\mathrm{wM} 1$, while the tegmentum targets several subcortical areas. The basal forebrain is composed of several areas that provide cholinergic output, including the nucleus basalis magnocellularis (NBM; known as the Meynert nucleus in primates) of the substantia innominata. NBM is active during waking and REM sleep, but not during slow-wave sleep (Lee et al., 2005). The main projection areas of the cholinergic neurons of NBM are the entire cerebral cortex and the amygdala (Wenk, 1997; Deurveilher and Semba, 2011). Electrical stimulation of the cholinergic neurons of the NBM leads to an increased effect of wM1 stimulation on whisker movements. This effect of NBM stimulation is only observed in sessile, but less so in aroused rats (Berg et al., 2005). This could indicate that NBM is already endogenously active in aroused rats.

In addition to enhancing motor performance, cholinergic afferents also increase the sensitivity to sensory stimuli. The response to whisker stimulation in $\mathrm{wS} 1$ is increased due to acetylcholine (ACh; Oldford and Castro-Alamancos, 2003; Constantinople and
Bruno, 2011). This effect is partly due to stimulation of the basal forebrain, which enhances especially the responses to nondominant whiskers (Kuo et al., 2009). In addition, cholinergic projections from PPTg and LDTg, increase the responses to whisker stimulation in VPM, and consequently also in wS1 (Hirata and Castro-Alamancos, 2010, 2011). Furthermore, the responsiveness to whisker input of Pom is increased by cholinergic input from PPTg as well as from LDTg, due to both direct connections to Pom, where the cholinergic fibers suppress the release of GABA from projections originating in ZI (Masri et al., 2006), as well as indirectly by decreasing the neuronal activity of GABAergic projection neurons in ZI (Trageser et al., 2006). In SpVi, a similar phenomenon occurs as in $\mathrm{wS} 1$ : activity of the cholinergic input from PPTg increases the responsivity of sensory neurons to inputs from adjacent whiskers (Timofeeva et al., 2005). Finally, there are also cholinergic projections from PPTg and LDTg to SC, PrV, and the lateral facial nucleus (Satoh and Fibiger, 1986; Beak et al., 2010), but their specific functions for the whisker system are currently unknown.

The nucleus basalis magnocellularis receives strong input from the amygdala, the hypothalamus, and the thalamus, as well as from specific areas of the cerebral cortex, probably including the prefrontal and motor cortex (Haring and Wang, 1986; Irle and Markowitsch, 1986). In addition, there are weaker inputs from many other (subcortical) regions (Haring and Wang, 1986; Irle and Markowitsch, 1986). Inputs to PPTg and LDTg come from a wide range of brain regions, including the medial prefrontal and cingulate cortex (but not wS1, wS2, and wM1), the thalamus, the hypothalamus, ZI, the periaqueductal gray, SC, the pontomedullary RF, the dorsal raphe nuclei as well as from many other regions not directly involved in the whisker system (Semba and Fibiger, 1992). The input from the trigeminal and cerebellar nuclei is relatively weak (Semba and Fibiger, 1992).

In conclusion, when the cholinergic system is quiet, as during slow-wave sleep (Lee et al., 2005), whisker sensitivity is reduced, and primarily focused on the dominant whiskers. During more attentive states, input from non-dominant whiskers is processed, yielding a more detailed impression of the environment. At the same time, the cholinergic system facilitates whisker movements during arousal, which increases the sensitivity of the whisker system even further.

\section{NORADRENALINE}

Noradrenergic projections have similar effects on the sensitivity to whisker stimulation as cholinergic projections. The origin of noradrenaline is the locus coeruleus and adjacent brainstem regions (Aston-Jones and Cohen, 2005). Noradrenaline suppresses spontaneous activity of VPM via RT. As a consequence, sensory input is passed on to wS1 with a higher signal-to-noise ratio (Hirata et al., 2006; Hirata and Castro-Alamancos, 2011). In addition, the locus coeruleus can directly modulate the network dynamics of wS1 (Constantinople and Bruno, 2011). Activity of the locus coeruleus is closely related to awakeness and alertness (Aston-Jones and Cohen, 2005). Indeed, a novel environment can stimulate activity of the locus coeruleus and the anterior cingulate cortex, and thus keep the animal fully awake (Gompf et al., 2010). The main inputs to the locus coeruleus come from RF and the hypoglossal nucleus 
(Jones, 1991). Other relevant outputs are directed to RF, the facial nucleus, ZI, and NBM (Jones, 1991). Thus, although noradrenaline works via different mechanisms than $\mathrm{ACh}$, both increase the level of arousal as well as the sensitivity toward whisker input.

\section{HISTAMINE}

Histamine is also only released during wakefulness (Takahashi et al., 2006). It promotes, amongst others, vigilance (Anaclet et al., 2009; Thakkar, 2011) and the coordination of goal-directed behaviors (Valdés et al., 2010). The sole source of histamine in the brain is the hypothalamus, most notably the tuberomammillary nuclei and perhaps also the surrounding tissue (Wouterlood et al., 1986; Passani and Blandina, 2011). The tuberomammillary nuclei project to almost all brain regions, including cerebral cortex, thalamus, brainstem, and cerebellum (Pillot et al., 2002). Histaminergic connections of particular importance for the whisker system include ipsilateral projections from the ventrolateral tuberomammillary nucleus to wS1 and wM1 (Hong et al., 2010). The dorsomedial tuberomammillary nucleus projects bilaterally to $\mathrm{PrV}$ and the lateral facial nucleus (Hong et al., 2010). In addition, all layers of SC, but mainly the superficial ones, receive histaminergic input (Manning et al., 1996). Thus, there are histaminergic connections to many of the important whisker regions, and although the specific functions of these connections are currently unknown, it seems likely that histamine has a general, stimulating effect on the whisker system, comparable to that of acetylcholine and noradrenaline.

\section{SEROTONIN}

The activity of most serotonergic neurons of the dorsal raphe nucleus is strongly affected by the sleep/wake rhythm. In the awake state, they fire at very regular intervals (McGinty and Harper, 1976; Kocsis et al., 2006; Urbain et al., 2006). The dorsal raphe nucleus projects to the lateral facial nucleus (Hattox et al., 2003; Cramer and Keller, 2006; Lee et al., 2008c), where serotonin facilitates a persistent inward current (PIC) in the whisker motor neurons. This lowers their activation thresholds (Cramer et al., 2007). Indeed, spontaneous as well as wM1-induced whisker movements are largely abolished following block of serotonin receptors (Figure 7B; Hattox et al., 2003; Cramer and Keller, 2006). Thus, serotonin is both required and sufficient to generate a rhythmic whisker movement pattern, and it also modulates inputs from wM1. That makes the serotonergic system a fourth system that modulates the whisker system according to the state of alertness of the animal, together with the cholinergic, noradrenergic, and histaminergic systems.

The dorsal raphe nucleus receives inputs from wM1, but also from a wide range of cortical and subcortical areas. Particularly strong inputs come from regions with an emotional and/or cognitive function, such as the medial prefrontal cortex and the amygdala (Lee et al., 2003; Hale and Lowry, 2011). The regular spiking patterns of the dorsal raphe nucleus are in line with its putative function as CPG for rhythmic whisker movements (Hattox et al., 2003). The spiking pattern of the dorsal raphe nucleus can be perturbed by, amongst others, whisker touch and, to a lesser extent, free whisking in air (Waterhouse et al., 2004). The dorsal raphe nucleus projects to the prefrontal cortex and many

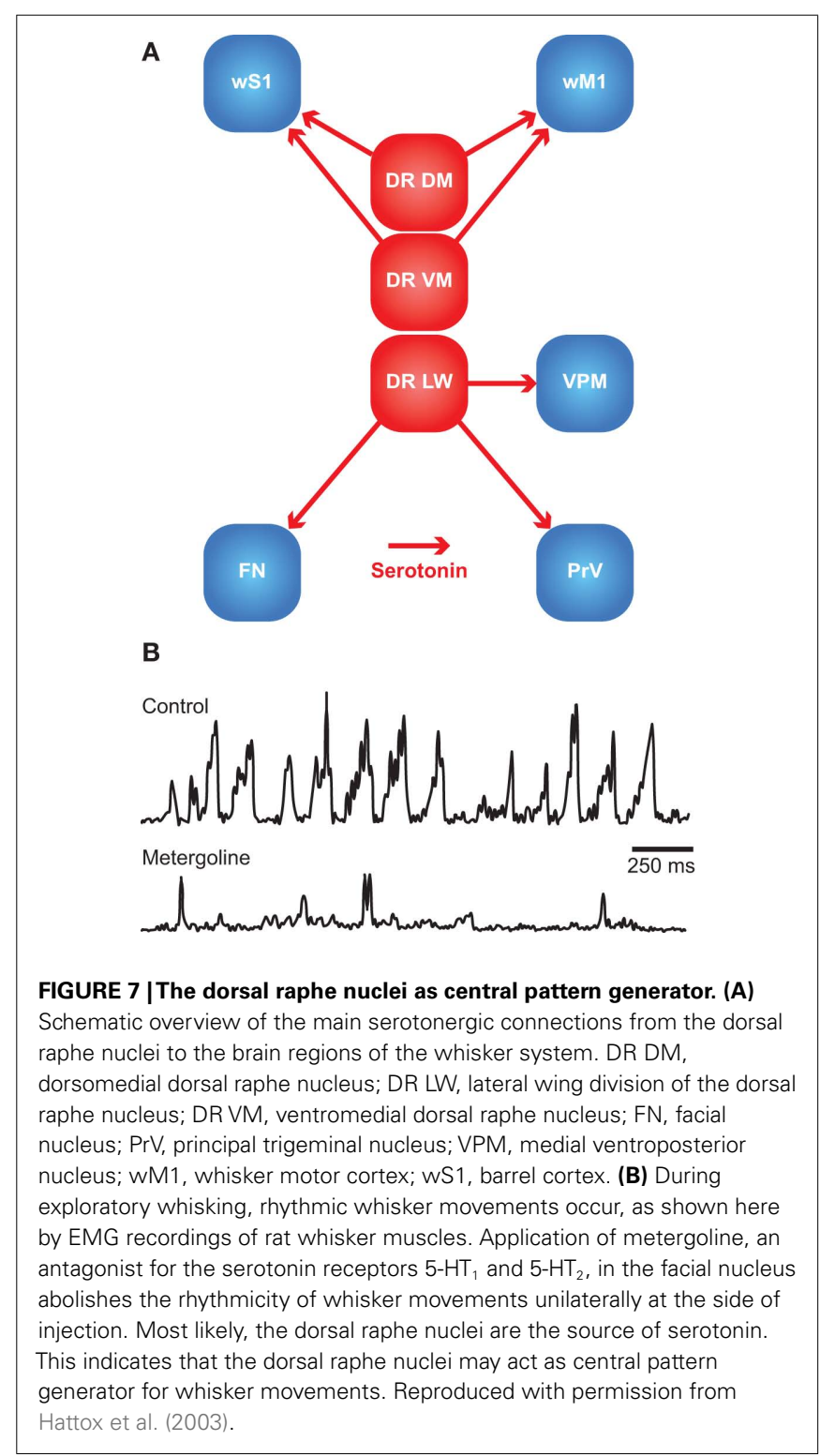

regions directly involved in the whisker system. The midline region projects to ipsilateral $\mathrm{wS} 1$ and $\mathrm{wM} 1$, and the lateral wing division to ipsilateral VPMvl, PrV, and facial nucleus (Figure 7A; Kirifides et al., 2001; Sheibani and Farazifard, 2006; Lee et al., 2008c). Thus, next to being a CPG for rhythmic whisker movements via its direct connection to the lateral facial nucleus, the dorsal raphe nucleus affects several other regions of the whisker system.

\section{TIMING IN THE WHISKER SYSTEM}

Timing is essential for the whisker system. During active touch, rats move their whiskers rhythmically over an object. Irregularities in the surface texture cause small disruptions in the whisker movements, which evoke neuronal responses (Figures 1B,C; Szwed et al., 2003; Hartmann, 2009; Jadhav and Feldman, 2010). Active touch can be instrumental for several forms of behavior. For instance, Etruscan shrews use their whiskers to locate prey. On 


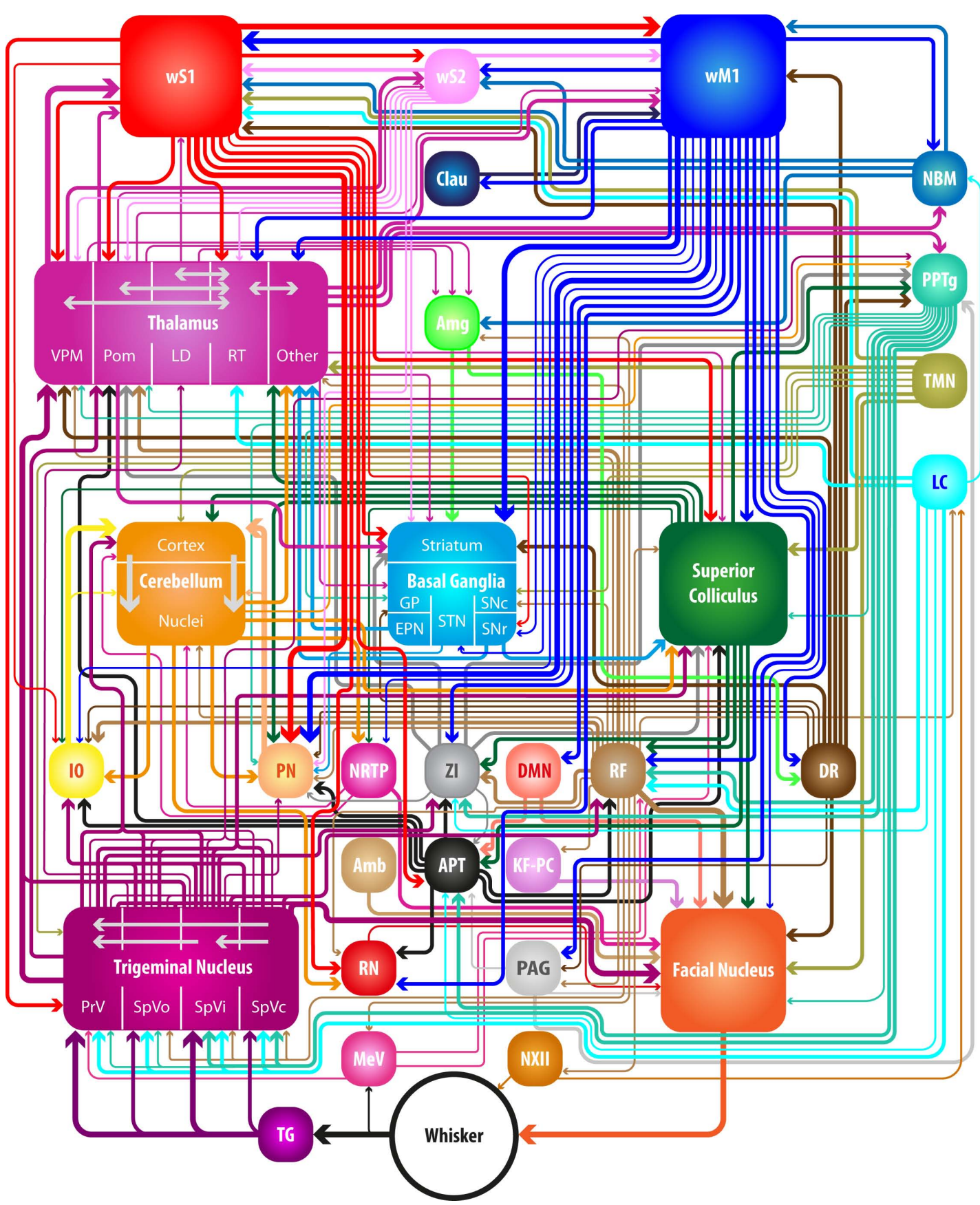

FIGURE 8 | Neuronal connections in the whisker system. Many brain regions are involved in controlling the whiskers. Schematic

representation of the connections discussed in the main text. Thickness of the arrows corresponds to the robustness of the connection involved (divided among three different levels). Some local connections are indicated, but for the connections between the nuclei of the basal ganglia, see Figure 5A. Amb, ambiguus nucleus; Amg, amygdala; APT, anterior pretectal nucleus; Clau, claustrum; DMN, deep mesencephalic nucleus; DR, dorsal raphe nucleus; EPN, entopeduncular nucleus; GP, globus pallidus; 1O, inferior olive; KF-PC, Kölliker-Fuse nucleus and parabrachial complex; LC, locus coeruleus; LD, laterodorsal nucleus; $\mathrm{MeV}$, mesencephalic trigeminal nucleus; NBM, nucleus basalis magnocellularis; NRTP, nucleus reticularis tegmenti pontis; NXII, hypoglossal nucleus; PAG, periaqueductal gray; PN, pontine nucleus; Pom, medial posterior nucleus; PPTg, pedunculopontine tegmental nucleus and the laterodorsal tegmental nucleus; PrV, principal trigeminal nucleus; RF, pontomedullar reticular formation; RN, red nucleus; RT, reticular nucleus; SNc, substantia nigra pars compacta; SNr, substantia nigra pars reticulata; SpVc, spinal trigeminal nucleus pars caudalis; SpVi, spinal trigeminal nucleus pars interpolaris; SpVo, spinal trigeminal nucleus pars oralis; STN, subthalamic nucleus; TG, trigeminal ganglion; TMN, tuberomammillary nucleus; VPM, medial venteroposterior nucleus; wM1, whisker motor cortex; wS1, barrel cortex; wS2, whisker part of the secondary somatosensory cortex; ZI, zona incerta. 
average, they initiate an attack on average $179 \mathrm{~ms}$ after the first whisker contact, but this interval can be as short as $53 \mathrm{~ms}$ (Munz et al., 2010). Indeed, the vibrissae can be used experimentally to explore interval timing. Stimulation of the vibrissae can act as a CS in eyeblink conditioning (Das et al., 2001; Leal-Campanario et al., 2006; Galvez et al., 2009). The reverse is also possible: to evoke vibrissal movements as an unconditioned response (UR; Troncoso et al., 2004).

Whisker responses are rapidly distributed over the brain. Many brain regions receive direct input from the trigeminal nuclei, often in addition to input from wS1 (Figure 8). As a consequence, the whisker responses in the cerebellum (Bosman et al., 2010) and SC (Bezdudnaya and Castro-Alamancos, 2011) are bi-phasic. Fast, direct whisker responses are followed by wS1-mediated responses with longer latencies. This allows for fast, multi-center processing of whisker data.

Although wM1 is able to evoke, on a cycle-by-cycle base, rhythmic whisker movements under experimental conditions involving artificial disinhibition (Castro-Alamancos, 2006), under more physiological conditions, the frequency of microstimulation in wM1 does not necessarily correspond to the frequency of the evoked whisker movements (Berg and Kleinfeld, 2003b; Haiss and Schwarz, 2005). However, widespread rhythmic activity (at $7-12 \mathrm{~Hz}$ ) involving cerebral cortex, thalamus, and brainstem often precedes the onset of rhythmic whisker movements, which is then phase-locked to the brain oscillations (Nicolelis et al., 1995a). Nevertheless, it is likely that subcortical structures critically participate in the generation of rhythmicity of the whisker movements. The serotonergic projection from the dorsal raphe nuclei to the facial nucleus has especially been found to be effective in generating rhythmic whisker movements (Hattox et al., 2003). However also the cerebellum and IO may be involved. After blocking IO pharmacologically, as well as following cerebellectomy, the frequencydependence of whisker movements following wM1 stimulation was altered (Lang et al., 2006). In contrast, SC does not seem to be involved in the generation of rhythmic movements, as its activity causes prolonged whisker protractions (Hemelt and Keller, 2008).

\section{REFERENCES}

Ahissar, E., Sosnik, R., and Haidarliu, S. (2000). Transformation from temporal to rate coding in a somatosensory thalamocortical pathway. Nature 406, 302-306.

Ahl, A. S. (1982). Evidence of use of vibrissae in swimming in Sigmodon fulviventer. Anim. Behav. 30, 1203-1206.

Ahl, A. S. (1986). The role of vibrissae in behavior: a status review. Vet. Res. Commun. 10, 245-268.

Akaike, T. (1992). The tectorecipient zone in the inferior olivary nucleus in the rat. J. Comp. Neurol. 320, 398-414.

Alloway, K. D. (2008). Information processing streams in rodent barrel cortex: the differential functions of barrel and septal circuits. Cereb. Cortex 18, 979-989.
Alloway, K. D., Crist, J., Mutic, J. J., and Roy, S. A. (1999). Corticostriatal projections from rat barrel cortex have an anisotropic organization that correlates with vibrissal whisking behavior. J. Neurosci. 19, 10908-10922.

Alloway, K. D., Lou, L., NwabuezeOgbo, F., and Chakrabarti, S. (2006). Topography of cortical projections to the dorsolateral neostriatum in rats: multiple overlapping sensorimotor pathways. J. Comp. Neurol. 499, 33-48.

Alloway, K. D., Mutic, J. J., Hoffer, Z. S., and Hoover, J. E. (2000). Overlapping corticostriatal projections from the rodent vibrissal representations in primary and secondary somatosensory cortex. J. Comp. Neurol. 428, 51-67.

\section{CONCLUSION}

Whiskers play a central role in the lives and loves of rodents. Accordingly, many brain regions can affect whisker movements. Whisker movements depend on the general state of arousal, they are coupled to the movements of other mobile senses, like the eyes and the auricles, and integrated with other forms of behavior, like sniffing, swallowing, and locomotion. Animals orient their whiskers based on reward expectancy, for instance when searching for food. With respect to whisker input, the level of detail that is transmitted to higher brain areas depends on the general state of arousal as well as on the activity of the whisker motor cortex, and the context of the animal's environment. The sensory and motor systems of the whiskers are coupled by a number of sensorimotor feedback loops, allowing the animals to adjust whisker movements to sensory input. Unfortunately, many of the brain regions involved in these feedback loops have received relatively little attention with respect to the whisker system. Hence, our knowledge on the relative importance of these areas and their connections is incomplete. Yet, based on the current data available to us, we present a scheme of the relevant anatomical connections in Figure 8. Although these brain structures have many more connections, we have attempted to highlight the most prominent ones. However, the complexity of the whisker system seems to depend on the behavioral state; the more active an animal is, the more complex its whisker movements are and therefore a greater level of detail results during sensory and motor information processing.

\section{ACKNOWLEDGMENTS}

The authors thank Drs. Frank Rice and Hans Dringenberg for their comments on a previous version of the manuscript and Dr. Reha Erzurumlu for contributing an unpublished photomicrograph. We kindly thank the Netherlands Organization for Scientific Research (NWO; AH), the Dutch Organization for Medical Sciences (ZonMw; CIDZ), Life Sciences (ALW; CIDZ), Senter (Neuro-Bsik; CIDZ), Prinses Beatrix Fonds (CIDZ), and the SENSOPAC, CEREBNET, and C7 programs of the European Community (CIDZ) for their financial support. We also thank our lab members for valuable discussions.

Alloway, K. D., Olson, M. L., and Smith, J. B. (2008). Contralateral corticothalamic projections from MI whisker cortex: potential route for modulating hemispheric interactions. J. Comp. Neurol. 510, 100-116.

Alloway, K. D., Smith, J. B., and Beauchemin, K. J. (2010). Quantitative analysis of the bilateral brainstem projections from the whisker and forepaw regions in rat primary motor cortex. J. Comp. Neurol. 518, 4546-4566.

Alloway, K. D., Smith, J. B., Beauchemin, K. J., and Olson, M. L. (2009). Bilateral projections from rat MI whisker cortex to the neostriatum, thalamus, and claustrum: forebrain circuits for modulating whisking behavior. J. Comp. Neurol. 515, 548-564.
Alloway, K. D., Zhang, M., and Chakrabarti, S. (2004). Septal columns in rodent barrel cortex: functional circuits for modulating whisking behavior. J. Comp. Neurol. 480, 299-309.

Anaclet, C., Parmentier, R., Ouk, K., Guidon, G., Buda, C., Sastre, J. P., Akaoka, H., Sergeeva, O. A., Yanagisawa, M., Ohtsu, H., Franco, P., Haas, H. L., and Lin, J. S. (2009). Orexin/hypocretin and histamine: distinct roles in the control of wakefulness demonstrated using knockout mouse models. J. Neurosci. 29, 14423-14438.

Andermann, M. L., and Moore, C. I. (2006). A somatotopic map of vibrissa motion direction within a barrel column. Nat. Neurosci. 9, 543-551. 
Anjum, F., Turni, H., Mulder, P. G. H., van der Burg, J., and Brecht, M. (2006). Tactile guidance of prey capture in Etruscan shrews. Proc. Natl. Acad. Sci. U.S.A. 103, 16544-16549.

Apps, R., and Hawkes, R. (2009). Cerebellar cortical organization: a onemap hypothesis. Nat. Rev. Neurosci. 10, 670-681.

Arabzadeh, E., Zorzin, E., and Diamond, M. E. (2005). Neuronal encoding of texture in the whisker sensory pathway. PLoS Biol. 3, e17. doi: 10.1371/journal.pbio.0030017

Armstrong-James, M., and Callahan, C. A. (1991). Thalamo-cortical processing of vibrissal information in the rat. II. Spatiotemporal convergence in the thalamic ventroposterior medial nucleus $(\mathrm{VPm})$ and its relevance to generation of receptive fields of S1 cortical "barrel" neurones. J. Comp. Neurol. 303, 211-224.

Armstrong-James, M., and Fox, K. (1987). Spatiotemporal convergence and divergence in the rat S1 "barrel” cortex. J. Comp. Neurol. 263, 265-281.

Aronoff, R., Matyas, F., Mateo, C., Ciron, C., Schneider, B., and Petersen, C. C. H. (2010). Long-range connectivity of mouse primary somatosensory barrel cortex. Eur. J. Neurosci. 31, 2221-2233.

Ashwell, K. W. (1982). The adult mouse facial nerve nucleus: morphology and musculotopic organization. $J$. Anat. 135, 531-538.

Aston-Jones, G., and Cohen, J. D. (2005). An integrative theory of locus coeruleus-norepinephrine function: adaptive gain and optimal performance. Annu. Rev. Neurosci. $28,403-450$.

Aumann, T. D., Rawson, J. A., Finkelstein, D. I., and Horne, M. K. (1994). Projections from the lateral and interposed cerebellar nuclei to the thalamus of the rat: a light and electron microscopic study using single and double anterograde labelling. $J$. Comp. Neurol. 349, 165-181.

Axelrad, H., and Crepel, F. (1977). Représentation sélective des vibrisses mystaciales au niveau des cellules de Purkinje du cervelet par la voie des fibres grimpantes chez le rat. C.R. Hebd. Seances Acad. Sci. Ser. D Sci. Nat. 284, 1321-1324.

Barthó, P., Freund, T. F., and Acsády, L. (2002). Selective GABAergic innervation of thalamic nuclei from zona incerta. Eur. J. Neurosci. 16, 999-1014.

Barthó, P., Slézia, A., Varga, V., Bokor, H., Pinault, D., Buzsáki, G., and Acsády, L. (2007). Cortical control of zona incerta. J. Neurosci. 27, 1670-1681.
Beak, S. K., Hong, E. Y., and Lee, H. S. (2010). Collateral projection from the forebrain and mesopontine cholinergic neurons to whiskerrelated, sensory and motor regions of the rat. Brain Res. 1336, 30-45.

Beckstead, R. M., Domesick, V. B., and Nauta, W. J. H. (1979). Efferent connections of the substantia nigra and ventral tegmental area in the rat. Brain Res. 175, 191-217.

Behbehani, M. M. (1995). Functional characteristics of the midbrain periaqueductal gray. Prog. Neurobiol. 46 , 575-605.

Beitz, A. J. (1989). Possible origin of glutamatergic projections to the midbrain periaqueductal gray and deep layer of the superior colliculus of the rat. Brain Res. Bull. 23, 25-35.

Belford, G. R., and Killackey, H. P. (1979). Vibrissae representation in subcortical trigeminal centers of the neonatal rat. J. Comp. Neurol. 183, 305-321.

Benison, A. M., Rector, D. M., and Barth, D. S. (2007). Hemispheric mapping of secondary somatosensory cortex in the rat. J. Neurophysiol. 97, 200-207.

Berg, R. W., Friedman, B., Schroeder, L. F., and Kleinfeld, D. (2005). Activation of nucleus basalis facilitates cortical control of a brain stem motor program. J. Neurophysiol. 94, 699-711.

Berg, R. W., and Kleinfeld, D. (2003a). Rhythmic whisking by rat: retraction as well as protraction of the vibrissae is under active muscular control. J. Neurophysiol. 89, 104-117.

Berg, R. W., and Kleinfeld, D. (2003b). Vibrissa movement elicited by rhythmic electrical microstimulation to motor cortex in the aroused rat mimics exploratory whisking. $J$. Neurophysiol. 90, 2950-2963.

Bermejo, R., Friedman, W., and Zeigler, H. P. (2005). Topography of whisking II: interaction of whisker and pad. Somatosens. Mot. Res. 22, 213-220.

Bermejo, R., Vyas, A., and Zeigler, H. P. (2002). Topography of rodent whisking I. Two-dimensional monitoring of whisker movements. Somatosens. Mot. Res. 19, 341-346.

Bezdudnaya, T., and Castro-Alamancos, M. A. (2011). Superior colliculus cells sensitive to active touch and texture during whisking. J. Neurophysiol. 106, 332-346.

Bezdudnaya, T., and Keller, A. (2008). Laterodorsal nucleus of the thalamus: a processor of somatosensory inputs. J. Comp. Neurol. 507, 1979-1989.

Blanchard, R. J., Takahashi, L. K., Fukunaga, K. K., and Blanchard, D. C.
(1977). Functions of the vibrissae in the defensive and aggressive behavior of the rat. Aggress. Behav. 3 , 231-240.

Boehnke, S. E., and Munoz, D. P. (2008). On the importance of the transient visual response in the superior colliculus. Curr. Opin. Neurobiol. 18, 544-551.

Bokor, H., Acsády, L., and Deschênes, M. (2008). Vibrissal responses of thalamic cells that project to the septal columns of the barrel cortex and to the second somatosensory area. $J$. Neurosci. 28, 5169-5177.

Bokor, H., Frère, S. G. A., Eyre, M. D., Slézia, A., Ulbert, I., Lüthi, A., and Acsády, L. (2005). Selective GABAergic control of higher-order thalamic relays. Neuron 45, 929-940.

Bosman, L. W. J., Koekkoek, S. K. E., Shapiro, J., Rijken, B. F. M., Zandstra, F., van der Ende, B., Owens, C. B., Potters, J. W., de Gruijl, J. R., Ruigrok, T. J. H., and De Zeeuw, C. I. (2010). Encoding of whisker input by cerebellar Purkinje cells. $J$. Physiol. (Lond.) 588, 3757-3783.

Bosman, L. W. J., Takechi, H., Hartmann, J., Eilers, J., and Konnerth A. (2008). Homosynaptic LTP of the "winner" climbing fiber synapse in developing Purkinje cells. J. Neurosci. 28, 798-807.

Bostan, A. C., Dum, R. P., and Strick, P. L. (2010). The basal ganglia communicate with the cerebellum. Proc. Natl. Acad. Sci. U.S.A. 107, 8452-8456.

Bouhassira, D., Villanueva, L., Bing, Z., and le Bars, D. (1992). Involvement of the subnucleus reticularis dorsalis in diffuse noxious inhibitory controls in the rat. Brain Res. 595, 353-357.

Bourassa, J., Pinault, D., and Deschênes, M. (1995). Corticothalamic projections from the cortical barrel field to the somatosensory thalamus in rats: a single-fibre study using biocytin as an anterograde tracer. Eur. J. Neurosci. 7, 19-30.

Brecht, M. (2007). Barrel cortex and whisker-mediated behaviors. Curr. Opin. Neurobiol. 17, 408-416.

Brecht, M., Krauss, A., Muhammad, S., Sinai-Esfahani, L., Bellanca, S. and Margrie, T. W. (2004a). Organization of rat vibrissa motor cortex and adjacent areas according to cytoarchitectonics, microstimulation, and intracellular stimulation of identified cells. J. Comp. Neurol. 479, 360-373.

Brecht, M., Schneider, M., Sakmann, B. and Margrie, T. W. (2004b). Whisker movements evoked by stimulation of single pyramidal cells in rat motor cortex. Nature 427, 704-710.
Brecht, M., Preilowski, B., and Merzenich, M. M. (1997). Functional architecture of the mystacial vibrissae. Behav. Brain Res. 84, 81-97.

Brecht, M., Roth, A., and Sakmann, B. (2003). Dynamic receptive fields of reconstructed pyramidal cells in layers 3 and 2 of rat somatosensory barrel cortex. J. Physiol. (Lond.) 553, 243-265.

Brecht, M., and Sakmann, B. (2002a). Dynamic representation of whisker deflection by synaptic potentials in spiny stellate and pyramidal cells in the barrels and septa of layer 4 rat somatosensory cortex. J. Physiol. (Lond.) 543, 49-70.

Brecht, M., and Sakmann, B. (2002b). Whisker maps of neuronal subclasses of the rat ventral posterior medial thalamus, identified by whole-cell voltage recording and morphological reconstruction. J. Physiol. (Lond.) 538, 495-515.

Brodal, P. (1980). The cortical projection to the nucleus reticularis tegmenti pontis in the rhesus monkey. Exp. Brain Res. 38, 19-27.

Brodal, P., and Bjaalie, J. G. (1992). Organization of the pontine nuclei. Neurosci. Res. 13, 83-118.

Broussard, D. L., and Altschuler, S. M. (2000). Brainstem viscerotopic organization of afferents and efferents involved in the control of swallowing. Am. J. Med. 108(Suppl. 4a), 79S-86S.

Brown, I. E., and Bower, J. M. (2001). Congruence of mossy fiber and climbing fiber tactile projections in the lateral hemispheres of the rat cerebellum. J. Comp. Neurol. 429, 59-70.

Brown, J. T., Chan-Palay, V., and Palay, S. L. (1977). A study of afferent input to the inferior olivary complex in the rat by retrograde axonal transport of horseradish peroxidase. J. Comp. Neurol. 176, 1-22.

Brumberg, J. C., Pinto, D. J., and Simons, D. J. (1999). Cortical columnar processing in the rat whiskerto-barrel system. J. Neurophysiol. 82, 1808-1817.

Bruno, R. M., Khatri, V., Land, P. W., and Simons, D. J. (2003). Thalamocortical angular tuning domains within individual barrels of rat somatosensory cortex. J. Neurosci. 23, 9565-9574.

Bureau, I., von Saint Paul, F., and Svoboda, K. (2006). Interdigitated paralemniscal and lemniscal pathways in the mouse barrel cortex PLoS Biol. 4, e382. doi: 10.1371/journal.pbio.0040382 
Burne, R. A., Azizi, S. A., Mihailoff, G. A., and Woodward, D. J. (1981). The tectopontine projection the the rat with comments on visual pathways to the basilar pons. J. Comp. Neurol. 202, 287-307.

Cadusseau, J., and Roger, M. (1991). Cortical and subcortical connections of the pars compacta of the anterior pretectal nucleus in the rat. Neurosci. Res. 12, 83-100.

Carvell, G. E., and Simons, D. J. (1986). Somatotopic organization of the second somatosensory area (SII) in the cerebral cortex of the mouse. Somatosens. Res. 3, 213-237.

Carvell, G. E., and Simons, D. J. (1987). Thalamic and corticocortical connections of the second somatic sensory area of the mouse. J. Comp. Neurol. 265, 409-427.

Carvell, G. E., and Simons, D. J. (1990). Biometric analyses of vibrissal tactile discrimination in the rat. J. Neurosci. 10, 2638-2648.

Carvell, G. E., and Simons, D. J. (1995). Task- and subject-related differences in sensorimotor behavior during active touch. Somatosens. Mot. Res. 12, 1-9.

Castro-Alamancos, M. A. (2006). Vibrissa myoclonus (rhythmic retractions) driven by resonance of excitatory networks in motor cortex. J. Neurophysiol. 96, 1691-1698.

Cauller, L. J., Clancy, B., and Connors, B. W. (1998). Backward cortical projections to primary somatosensory cortex in rats extend long horizontal axons in layer I. J. Comp. Neurol. 390, 297-310.

Chakrabarti, S., and Alloway, K. D. (2006). Differential origin of projections from SI barrel cortex to the whisker representations in SII and MI. J. Comp. Neurol. 498, 624-636.

Chakrabarti, S., Zhang, M., and Alloway, K. D. (2008). MI neuronal responses to peripheral whisker stimulation: relationship to neuronal activity in si barrels and septa. J. Neurophysiol. 100, 50-63.

Chapin, J. K., Sadeq, M., and Guise, J. L. U. (1987). Corticocortical connections within the primary somatosensory cortex of the rat. J. Comp. Neurol. 263, 326-346.

Chernova, O. F. (2006). Evolutionary aspects of hair polymorphism. Biol. Bull. 33, 43-52.

Chmielowska, J., Carvell, G. E., and Simons, D. J. (1989). Spatial organization of thalamocortical and corticothalamic projection systems in the rat SmI barrel cortex. J. Comp. Neurol. 285, 325-338.

Chu, C. P., Bing, Y. H., and Qiu, D. L. (2011). Sensory stimulus evokes inhibition rather than excitation in cerebellar Purkinje cells in vivo in mice. Neurosci. Lett. 487, 182-186.

Cicirata, F., Angaut, P., Cioni, M., Serapide, M. F., and Papale, A. (1986). Functional organization of thalamic projections to the motor cortex. An anatomical and electrophysiological study in the rat. Neuroscience 19, 81-99.

Cohen, J. D., Hirata, A., and CastroAlamancos, M. A. (2008). Vibrissa sensation in superior colliculus: wide-field sensitivity and statedependent cortical feedback. J. Neurosci. 28, 11205-11220.

Colechio, E. M., and Alloway, K. D. (2009). Differential topography of the bilateral cortical projections to the whisker and forepaw regions in rat motor cortex. Brain Struct. Funct. 213, 423-439.

Constantinople, C. M., and Bruno, R. M. (2011). Effects and mechanisms of wakefulness on local cortical networks. Neuron 69, 1061-1068.

Cosenza, R. M., and Moore, R. Y. (1984). Afferent connections of the ventral lateral geniculate nucleus in the rat: an HRP study. Brain Res. 310, 367-370.

Cox, C. L., Huguenard, J. R., and Prince, D. A. (1997). Nucleus reticularis neurons mediate diverse inhibitory effects in thalamus. Proc. Natl. Acad. Sci. U.S.A. 94, 8854-8859.

Crabtree, J. W., Collingridge, G. L., and Isaac, J. T. R. (1998). A new intrathalamic pathway linking modalityrelated nuclei in the dorsal thalamus. Nat. Neurosci. 1, 389-394.

Cramer, N. P., and Keller, A. (2006). Cortical control of a whisking central pattern generator. J. Neurophysiol. 96, 209-217.

Cramer, N. P., Li, Y., and Keller, A. (2007). The whisking rhythm generator: a novel mammalian network for the generation of movement. $J$. Neurophysiol. 97, 2148-2158.

Crandall, J. E., Korde, M., and Caviness, V. S. Jr. (1986). Somata of layer $\mathrm{V}$ projection neurons in the mouse barrelfield cortex are in preferential register with the sides and septa of the barrels. Neurosci. Lett. 67, 19-24.

Crochet, S., and Petersen, C. C. H. (2006). Correlating whisker behavior with membrane potential in barrel cortex of awake mice. Nat. Neurosci. 9, 608-610.

Crochet, S., Poulet, J. F. A., Kremer, Y., and Petersen, C. C. H. (2011). Synaptic mechanisms underlying sparse coding of active touch. Neuron 69, 1160-1175.

Cruikshank, S. J., Lewis, T. J., and Connors, B. W. (2007). Synaptic basis for intense thalamocortical activation of feedforward inhibitory cells in neocortex. Nat. Neurosci. 10, 462-468.

Cruikshank, S. J., Urabe, H., Nurmikko, A. V., and Connors, B. W. (2010). Pathway-specific feedforward circuits between thalamus and neocortex revealed by selective optical stimulation of axons. Neuron 65, 230-245.

Curtis, J. C., and Kleinfeld, D. (2009). Phase-to-rate transformations encode touch in cortical neurons of a scanning sensorimotor system. Nat. Neurosci. 12, 492-501.

Dani, J. A., and Bertrand, D. (2007). Nicotinic acetylcholine receptors and nicotinic cholinergic mechanisms of the central nervous system. Annu. Rev. Pharmacol. Toxicol. 47, 699-729.

Das, S., Weiss, C., and Disterhoft, J. F. (2001). Eyeblink conditioning in the rabbit (Oryctolagus cuniculus) with stimulation of the mystacial vibrissae as a conditioned stimulus. Behav. Neurosci. 115, 731-736.

Dauvergne, C., Pinganaud, G., Buisseret, P., Buisseret-Delmas, C., and ZerariMailly, F. (2001). Reticular premotor neurons projecting to both facial and hypoglossal nuclei receive trigeminal afferents in rats. Neurosci. Lett. 311, 109-112.

Davie, J. T., Clark, B. A., and Häusser, M. (2008). The origin of the complex spike in cerebellar Purkinje cells. J. Neurosci. 28, 7599-7609.

De Kock, C. P. J., Bruno, R. M., Spors, H., and Sakmann, B. (2007). Layer and cell type specific suprathreshold stimulus representation in primary somatosensory cortex. J. Physiol. (Lond.) 581, 139.

De Kock, C. P. J., and Sakmann, B. (2009). Spiking in primary somatosensory cortex during natural whisking in awake headrestrained rats is cell-type specific. Proc. Natl. Acad. Sci. U.S.A. 106, 16446-16450.

De Zeeuw, C. I., Hoebeek, F. E., Bosman, L. W. J., Schonewille, M., Witter, L., and Koekkoek, S. K. (2011). Spatiotemporal firing patterns in the cerebellum. Nat. Rev. Neurosci. 12, 327-344.

De Zeeuw, C. I., and Yeo, C. H. (2005). Time and tide in cerebellar memory formation. Curr. Opin. Neurobiol. 15, 667-674.

Dehnhardt, G., Hyvärinen, H., Palviainen, A., and Klauer, G. (1999). Structure and innervation of the vibrissal follicle-sinus complex in the Australian water rat, Hydromys chrysogaster. J. Comp. Neurol. 411, 550-562.

Dehnhardt, G., and Kaminski, A. (1995). Sensitivity of the mystacial vibrissae of harbour seals (Phoca vitulina) for size differences of actively touched objects. J. Exp. Biol. 198, 2317-2323.

Dehnhardt, G., Mauck, B., Hanke, W., and Bleckmann, H. (2001). Hydrodynamic trail-following in harbor seals (Phoca vitulina). Science 293, 102-104.

Dehnhardt, G., Mauck, B., and Hyvärinen, H. (1998). Ambient temperature does not affect the tactile sensitivity of mystacial vibrissae in harbour seals. J. Exp. Biol. 201, 3023-3029.

Delgado-García, J. M., López-Barneo, J., Serra, R., and González-Barón, S. (1983). Electrophysiological and functional identification of different neuronal types within the nucleus ambiguus in the cat. Brain Res. 277, 231-240.

Deschênes, M., Timofeeva, E., Lavallée, P., and Dufresne, C. (2005). The vibrissal system as a model of thalamic operations. Prog. Brain Res. 149, 31-40.

Deschênes, M., Veinante, P., and Zhang, Z. W. (1998). The organization of corticothalamic projections: reciprocity versus parity. Brain Res. Brain Res. Rev. 28, 286-308.

Desilets-Roy, B., Varga, C., Lavallée, P., and Deschênes, M. (2002). Substrate for cross-talk inhibition between thalamic barreloids. J. Neurosci. 22, RC218.

Deurveilher, S., and Semba, K. (2011). Basal forebrain regulation of cortical activity and sleep-wake states: roles of cholinergic and non-cholinergic neurons. Sleep Biol. Rhythms 9, 65-70.

Di Chiara, G., Porceddu, M. L., Morelli, M., Mulas, M. L., and Gessa, G. L. (1979). Evidence for a GABAergic projection from the substantia nigra to the ventromedial thalamus and to the superior colliculus of the rat. Brain Res. 176, 273-284.

Di Matteo, V., Pierucci, M., Esposito, E., Crescimanno, G., Benigno, A., and Di Giovanni, G. (2008). Serotonin modulation of the basal ganglia circuitry: therapeutic implication for Parkinson's disease and other motor disorders. Prog. Brain Res. 172, 423-463.

Diamond, M. E., Armstrong-James, M., Budway, M. J., and Ebner, F. F. (1992a). Somatic sensory responses in the rostral sector of the posterior group $(\mathrm{POm})$ and in the ventral posterior medial nucleus (VPM) of the rat thalamus: dependence on the barrel field cortex. J. Comp. Neurol. 319, 66-84. 
Diamond, M. E., Armstrong-James, M., and Ebner, F. F. (1992b). Somatic sensory responses in the rostral sector of the posterior group (POm) and in the ventral posterior medial nucleus (VPM) of the rat thalamus. J. Comp. Neurol. 318, 462-476.

Diamond, M. E., von Heimendahl, M., Knutsen, P. M., Kleinfeld, D., and Ahissar, E. (2008). 'Where' and 'what' in the whisker sensorimotor system. Nat. Rev. Neurosci. 9, 601-612.

Dörfl, J. (1982). The musculature of the mystacial vibrissae of the white mouse. J. Anat. 135, 147-154.

Dörfl, J. (1985). The innervation of the mystacial region of the white mouse: a topographical study. J. Anat. 142, 173-184.

Ebara, S., Kumamoto, K., Matsuura, T., Mazurkiewicz, J. E., and Rice, F. L. (2002). Similarities and differences in the innervation of mystacial vibrissal follicle-sinus complexes in the rat and cat: a confocal microscopic study. J. Comp. Neurol. 449, 103-119.

Eccles, J., Llinás, R., and Sasaki, K. (1964). Excitation of cerebellar Purkinje cells by the climbing fibres. Nature 203, 245-246.

Eller, T., and Chan-Palay, V. (1976). Afferents to the cerebellar lateral nucleus. Evidence from retrograde transport of horseradish peroxidase after pressure injections through micropipettes. J. Comp. Neurol. 166, 285-301.

Erzurumlu, R. S., Bates, C. A., and Killackey, H. P. (1980). Differential organization of thalamic projection cells in the brain stem trigeminal complex of the rat. Brain Res. 198, 427-433.

Erzurumlu, R. S., and Killackey, H. P. (1979). Efferent connections of the brainstem trigeminal complex with the facial nucleus of the rat. J. Comp. Neurol. 188, 75-86.

Erzurumlu, R. S., and Killackey, H. P. (1980). Diencephalic projections of the subnucleus interpolaris of the brainstem trigeminal complex in the rat. Neuroscience 5, 1891-1901.

Erzurumlu, R. S., and Killackey, H. P. (1983). Development of order in the rat trigeminal system. J. Comp. Neurol. 213, 365-380.

Erzurumlu, R. S., Murakami, Y., and Rijli, F. M. (2010). Mapping the face in the somatosensory brainstem. Nat. Rev. Neurosci. 11, 252-263.

Esakov, S. A., and Pronichev, I. V. (2001). Movement representations of facial muscles and vibrissae in cerebellar cortex of the white mouse Mus musculus. J. Evol. Biochem. Physiol. 37, 642-647.

Esposito, E., Di Matteo, V., and Di Giovanni, G. (2007). Death in the substantia nigra: a motor tragedy. Expert Rev. Neurother. 7, 677-697.

Fabri, M., and Burton, H. (1991). Ipsilateral cortical connections of primary somatic sensory cortex in rats. J. Comp. Neurol. 311, 405-424.

Favaro, P. D. N., Gouvêa, T. S., de Oliveira, S. R., Vautrelle, N., Redgrave, P., and Comoli, E. (2011). The influence of vibrissal somatosensory processing in rat superior colliculus on prey capture. Neuroscience 176, 318-327.

Fee, M. S., Mitra, P. P., and Kleinfeld, D. (1997). Central versus peripheral determinants of patterned spike activity in rat vibrissa cortex during whisking. J. Neurophysiol. 78, 1144-1149.

Feldmeyer, D., Lübke, J., Silver, R. A., and Sakmann, B. (2002). Synaptic connections between layer 4 spiny neurone-layer $2 / 3$ pyramidal cell pairs in juvenile rat barrel cortex: physiology and anatomy of interlaminar signalling within a cortical column. J. Physiol. (Lond.) 538, 803-822.

Feldmeyer, D., Roth, A., and Sakmann, B. (2005). Monosynaptic connections between pairs of spiny stellate cells in layer 4 and pyramidal cells in layer $5 \mathrm{~A}$ indicate that lemniscal and paralemniscal afferent pathways converge in the infragranular somatosensory cortex. J. Neurosci. 25, 3423-3431.

Ferezou, I., Haiss, F., Gentet, L. J., Aronoff, R., Weber, B., and Petersen, C. C. H. (2007). Spatiotemporal dynamics of cortical sensorimotor integration in behaving mice. $\mathrm{Neu}$ ron 56, 907-923.

Fitzgerald, O. (1940). Discharges from the sensory organs of the cat's vibrissae and the modification in their activity by ions. J. Physiol. (Lond.) 98, 163-178.

Foster, G. A., Sizer, A. R., Rees, H., and Roberts, M. H. T. (1989). Afferent projections to the rostral anterior pretectal nucleus of the rat: a possible role in the processing of noxious stimuli. Neuroscience 29, 685-694.

Fundin, B. T., Rice, F. L., Pfaller, K., and Arvidsson, J. (1994). The innervation of the mystacial pad in the adult rat studied by anterograde transport of HRP conjugates. Exp. Brain Res. 99, 233-246.

Furuta, T., Kaneko, T., and Deschênes, M. (2009). Septal neurons in barrel cortex derive their receptive field input from the lemniscal pathway. $J$. Neurosci. 29, 4089-4095.

Furuta, T., Timofeeva, E., Nakamura, K., Okamoto-Furuta, K., Togo, M., Kaneko, T., and Deschenes, M. (2008). Inhibitory gating of vibrissal inputs in the brainstem. J. Neurosci. 28, 1789-1797.

Furuta, T., Urbain, N., Kaneko, T., and Deschênes, M. (2010). Corticofugal control of vibrissa-sensitive neurons in the interpolaris nucleus of the trigeminal complex. J. Neurosci. 30, 1832-1838.

Gabernet, L., Jadhav, S. P., Feldman, D. E., Carandini, M., and Scanziani, M. (2005). Somatosensory integration controlled by dynamic thalamocortical feed-forward inhibition. Neuron 48, 315-327.

Galvez, R., Weiss, C., Cua, S., and Disterhoft, J. (2009). A novel method for precisely timed stimulation of mouse whiskers in a freely moving preparation: application for delivery of the conditioned stimulus in trace eyeblink conditioning. J. Neurosci. Methods 177, 434-439.

Gandhi, N. J., and Katnani, H. A. (2011). Motor functions of the superior colliculus. Annu. Rev. Neurosci. 34, 205-231.

Ganmor, E., Katz, Y., and Lampl, I. (2010). Intensity-dependent adaptation of cortical and thalamic neurons is controlled by brainstem circuits of the sensory pathway. Neuron 66, 273-286.

Gao, P., Hattox, A. M., Jones, L. M., Keller, A., and Zeigler, H. P. (2003). Whisker motor cortex ablation and whisker movement patterns. Somatosens. Mot. Res. 20 191-198.

Gellman, R., Gibson, A. R., and Houk, J. C. (1985). Inferior olivary neurons in the awake cat: detection of contact and passive body displacement. J. Neurophysiol. 54, 40-60.

Gentet, L. J., Avermann, M., Matyas, F., Staiger, J. F., and Petersen, C. C. H. (2010). Membrane potential dynamics of GABAergic neurons in the barrel cortex of behaving mice. Neuron 65, 422-435.

Gerdjikov, T. V., Bergner, C. G., Stüttgen, M. C., Waiblinger, C., and Schwarz, C. (2010). Discrimination of vibrotactile stimuli in the rat whisker system: behavior and neurometrics. Neuron 65, 530-540.

Gibb, W. R. G., and Lees, A. J. (1988). The relevance of the Lewy body to the pathogenesis of idiopathic Parkinson's disease. J. Neurol. Neurosurg. Psychiatr. 51, 745-752.

Giber, K., Slézia, A., Bokor, H., Bodor, A. L., Ludányi, A., Katona, I., and
Acsády, L. (2008). Heterogeneous output pathways link the anterior pretectal nucleus with the zona incerta and the thalamus in rat. $J$. Comp. Neurol. 506, 122-140.

Gibson, A. R., Horn, K. M., and Pong, M. (2004). Activation of climbing fibers. Cerebellum 3, 212-221.

Gibson, J. M., and Welker, W. I. (1983). Quantitative studies of stimulus coding in first-order vibrissa afferents of rats. 1. Receptive field properties and threshold distributions. Somatosens. Mot. Res. 1, 51-67.

Gioanni, Y., and Lamarche, M. (1985). A reappraisal of rat motor cortex organization by intracortical microstimulation. Brain Res. 344, 49-61.

Gogan, P., Guéritaud, J. P., HorcholleBossavit, G., and Tyc-Dumont, S. (1981). The vibrissal pad as a source of sensory information for the oculomotor system of the cat. Exp. Brain Res. 44, 409-418.

Gompf, H. S., Mathai, C., Fuller, P. M., Wood, D. A., Pedersen, N. P., Saper, C. B., and Lu, J. (2010). Locus ceruleus and anterior cingulate cortex sustain wakefulness in a novel environment. J. Neurosci. 30, 14543-14551.

Gonzales, C., and Chesselet, M. F. (1990). Amygdalonigral pathway: an anterograde study in the rat with Phaseolus vulgaris leucoagglutinin (PHA-L). J. Comp. Neurol. 297, 182-200.

Gottschaldt, K. M., Iggo, A., and Young, D. W. (1973). Functional characteristics of mechanoreceptors in sinus hair follicles of the cat. J. Physiol. (Lond.) 235, 287-315.

Graeff, F. G. (2004). Serotonin, the periaqueductal gray and panic. Neurosci. Biobehav. Rev. 28, 239-259.

Grant, R. A., Mitchinson, B., Fox, C. W., and Prescott, T. J. (2009). Active touch sensing in the rat: anticipatory and regulatory control of whisker movements during surface exploration. J. Neurophysiol. 101, 862-874.

Grinevich, V., Brecht, M., and Osten, P. (2005). Monosynaptic pathway from rat vibrissa motor cortex to facial motor neurons revealed by lentivirus-based axonal tracing. $J$. Neurosci. 25, 8250-8258.

Groenewegen, H. J., and Witter, M. P. (2004). "Thalamus," in The Rat Ner vous System, ed. G. Paxinos, 3rd Edn (Sydney: Academic Press), 407-453.

Grofova, I., Deniau, J. M., and Kitai, S. T. (1982). Morphology of the substantia nigra pars reticulata projection neurons intracellularly labeled with HRP. J. Comp. Neurol. 208, 352-368. 
Groh, A., de Kock, C. P. J., Wimmer, V. C., Sakmann, B., and Kuner, T. (2008). Driver or coincidence detector: modal switch of a corticothalamic giant synapse controlled by spontaneous activity and shortterm depression. J. Neurosci. 28, 9652-9663.

Guillery, R. W., and Harting, J. K. (2003). Structure and connections of the thalamic reticular nucleus: advancing views over half a century. J. Comp. Neurol. 463, 360-371.

Haidarliu, S., and Ahissar, E. (2001). Size gradients of barreloids in the rat thalamus. J. Comp. Neurol. 429, 372-387.

Haidarliu, S., Simony, E., Golomb, D., and Ahissar, E. (2010). Muscle architecture in the mystacial pad of the rat. Anat. Rec. (Hoboken) 293, 1192-1206.

Haiss, F., and Schwarz, C. (2005). Spatial segregation of different modes of movement control in the whisker representation of rat primary motor cortex. J. Neurosci. 25, 1579-1587.

Halata, Z., Grim, M., and Baumann, K. I. (2010). Current understanding of Merkel cells, touch reception and the skin. Expert Rev. Dermatol. 5, 109-116.

Hale, M. W., and Lowry, C. A. (2011). Functional topography of midbrain and pontine serotonergic systems: implications for synaptic regulation of serotonergic circuits. Psychopharmacology (Berl.) 213, 243-264.

Hammond, C., Deniau, J. M., RouzaireDubois, B., and Feger, J. (1978). Pepipheral input to the rat subthalamic nucleus, an electrophysiological study. Neurosci. Lett. 9, 171-176.

Haring, J. H., and Wang, R. Y. (1986). The identification of some sources of afferent input to the rat nucleus basalis magnocellularis by retrograde transport of horseradish peroxidase. Brain Res. 366, 152-158.

Hartings, J. A., Temereanca, S., and Simons, D. J. (2003). Processing of periodic whisker deflections by neurons in the ventroposterior medial and thalamic reticular nuclei. J. Neurophysiol. 90, 3087-3094.

Hartmann, M. J. Z. (2009). Active touch, exploratory movements, and sensory prediction. Integr. Comp. Biol. 49, 681-690.

Hartmann, M. J. Z. (2011). A night in the life of a rat: vibrissal mechanics and tactile exploration. Ann. N. Y. Acad. Sci. 1225, 110-118.

Harvey, M. A., Bermejo, R., and Zeigler, H. P. (2001). Discriminative whisking in the head-fixed rat: optoelectronic monitoring during tactile detection and discrimination tasks. Somatosens. Mot. Res. 18, 211-222.
Hattox, A., Li, Y., and Keller, A. (2003). Serotonin regulates rhythmic whisking. Neuron 39, 343-352.

Hattox, A. M., Priest, C. A., and Keller, A. (2002). Functional circuitry involved in the regulation of whisker movements. J. Comp. Neurol. 442, 266-276.

Hayashi, H. (1980). Distributions of vibrissae afferent fiber collaterals in the trigeminal nuclei as revealed by intra-axonal injection of horseradish peroxidase. Brain Res. 183, 442-446.

Heise, C. E., and Mitrofanis, J. (2004). Evidence for a glutamatergic projection from the zona incerta to the basal ganglia of rats. J. Comp. Neurol. 468, 482-495.

Helmstaedter, M., Sakmann, B., and Feldmeyer, D. (2009). Neuronal correlates of local, lateral, and translaminar inhibition with reference to cortical columns. Cereb. Cortex 19, 926-937.

Hemelt, M. E., and Keller, A. (2008). Superior colliculus control of vibrissa movements. J. Neurophysiol. 100, 1245-1254

Herfst, L. J., and Brecht, M. (2008). Whisker movements evoked by stimulation of single motor neurons in the facial nucleus of the rat. $\mathrm{J}$. Neurophysiol. 99, 2821-2832.

Hikosaka, O., Nakamura, K., and Nakahara, H. (2006). Basal ganglia orient eyes to reward. J. Neurophysiol. 95, 567-584.

Hill, D. N., Bermejo, R., Zeigler, H. P., and Kleinfeld, D. (2008). Biomechanics of the vibrissa motor plant in rat: rhythmic whisking consists of triphasic neuromuscular activity. $J$. Neurosci. 28, 3438-3455.

Hirata, A., Aguilar, J., and CastroAlamancos, M. A. (2006). Noradrenergic activation amplifies bottom-up and top-down signal-to-noise ratios in sensory thalamus. J. Neurosci. 26, 4426-4436.

Hirata, A., and Castro-Alamancos, M. A. (2010). Neocortex network activation and deactivation states controlled by the thalamus. J. Neurophysiol. 103, 1147-1157.

Hirata,A., and Castro-Alamancos, M. A. (2011). Effects of cortical activation on sensory responses in barrel cortex. J. Neurophysiol. 105, 1495-1505.

Hoeflinger, B. F., Bennett-Clarke, C. A., Chiaia, N. L., Killackey, H. P., and Rhoades, R. W. (1995). Patterning of local intracortical projections within the vibrissae representation of rat primary somatosensory cortex. J. Comp. Neurol. 354, 551-563.

Hoffer, Z. S., Hoover, J. E., and Alloway, K. D. (2003). Sensorimotor corticocortical projections from rat barrel cortex have an anisotropic organization that facilitates integration of inputs from whiskers in the same row. J. Comp. Neurol. 466, 525-544.

Hollis, D. E., and Lyne, A. G. (1974). Innervation of vibrissa follicles in the marsupial Trichosurus vulpecula. Aust. J. Zool. 22, 263-276.

Hong, E. Y., Beak, S. K., and Lee, H. S. (2010). Dual projections of tuberomammillary neurons to whisker-related, sensory and motor regions of the rat. Brain Res. 1354 64-73.

Hoogland, P. V., Welker, E., and Van der Loos, H. (1987). Organization of the projections from barrel cortex to thalamus in mice studied with Phaseolus vulgarisleucoagglutinin and HRP. Exp. Brain Res. 68, 73-87.

Hoogland, P. V., Wouterlood, F. G. Welker, E., and Van der Loos, H. (1991). Ultrastructure of giant and small thalamic terminals of cortical origin: a study of the projections from the barrel cortex in mice using Phaseolus vulgaris leucoagglutinin (PHA-L). Exp. Brain Res. 87, 159-172.

Hooks, B. M., Hires, S. A., Zhang, Y X., Huber, D., Petreanu, L., Svoboda, K., and Shepherd, G. M. G. (2011). Laminar analysis of excitatory local circuits in vibrissal motor and sensory cortical areas. PLoS Biol. 9, e1000572. doi: 10.1371/journal.pbio. 1000572

Hoshi, E., Tremblay, L., Féger, J., Carras, P. L., and Strick, P. L. (2005) The cerebellum communicates with the basal ganglia. Nat. Neurosci. 8 , 1491-1493.

Huber, D., Petreanu, L., Ghitani, N., Ranade, S., Hromádka, T., Mainen, Z., and Svoboda, K. (2008). Sparse optical microstimulation in barrel cortex drives learned behaviour in freely moving mice. Nature 451, 61-64.

Huerta, M. F., Frankfurter, A., and Harting, J. K. (1983). Studies of the principal sensory and spinal trigeminal nuclei of the rat: projections to the superior colliculus, inferior olive, and cerebellum. J. Comp. Neurol. 220, 147-167.

Hutson, K. A., and Masterton, R. B. (1986). The sensory contribution of a single vibrissa's cortical barrel. $J$. Neurophysiol. 56, 1196-1223.

Hyvärinen, H., Palviainen, A., Strandberg, U., and Holopainen, I. J. (2009). Aquatic environment and differentiation of vibrissae: comparison of sinus hair systems of ringed seal, otter and pole cat. Brain Behav. Evol. 74, 268-279.
Irle, E., and Markowitsch, H. J. (1986). Afferent connections of the substantia innominata/basal nucleus of Meynert in carnivores and primates. J. Hirnforsch. 27, 343-367.

Isokawa-Akesson, M., and Komisaruk, B. R. (1987). Difference in projections to the lateral and medial facial nucleus: anatomically separate pathways for rhythmical vibrissa movement in rats. Exp. Brain Res. 65, 385-398.

Ito, M. (1988). Response properties and topography of vibrissa-sensitive VPM neurons in the rat. J. Neurophysiol. 60, 1181-1197.

Ito, M. (2000). Mechanisms of motor learning in the cerebellum. Brain Res. 886, 237-245.

Izraeli, R., and Porter, L. L. (1995). Vibrissal motor cortex in the rat: connections with the barrel field. Exp. Brain Res. 104, 41-54.

Jacquin, M. F., Barcia, M., and Rhoades, R. W. (1989a). Structure-function relationships in rat brainstem subnucleus interpolaris: IV. Projection neurons. J. Comp. Neurol. 282, 45-62.

Jacquin, M. F., Golden, J., and Rhoades, R. W. (1989b). Structure-function relationships in rat brainstem subnucleus interpolaris: III. Local circuit neurons. J. Comp. Neurol. 282, 24-44.

Jacquin, M. F., and Rhoades, R. W. (1990). Cell structure and response properties in the trigeminal subnucleus oralis. Somatosens. Mot. Res. 7, 265-288.

Jadhav, S. P., and Feldman, D. E. (2010). Texture coding in the whisker system. Curr. Opin. Neurobiol. 20, 313-318.

Jadhav, S. P., Wolfe, J., and Feldman, D. E. (2009). Sparse temporal coding of elementary tactile features during active whisker sensation. Nat. Neurosci. 12, 792-800.

Jin, T. E., Witzemann, V., and Brecht, M. (2004). Fiber types of the intrinsic whisker muscle and whisking behavior. J. Neurosci. 24, 3386-3393.

Joel, D., and Weiner, I. (1997). The connections of the primate subthalamic nucleus: indirect pathways and the open-interconnected scheme of basal ganglia-thalamocortical circuitry. Brain Res. Brain Res. Rev. 23, 62-78.

Jones, B. E. (1990). Immunohistochemical study of choline acetyltransferase-immunoreactive processes and cells innervating the pontomedullary reticular formation in the rat. J. Comp. Neurol. 295, 485-514. 
Jones, B. E. (1991). Noradrenergic locus coeruleus neurons: their distant connections and their relationship to neighboring (including cholinergic and GABAergic) neurons of the central gray and reticular formation. Prog. Brain Res. 88, 15-30.

Jones, L. M., Depireux, D. A., Simons, D. J., and Keller, A. (2004). Robust temporal coding in the trigeminal system. Science 304, 1986-1989.

Joseph, J. W., Shambes, G. M., Gibson, J. M., and Welker, W. (1978). Tactile projections to granule cells in caudal vermis of the rat's cerebellum. Brain Behav. Evol. 15, 141-149.

Kaneda, K., Isa, K., Yanagawa, Y., and Isa, T. (2008). Nigral inhibition of GABAergic neurons in mouse superior colliculus. J. Neurosci. 28, 11071-11078.

Kätzel, D., Zemelman, B. V., Buetfering, C., Wölfel, M., and Miesenböck, G. (2011). The columnar and laminar organization of inhibitory connections to neocortical excitatory cells. Nat. Neurosci. 14, 100-107.

Kelley, A. E., Domesick, V. B., and Nauta, W. J.H. (1982). The amygdalostriatal projection in the rat - an anatomical study by anterograde and retrograde tracing methods. Neuroscience 7, 615-630.

Kennedy, T. T., Grimm, R. J., and Towe, A. L. (1966). The role of cerebral cortex in evoked somatosensory activity in cat cerebellum. Exp. Neurol. 14, 13-32.

Kerr, F. W. L., and Lysak, W. R. (1964). Somatotopic organization of trigeminal-ganglion neurones. Arch. Neurol. 11, 593-602.

Khatri, V., Bermejo, R., Brumberg, J. C., Keller, A., and Zeigler, H. P. (2009). Whisking in air: encoding of kinematics by trigeminal ganglion neurons in awake rats. J. Neurophysiol. 101, 1836-1846.

Killackey, H. P. (1973). Anatomical evidence for cortical subdivisions based on vertically discrete thalamic projections from the ventral posterior nucleus to cortical barrels in the rat. Brain Res. 51, 326-331.

Killackey, H. P., and Sherman, S. M. (2003). Corticothalamic projections from the rat primary somatosensory cortex. J. Neurosci. 23, 7381-7384.

Kim, J. N., Koh, K. S., Lee, E., Park, S. C., and Song, W. C. (2011). The morphology of the rat vibrissal folliclesinus complex revealed by threedimensional computer-aided reconstruction. Cells Tissues Organs 193, 207-214.

Kim, U., and Ebner, F. F. (1999). Barrels and septa: separate circuits in rat barrels field cortex. J. Comp. Neurol. 408, 489-505.

Kim, U., Gregory, E., and Hall, W. C. (1992). Pathway from the zona incerta to the superior colliculus in the rat. J. Comp. Neurol. 321, 555-575.

Kirifides, M. L., Simpson, K. L., Lin, R. C. S., and Waterhouse, B. D. (2001). Topographic organization and neurochemical identity of dorsal raphe neurons that project to the trigeminal somatosensory pathway in the rat. J. Comp. Neurol. 435 , 325-340.

Kita, H. (2007). Globus pallidus external segment. Prog. Brain Res. 160, 111-133.

Kita, H., and Kitai, S. T. (1987). Efferent projections of the subthalamic nucleus in the rat: light and electron microscopic analysis with the PHA-L method. J. Comp. Neurol. $260,435-452$.

Klein, B. G., and Rhoades, R. W. (1985). Representation of whisker follicle intrinsic musculature in the facial motor nucleus of the rat. J. Comp. Neurol. 232, 55-69.

Kleinfeld, D., Berg, R. W., and O'Connor, S. M. (1999). Anatomical loops and their electrical dynamics in relation to whisking by rat. Somatosens. Mot. Res. 16, 69-88.

Knutsen, P. M., Pietr, M., and Ahissar, E. (2006). Haptic object localization in the vibrissal system: behavior and performance. J. Neurosci. 26, 8451-8464.

Kocsis, B., Varga, V., Dahan, L. and Sik, A. (2006). Serotonergic neuron diversity: identification of raphe neurons with discharges timelocked to the hippocampal theta rhythm. Proc. Natl. Acad. Sci. U.S.A. 103, 1059-1064.

Kolmac, C. I., Power, B. D., and Mitrofanis, J. (1998). Patterns of connections between zona incerta and brainstem in rats. J. Comp. Neurol. 396, 544-555.

Koralek, K. A., Jensen, K. F., and Killackey, H. P. (1988). Evidence for two complementary patterns of thalamic input to the rat somatosensory cortex. Brain Res. 463 346-351.

Koralek, K. A., Olavarria, J., and Killackey, H. P. (1990). Areal and laminar organization of corticocortical projections in the rat somatosensory cortex. J. Comp. Neurol. 299, 133-150.

Krakauer, J. W., and Shadmehr, R. (2006). Consolidation of motor memory. Trends Neurosci. 29, 58-64.

Kremer, Y., Léger, J. F., Goodman, D., Brette, R., and Bourdieu, L. (2011).
Late emergence of the vibrissa direction selectivity map in the rat barrel cortex. J. Neurosci. 31, 10689-10700.

Krupa, D. J., Matell, M. S., Brisben, A. J., Oliveira, L. M., and Nicolelis, M. A. L. (2001). Behavioral properties of the trigeminal somatosensory system in rats performing whiskerdependent tactile discriminations. $J$. Neurosci. 21, 5752-5763.

Krupa, D. J., Wiest, M. C., Shuler, M. G., Laubach, M., and Nicolelis, M. A. L. (2004). Layer-specific somatosensory cortical activation during active tactile discrimination. Science 304 1989-1992.

Kuo, M. C., Rasmusson, D. D., and Dringenberg, H. C. (2009). Inputselective potentiation and rebalancing of primary sensory cortex afferents by endogenous acetylcholine. Neuroscience 163, 430-441.

Kwegyir-Afful, E. E., and Keller, A. (2004). Response properties of whisker-related neurons in rat second somatosensory cortex. J. Neurophysiol. 92, 2083-2092.

Lam, Y. W., and Sherman, S. M. (2010). Functional organization of the somatosensory cortical layer 6 feedback to the thalamus. Cereb. Cortex 20, 13-24.

Lam, Y. W., and Sherman, S. M. (2011). Functional organization of the thalamic input to the thalamic reticular nucleus. J. Neurosci. 31, 6791-6799.

Land, P. W., Buffer, S. A. Jr., and Yaskosky, J. D. (1995). Barreloids in adult rat thalamus: threedimensional architecture and relationship to somatosensory cortical barrels. J. Comp. Neurol. $355,573-588$

Lang, E. J. (2002). GABAergic and glutamatergic modulation of spontaneous and motor-cortex-evoked complex spike activity. J. Neurophysiol. 87, 1993-2008.

Lang, E. J., Sugihara, I., and Llinás, R. (2006). Olivocerebellar modulation of motor cortex ability to generate vibrissal movements in rat. J. Physiol. (Lond.) 571, 101-120.

Langford, D. J., Bailey, A. L., Chanda, M. L., Clarke, S. E., Drummond, T. E., Echols, S., Glick, S., Ingrao, J., Klassen-Ross, T., Lacroix-Fralish, M. L., Matsumiya, L., Sorge, R. E. Sotocinal, S. G., Tabaka, J. M., Wong, D., van den Maagdenberg, A. M. J. M., Ferrari, M. D., Craig, K. D., and Mogil, J. S. (2010). Coding of facial expressions of pain in the laboratory mouse. Nat. Methods 7, 447-449.

Larsen, D. D., Wickersham, I. R., and Callaway, E. M. (2007). Retrograde tracing with recombinant rabies virus reveals correlations between projection targets and dendritic architecture in layer 5 of mouse barrel cortex. Front. Neural Circuits 1:5. doi: 10.3389/neuro.04.005.2007

Lavallée, P., Urbain, N., Dufresne, C., Bokor, H., Acsády, L., and Deschênes, M. (2005). Feedforward inhibitory control of sensory information in higher-order thalamic nuclei. J. Neurosci. 25, 7489-7498.

Lazarov, N. E. (2002). Comparative analysis of the chemical neuroanatomy of the mammalian trigeminal ganglion and mesencephalic trigeminal nucleus. Prog. Neurobiol. 66, 19-59.

Leal-Campanario, R., Delgado-García, J. M., and Gruart, A. (2006). Microstimulation of the somatosensory cortex can substitute for vibrissa stimulation during Pavlovian conditioning. Proc. Natl. Acad. Sci. U.S.A. 103, 10052-10057.

Lee, H. S., Kim, M. A., Valentino, R. J., and Waterhouse, B. D. (2003). Glutamatergic afferent projections to the dorsal raphe nucleus of the rat. Brain Res. 963, 57-71.

Lee, M. G., Hassani, O. K., Alonso, A. and Jones, B. E. (2005). Cholinergic basal forebrain neurons burst with theta during waking and paradoxical sleep. J. Neurosci. 25, 4365-4369.

Lee, S., Carvell, G. E., and Simons, D. J. (2008a). Motor modulation of afferent somatosensory circuits. Nat. Neurosci. 11, 1430-1438.

Lee, S. B., Chang, B. J., and Lee, H. S. (2008b). Organization of histamine-immunoreactive, tuberomammillary neurons projecting to the dorsal tier of the substantia nigra compacta in the rat. Brain Res. 1203, 79-88.

Lee, S. B., Lee, H. S., and Waterhouse, B. D. (2008c). The collateral projection from the dorsal raphe nucleus to whisker-related, trigeminal sensory and facial motor systems in the rat. Brain Res. 1214, 11-22.

Leergaard, T. B., Alloway, K. D., Pham, T. A. T., Bolstad, I., Hoffer, Z. S., Pettersen, C., and Bjaalie, J. G. (2004). Three-dimensional topography of corticopontine projections from rat sensorimotor cortex: comparisons with corticostriatal projections reveal diverse integrative organization. J. Comp. Neurol. 478, 306-322.

Leergaard, T. B., Lillehaug, S., De Schutter, E., Bower, J. M., and Bjaalie, J. G. (2006). Topographical organization of pathways from somatosensory cortex through the pontine nucle to tactile regions of the rat cerebellar hemispheres. Eur. J. Neurosci. 24, 2801-2812. 
Lefort, S., Tomm, C., Floyd Sarria, J. C., and Petersen, C. C. H. (2009). The excitatory neuronal network of the $\mathrm{C} 2$ barrel column in mouse primary somatosensory cortex. Neuron 61, 301-316.

Legg, C. R., Mercier, B., and Glickstein, M. (1989). Corticopontine projection in the rat: the distribution of labelled cortical cells after large injections of horseradish peroxidase in the pontine nuclei. J. Comp. Neurol. 286, 427-441.

Leiser, S. C., and Moxon, K. A. (2006). Relationship between physiological response type (RA and SA) and vibrissal receptive field of neurons within the rat trigeminal ganglion. J. Neurophysiol. 95, 3129-3145.

Leiser, S. C., and Moxon, K. A. (2007). Responses of trigeminal ganglion neurons during natural whisking behaviors in the awake rat. Neuron 53, 117-133.

Leite-Almeida, H., Valle-Fernandes, A., and Almeida, A. (2006). Brain projections from the medullary dorsal reticular nucleus: an anterograde and retrograde tracing study in the rat. Neuroscience 140, 577-595.

Li, Y., Erzurumlu, R. S., Chen, C., Jhaveri, S., and Tonegawa, S. (1994). Whisker-related neuronal patterns fail to develop in the trigeminal brainstem nuclei of NMDAR1 knockout mice. Cell 76, 427-437.

Liao, C. C., Chen, R. F., Lai, W. S., Lin, R. C. S., and Yen, C. T. (2010). Distribution of large terminal inputs from the primary and secondary somatosensory cortices to the dorsal thalamus in the rodent. J. Comp. Neurol. 518, 2592-2611.

Lichtenstein, S. H., Carvell, G. E., and Simons, D. J. (1990). Responses of rat trigeminal ganglion neurons to movements of vibrissae in different directions. Somatosens. Mot. Res. 7, 47-65.

Lin, C. S., Nicolelis, M. A. L., Schneider, J. S., and Chapin, J. K. (1990). A major direct GABAergic pathway from zona incerta to neocortex. Science 248, 1553-1556.

Loewenstein, Y., Mahon, S., Chadderton, P., Kitamura, K., Sompolinsky, H., Yarom, Y., and Häusser, M. (2005). Bistability of cerebellar Purkinje cells modulated by sensory stimulation. Nat. Neurosci. 8 , 202-211.

Lu, S. M., and Lin, R. C. S. (1993). Thalamic afferents of the rat barrel cortex: a light- and electron-microscopic study using Phaseolus vulgaris leucoagglutinin as an anterograde tracer. Somatosens. Mot. Res. 10, 1-16.

Lübke, J., Egger, V., Sakmann, B., and Feldmeyer, D. (2000). Columnar organization of dendrites and axons of single and synaptically coupled excitatory spiny neurons in layer 4 of the rat barrel cortex. J. Neurosci. 20, 5300-5311.

Lübke, J., and Feldmeyer, D. (2007). Excitatory signal flow and connectivity in a cortical column: focus on barrel cortex. Brain Struct. Funct. 212, 3-17.

Lumpkin, E. A., Marshall, K. L., and Nelson, A. M. (2010). The cell biology of touch. J. Cell Biol. 191, 237-248.

Ma, P. M. (1991). The barrelettes architectonic vibrissal representations in the brainstem trigeminal complex of the mouse. I. Normal structural organization. J. Comp. Neurol. 309, 161-199.

Ma, T. P., Hu, X. J., Anavi, Y., and Rafols, J. A. (1992). Organization of the zona incerta in the macaque: a Niss and Golgi study. J. Comp. Neurol. 320, 273-290.

Mameli, O., Stanzani, S., Mulliri, G., Pellitteri, R., Caria, M. A., Russo, A., and De Riu, P. (2010). Role of the trigeminal mesencephalic nucleus in rat whisker pad proprioception. Behav. Brain Funct. 6, 69.

Mameli, O., Stanzani, S., Russo, A. Romeo, R., Pellitteri, R., Spatuzza, M., Caria, M. A., and De Riu, P. L. (2008). Hypoglossal nuclei participation in rat mystacial pad control. Pflugers Arch. 456, 1189-1198.

Manning, K. A., Wilson, J. R., and Uhlrich, D. J. (1996). Histamineimmunoreactive neurons and their innervation of visual regions in the cortex, tectum, and thalamus in the primate Macaca mulatta. J. Comp. Neurol. 373, 271-282.

Manns, I. D., Sakmann, B., and Brecht, M. (2004). Sub- and suprathreshold receptive field properties of pyramidal neurones in layers $5 \mathrm{~A}$ and $5 \mathrm{~B}$ of rat somatosensory barrel cortex. $J$. Physiol. (Lond.) 556, 601-622.

Marotte, L. R., Rice, F. L., and Waite, P. M. E. (1992). The morphology and innervation of facial vibrissae in the tammar wallaby, Macropus eugenii. J. Anat. 180, 401-417.

Marti, M., Viaro, R., Guerrini, R., Franchi, G., and Morari, M. (2009). Nociceptin/orphanin FQ modulates motor behavior and primary motor cortex output through receptors located in substantia nigra reticulata. Neuropsychopharmacology 34, 341-355.

Masri, R., Trageser, J. C., Bezdudnaya, T., Li, Y., and Keller, A. (2006). Cholinergic regulation of the posterior medial thalamic nucleus. $J$. Neurophysiol. 96, 2265-2273.

Massion, J. (1988). Red nucleus: past and future. Behav. Brain Res. 28, 1-8.
Matesz, C. (1981). Peripheral and central distribution of fibres of the mesencephalic trigeminal root in the rat. Neurosci. Lett. 27, 13-17.

Matyas, F., Sreenivasan, V., Marbach, F. Wacongne, C., Barsy, B., Mateo, C. Aronoff, R., and Petersen, C. C. H. (2010). Motor control by sensory cortex. Science 330, 1240-1243.

May, P. J. (2006). The mammalian superior colliculus: laminar structure and connections. Prog. Brain Res. 151, 321-378.

May, P. J., Sun, W., and Hall, W. C. (1997). Reciprocal connections between the zona incerta and the pretectum and superior colliculus of the cat. Neuroscience 77, 1091-1114.

McGinty, D. J., and Harper, R. M. (1976). Dorsal raphe neurons: depression of firing during sleep in cats. Brain Res. 101, 569-575.

McHaffie, J. G., and Stein, B. E. (1982). Eye movements evoked by electrical stimulation in the superior colliculus of rats and hamsters. Brain Res. 247, 243-253.

McMullen, N. T., Smelser, C. B., and Rice, F. L. (1994). Parvalbumin expression reveals a vibrissa-related pattern in rabbit SI cortex. Brain Res. 660, 225-231.

Meyer, H. S., Wimmer, V. C., Hemberger, M., Bruno, R. M., de Kock, C. P. J., Frick, A., Sakmann, B., and Helmstaedter, M. (2010a). Cell typespecific thalamic innervation in a column of rat vibrissal cortex. Cereb. Cortex 20, 2287-2303.

Meyer, H. S., Wimmer, V. C., Oberlaender, M., de Kock, C. P. J., Sakmann, B., and Helmstaedter, M. (2010b). Number and laminar distribution of neurons in a thalamocortical projection column of rat vibrissal cortex. Cereb. Cortex 20, 2277-2286.

Mihailoff, G. A. (1993). Cerebellar nuclear projections from the basilar pontine nuclei and nucleus reticularis tegmenti pontis as demonstrated with PHA-L tracing in the rat. J. Comp. Neurol. 330, 130-146.

Mihailoff, G. A. (1995). Orthograde axonal transport studies of projections from the zona incerta and pretectum to the basilar pontine nuclei in the rat. J. Comp. Neurol. 360, 301-318.

Mihailoff, G. A., Kosinski, R. J., Azizi, S. A., and Border, B. G. (1989). Survey of noncortical afferent projections to the basilar pontine nuclei: a retrograde tracing study in the rat. $J$. Comp. Neurol. 282, 617-643.

Miller, E. H. (1975). A comparative study of facial expressions of two species of pinnipeds. Behaviour 53 268-284.
Misgeld, U. (2004). Innervation of the substantia nigra. Cell Tissue Res. 318, 107-114.

Miskolczy, D. (1931). Über die Endigungsweise der spino-cerebellaren Bahnen. Z. Anat. Entwicklungsgesch. 96, 537-542.

Mitchinson, B., Martin, C. J., Grant, R. A., and Prescott, T. J. (2007). Feedback control in active sensing: rat exploratory whisking is modulated by environmental contact. Proc. Biol. Sci. 274, 1035-1041.

Mitrofanis, J. (2005). Some certainty for the "zone of uncertainty"? Exploring the function of the zona incerta. Neuroscience 130, 1-15.

Mitrofanis, J., and Mikuletic, L. (1999). Organisation of the cortical projection to the zona incerta of the thalamus. J. Comp. Neurol. 412, 173-185.

Miyashita, E., Keller, A., and Asanuma, H. (1994). Input-output organization of the rat vibrissal motor cortex. Exp. Brain Res. 99, 223-232.

Miyashita, E., and Mori, S. (1995). The superior colliculus relays signals descending from the vibrissal motor cortex to the facial nerve nucleus in the rat. Neurosci. Lett. 195 , 69-71.

Molinari, H. H., Schultze, K. E., and Strominger, N. L. (1996). Gracile, cuneate, and spinal trigeminal projections to inferior olive in rat and monkey. J. Comp. Neurol. 375, 467-480.

Moore, R. Y., and Bloom, F. E. (1979). Central catecholamine neuron systems: anatomy and physiology of the norepinephrine and epinephrine systems. Annu. Rev. Neurosci. 2, 113-168.

Morisette, J., and Bower, J. M. (1996). Contribution of somatosensory cortex to responses in the rat cerebellar granule cell layer following peripheral tactile stimulation. Exp. Brain Res. 109, 240-250.

Mowery, T. M., Harrold, J. B., and Alloway, K. D. (2011). Repeated whisker stimulation evokes invariant neuronal responses in the dorsolateral striatum of anesthetized rats: a potential correlate of sensorimotor habits. J. Neurophysiol. 105, 2225-2238.

Muchlinski, M. N. (2010). A comparative analysis of vibrissa count and infraorbital foramen area in primates and other mammals. J. Hum. Evol. 58, 447-473.

Muir, G. D., and Whishaw, I. Q. (2000). Red nucleus lesions impair overground locomotion in rats: a kinetic analysis. Eur. J. Neurosci. 12, 1113-1122. 
Munz, M., Brecht, M., and Wolfe, J. (2010). Active touch during shrew prey capture. Front. Behav. Neurosci. 4:191. doi: 10.3389/fnbeh.2010.00191

Murray, P. D., Masri, R., and Keller, A. (2010). Abnormal anterior pretectal nucleus activity contributes to central pain syndrome. J. Neurophysiol. 103, 3044-3053.

Naito, A., and Kita, H. (1994). The cortico-nigral projection in the rat: an anterograde tracing study with biotinylated dextran amine. Brain Res. 637, 317-322.

Nambu, A. (2007). Globus pallidus internal segment. Prog. Brain Res. $160,135-150$.

Ndiaye, A., Pinganaud, G., VanderWerf, F., Buisseret-Delmas, C., and Buisseret, P. (2000). Connections between the trigeminal mesencephalic nucleus and the superior colliculus in the rat. Neurosci. Lett. 294, 17-20.

Neimark, M. A., Andermann, M. L., Hopfield, J. J., and Moore, C. I. (2003). Vibrissa resonance as a transduction mechanism for tactile encoding. J. Neurosci. 23, 6499-6509.

Nguyen, Q. T., and Kleinfeld, D. (2005). Positive feedback in a brainstem tactile sensorimotor loop. Neuron 45, 447-457.

Nicolelis, M. A. L., Baccala, L. A., Lin, R. C. S., and Chapin, J. K. (1995a). Sensorimotor encoding by synchronous neural ensemble activity at multiple levels of the somatosensory system. Science 268, 1353-1358.

Nicolelis, M. A. L., Chapin, J. K., and Lin, R. C. S. (1995b). Development of direct GABAergic projections from the zona incerta to the somatosensory cortex of the rat. Neuroscience 65, 609-631.

Nicolelis, M. A. L., Chapin, J. K., and Lin, R. C. S. (1992). Somatotopic maps within the zona incerta relay parallel GABAergic somatosensory pathways to the neocortex, superior colliculus, and brainstem. Brain Res. 577, 134-141.

Nilsson, B. Y. (1969). Structure and function of the tactile hair receptors on the cat's foreleg. Acta Physiol. Scand. 77, 396-416.

O'Connor, D. H., Clack, N. G., Huber, D., Komiyama, T., Myers, E. W., and Svoboda, K. (2010a). Vibrissa-based object localization in head-fixed mice. J. Neurosci. 30, 1947-1967.

O'Connor, D. H., Peron, S. P., Huber, D., and Svoboda, K. (2010b). Neural activity in barrel cortex underlying vibrissa-based object localization in mice. Neuron 67, 1048-1061.
Ojima, H. (1994). Terminal morphology and distribution of corticothalamic fibers originating from layers 5 and 6 of cat primary auditory cortex. Cereb. Cortex 4, 646-663.

Oldford, E., and Castro-Alamancos, M. A. (2003). Input-specific effects of acetylcholine on sensory and intracortical evoked responses in the "barrel cortex" in vivo. Neuroscience 117, 769-778.

Parenti, R., Zappalà, A., Serapide, M. F., Pantò, M. R., and Cicirata, F. (2002). Projections of the basilar pontine nuclei and nucleus reticularis tegmenti pontis to the cerebellar nuclei of the rat. J. Comp. Neurol. 452, 115-127.

Passani, M. B., and Blandina, P. (2011). Histamine receptors in the CNS as targets for therapeutic intervention. Trends Pharmacol. Sci. 32, 242-249.

Paul, G., and Gould, D. J. (2010). The red nucleus: past, present, and future. Neuroanatomy 9, 1-3.

Peschanski, M. (1984). Trigeminal afferents to the diencephalon in the rat. Neuroscience 12, 465-487.

Petersen, C. C. H. (2007). The functional organization of the barrel cortex. Neuron 56, 339-355.

Petersen, C. C. H., and Sakmann, B. (2000). The excitatory neuronal network of rat layer 4 barrel cortex. $J$. Neurosci. 20, 7579-7586.

Petreanu, L., Huber, D., Sobczyk, A., and Svoboda, K. (2007). Channelrhodopsin-2-assisted circuit mapping of long-range callosal projections. Nat. Neurosci. 10 663-668.

Petreanu, L., Mao, T., Sternson, S. M., and Svoboda, K. (2009). The subcellular organization of neocortical excitatory connections. Nature 457, 1142-1145.

Pidoux, M., Mahon, S., Deniau, J. M., and Charpier, S. (2011). Integration and propagation of somatosensory responses in the corticostriatal pathway: an intracellular study in vivo. $J$. Physiol. (Lond.) 589, 263-281.

Pierret, T., Lavallée, P., and Deschênes, M. (2000). Parallel streams for the relay of vibrissal information through thalamic barreloids. J. Neurosci. 20, 7455-7462.

Pillot, C., Heron, A., Cochois, V., Tardivel-Lacombe, J., Ligneau, X., Schwartz, J. C., and Arrang, J. M. (2002). A detailed mapping of the histamine $\mathrm{H}(3)$ receptor and its gene transcripts in rat brain. Neuroscience 114, 173-193.

Pinault, D. (2004). The thalamic reticular nucleus: structure, function and concept. Brain Res. Brain Res. Rev. 46, 1-31.
Pinault, D., Bourassa, J., and Deschênes, M. (1995). The axonal arborization of single thalamic reticular neurons in the somatosensory thalamus of the rat. Eur. J. Neurosci. 7 , 31-40.

Pinganaud, G., Bernat, I., Buisseret, P., and Buisseret-Delmas, C. (1999). Trigeminal projections to hypoglossal and facial motor nuclei in the rat. J. Comp. Neurol. 415, 91-104.

Popescu, A. T., Popa, D., and Paré, D. (2009). Coherent gamma oscillations couple the amygdala and striatum during learning. Nat. Neurosci. 12, 801-807.

Porter, L. L., and White, E. L. (1983). Afferent and efferent pathways of the vibrissal region of primary motor cortex in the mouse. J. Comp. Neurol. 214, 279-289.

Quessy, S., and Freedman, E. G. (2004). Electrical stimulation of rhesus monkey nucleus reticularis gigantocellularis. I. Characteristics of evoked head movements. Exp. Brain Res. 156, 342-356.

Redgrave, P., Gurney, K., and Reynolds, J. (2008). What is reinforced by phasic dopamine signals? Brain Res. Rev. 58, 322-339.

Reep, R. L., Stoll, M. L., Marshall, C. D., Homer, B. L., and Samuelson, D. A. (2001). Microanatomy of facial vibrissae in the Florida manatee: the basis for specialized sensory function and oripulation. Brain Behav. Evol. 58, 1-14.

Reyes, A., and Sakmann, B. (1999). Developmental switch in the shortterm modification of unitary EPSPs evoked in layer $2 / 3$ and layer 5 pyramidal neurons of rat neocortex. $J$. Neurosci. 19, 3827-3835.

Ricardo, J. A. (1981). Efferent connections of the subthalamic region in the rat. II. The zona incerta. Brain Res. 214, 43-60.

Rice, F. L. (1985). An attempt to find vibrissa-related barrels in the primary somatosensory cortex of the cat. Neurosci. Lett. 53, 169-172.

Rice, F. L. (1993). Structure, vascularization, and innervation of the mystacial pad of the rat as revealed by the lectin Griffonia simplicifolia. J. Comp. Neurol. 337, 386-399.

Rice, F. L., Mance, A., and Munger, B. L. (1986). A comparative light microscopic analysis of the sensory innervation of the mystacial pad. I. Innervation of vibrissal folliclesinus complexes. J. Comp. Neurol. 252, 154-174.

Ritt, J. T., Andermann, M. L., and Moore, C. I. (2008). Embodied information processing: vibrissa mechanics and texture features shape micromotions in actively sensing rats. Neuron 57, 599-613.

Roger, M., and Cadusseau, J. (1985). Afferents to the zona incerta in the rat: a combined retrograde and anterograde study. J. Comp. Neurol. 241, 480-492.

Ruigrok, T. J. H. (2011). Ins and outs of cerebellar modules. Cerebellum. 10, 464-474

Sarko, D. K., Reep, R. L., Mazurkiewicz, J. E., and Rice, F. L. (2007). Adaptations in the structure and innervation of follicle-sinus complexes to an aquatic environment as seen in the Florida manatee (Trichechus manatus latirostris). J. Comp. Neurol. 504, 217-237.

Sarko, D. K., Rice, F. L., and Reep, R. L. (2011). Mammalian tactile hair: divergence from a limited distribution. Ann. N. Y. Acad. Sci. 1225, 90-100.

Satoh, K., and Fibiger, H. C. (1986). Cholinergic neurons of the laterodorsal tegmental nucleus: efferent and afferent connections. J. Comp. Neurol. 253, 277-302.

Schneider, J. S., Morse, J. R., and Lidsky, T. I. (1982). Somatosensory properties of globus pallidus neurons in awake cats. Exp. Brain Res. 46, 311-314.

Schubert, D., Kötter, R., and Staiger, J. F. (2007). Mapping functional connectivity in barrel-related columns reveals layer- and cell type-specific microcircuits. Brain Struct. Funct. 212, 107-119.

Schubert, D., Staiger, J. F., Cho, N., Kötter, R., Zilles, K., and Luhmann, H. J. (2001). Layer-specific intracolumnar and transcolumnar functional connectivity of layer $\mathrm{V}$ pyramidal cells in rat barrel cortex. J. Neurosci. 21, 3580-3592.

Schwarz, C., and Möck, M. (2001). Spatial arrangement of cerebro-pontine terminals. J. Comp. Neurol. 435, 418-432.

Semba, K., and Fibiger, H. C. (1992). Afferent connections of the laterodorsal and the pedunculopontine tegmental nuclei in the rat: a retro- and antero-grade transport and immunohistochemical study. J. Comp. Neurol. 323, 387-410.

Semba, K., and Komisaruk, B. R. (1984). Neural substrates of two different rhythmical vibrissal movements in the rat. Neuroscience 12,761-774.

Shambes, G. M., Gibson, J. M., and Welker, W. (1978). Fractured somatotopy in granule cell tactile areas of rat cerebellar hemispheres revealed by micromapping. Brain Behav. Evol. $15,94-140$ 
Sheibani, V., and Farazifard, R. (2006). Dorsal raphe nucleus stimulation modulates the response of layers IV and $\mathrm{V}$ barrel cortical neurons in rat. Brain Res. Bull. 68, 430-435.

Shepherd, G. M. G., and Svoboda, K. (2005). Laminar and columnar organization of ascending excitatory projections to layer $2 / 3$ pyramidal neurons in rat barrel cortex. J. Neurosci. 25, 5670-5679.

Shosaku, A., Kayama, Y., and Sumitomo, I. (1984). Somatotopic organization in the rat thalamic reticular nucleus. Brain Res. 311, 57-63.

Simons, D. J. (1978). Response properties of vibrissa units in rat SI somatosensory neocortex. J. Neurophysiol. 41, 798-820.

Simons, D. J. (1985). Temporal and spatial integration in the rat SI vibrissa cortex. J. Neurophysiol. 54, 615-635.

Simons, D. J., and Carvell, G. E. (1989). Thalamocortical response transformation in the rat vibrissa/barrel system. J. Neurophysiol. 61, 311-330.

Simony, E., Bagdasarian, K., Herfst, L., Brecht, M., Ahissar, E., and Golomb, D. (2010). Temporal and spatial characteristics of vibrissa responses to motor commands. J. Neurosci. 30, 8935-8952.

Simpson, K., Wang, Y., and Lin, R. C. S. (2008). Patterns of convergence in rat zona incerta from the trigeminal nuclear complex: light and electron microscopic study. J. Comp. Neurol. 507, 1521-1541.

Smith, J. B., and Alloway, K. D. (2010). Functional specificity of claustrum connections in the rat: interhemispheric communication between specific parts of motor cortex. $J$. Neurosci. 30, 16832-16844.

Smith, J. C., Abdala, A. P. L., Rybak, I. A., and Paton, J. F. R. (2009). Structural and functional architecture of respiratory networks in the mammalian brainstem. Philos. Trans. R. Soc. Lond. B Biol. Sci. 364, 2577-2587.

Smith, Y., Raju, D. V., Pare, J. F., and Sidibe, M. (2004). The thalamostriatal system: a highly specific network of the basal ganglia circuitry. Trends Neurosci. 27, 520-527.

Spreafico, R., Barbaresi, P., Weinberg, R. J., and Rustioni, A. (1987). SII-projecting neurons in the rat thalamus: a single- and double-retrograde-tracing study. Somatosens. Res. 4, 359-375.

Stapley, P. J., and Drew, T. (2009). The pontomedullary reticular formation contributes to the compensatory postural responses observed following removal of the support surface in the standing cat. $\mathrm{J}$. Neurophysiol. 101, 1334-1350.
Steindler, D. A. (1985). Trigeminocerebellar, trigeminotectal, and trigeminothalamic projections: a double retrograde axonal tracing study in the mouse. J. Comp. Neurol. 237, 155-175.

Stephens, R. J., Beebe, I. J., and Poulter, T. C. (1973). Innervation of the vibrissae of the California sea lion, Zalophus californianus. Anat. Rec. 176, 421-441.

Stüttgen, M. C., and Schwarz, C. (2008). Psychophysical and neurometric detection performance under stimulus uncertainty. Nat. Neurosci. 11, 1091-1099.

Sun, Q. Q., Huguenard, J. R., and Prince, D. A. (2006). Barrel cortex microcircuits: thalamocortical feedforward inhibition in spiny stellate cells is mediated by a small number of fastspiking interneurons. J. Neurosci. 26, 1219-1230.

Swadlow, H. A. (2002). Thalamocortical control of feed-forward inhibition in awake somatosensory 'barrel' cortex. Philos. Trans. R. Soc. Lond. B Biol. Sci. 357, 1717-1727.

Swenson, R. S., and Castro, A. J. (1983). The afferent connections of the inferior olivary complex in rats. An anterograde study using autoradiographic and axonal degeneration techniques. Neuroscience 8, 259-275.

Swenson, R. S., Kosinski, R. J., and Castro, A. J. (1984). Topography of spinal, dorsal column nuclear, and spinal trigeminal projections to the pontine gray in rats. J. Comp. Neurol. $222,301-311$

Swenson, R. S., Sievert, C. F., Terreberry, R. R., Neafsey, E. J., and Castro, A. J. (1989). Organization of cerebral cortico-olivary projections in the rat. Neurosci. Res. 7, 43-54.

Syed, E. C. J., Sharott, A., Moll, C. K. E., Engel, A. K., and Kral, A. (2011). Effect of sensory stimulation in rat barrel cortex, dorsolateral striatum and on corticostriatal functional connectivity. Eur. J. Neurosci. $33,461-470$.

Szwed, M., Bagdasarian, K., and Ahissar, E. (2003). Encoding of vibrissal active touch. Neuron 40, 621-630.

Szymonowicz, W. (1895). Beiträge zur Kenntniss der Nervenendigungen in Hautgebilden. Arch. Mikrosk. Anat. $45,624-654$.

Takahashi, K., Lin, J. S., and Sakai, K. (2006). Neuronal activity of histaminergic tuberomammillary neurons during wake-sleep states in the mouse. J. Neurosci. 26, 10292-10298.

Taylor, A. M., and Lieberman, A. R. (1987). Ultrastructural organisation of the projection from the superior colliculus to the ventral lateral geniculate nucleus of the rat. $J$. Comp. Neurol. 256, 454-462.

ten Donkelaar, H. J. (1988). Evolution of the red nucleus and rubrospinal tract. Behav. Brain Res. 28, 9-20.

Tepper, J. M., Abercrombie, E. D., and Bolam, J. P. (2007). Basal ganglia macrocircuits. Prog. Brain Res. 160 3-7.

Terenzi, M. G., Zagon, A., and Roberts, M. H. T. (1995). Efferent connections from the anterior pretectal nucleus to the diencephalon and mesencephalon in the rat. Brain Res. 701, 183-191.

Teune, T. M., van der Burg, J., van der Moer, J., Voogd, J., and Ruigrok, T. J. (2000). Topography of cerebellar nuclear projections to the brain stem in the rat. Prog. Brain Res. 124, 141-172.

Thakkar, M. M. (2011). Histamine in the regulation of wakefulness. Sleep Med. Rev. 15, 65-74.

Theyel, B. B., Llano, D. A., and Sherman, S. M. (2010). The corticothalamocortical circuit drives higher-order cortex in the mouse. Nat. Neurosci. 13, 84-88.

Thomson, M. A., Piat, G., Cordonnier, V., Ellouze-Kallel, L., DelhayeBouchaud, N., and Mariani, J. (1989). Representation of vibrissae inputs through the climbing fiber pathway in lobule VII of the adult rat cerebellar vermis. Brain Res. 488 241-252.

Timofeeva, E., Dufresne, C., Sik, A. Zhang, Z. W., and Deschênes, M. (2005). Cholinergic modulation of vibrissal receptive fields in trigeminal nuclei. J. Neurosci. 25 , 9135-9143.

Timofeeva, E., Mérette, C., Émond, C., Lavallée, P., and Deschénes, M. (2003). A map of angular tuning preference in thalamic barreloids. J. Neurosci. 23, 10717-10723.

Tlamsa, A. P., and Brumberg, J. C. (2010). Organization and morphology of thalamocortical neurons of mouse ventral lateral thalamus. Somatosens. Mot. Res. 27, 34-43.

Torigoe, Y., Blanks, R. H., and Precht, W. (1986a). Anatomical studies on the nucleus reticularis tegmenti pontis in the pigmented rat. I. Cytoarchitecture, topography, and cerebral cortical afferents. J. Comp. Neurol. 243, 71-87.

Torigoe, Y., Blanks, R. H., and Precht, W. (1986b). Anatomical studies on the nucleus reticularis tegmenti pontis in the pigmented rat. II. Subcortical afferents demonstrated by the retrograde transport of horseradish peroxidase. J. Comp. Neurol. $243,88-105$.
Towal, R. B., and Hartmann, M. J. (2006). Right-left asymmetries in the whisking behavior of rats anticipate head movements. J. Neurosci. 26, 8838-8846.

Towal, R. B., and Hartmann, M. J. (2008). Variability in velocity profiles during free-air whisking behavior of unrestrained rats. J. Neurophysiol. 100, 740-752.

Towal, R. B., Quist, B. W., Gopal, V., Solomon, J. H., and Hartmann, M. J. Z. (2011). The morphology of the rat vibrissal array: a model for quantifying spatiotemporal patterns of whisker-object contact. PLoS Comput. Biol. 7, e1001120. doi: 10.1371/journal.pcbi.1001120

Trageser, J. C., Burke, K. A., Masri, R., Li, Y., Sellers, L., and Keller, A. (2006). State-dependent gating of sensory inputs by zona incerta. $J$. Neurophysiol. 96, 1456-1463.

Trageser, J. C., and Keller, A. (2004). Reducing the uncertainty: gating of peripheral inputs by zona incerta. $J$. Neurosci. 24, 8911-8915.

Troncoso, J., Múnera, A., and DelgadoGarcía, J. M. (2004). Classical conditioning of eyelid and mystacial vibrissae responses in conscious mice. Learn. Mem. 11, 724-726.

Troncoso, J., Múnera, A., and DelgadoGarcía, J. M. (2007). Learningdependent potentiation in the vibrissal motor cortex is closely related to the acquisition of conditioned whisker responses in behaving mice. Learn. Mem. 14, 84-93.

Urbain, N., Creamer, K., and Debonnel, G. (2006). Electrophysiological diversity of the dorsal raphe cells across the sleep-wake cycle of the rat. J. Physiol. (Lond.) 573, 679-695.

Urbain, N., and Deschênes, M. (2007a). Motor cortex gates vibrissal responses in a thalamocortical projection pathway. Neuron 56, 714-725.

Urbain, N., and Deschênes, M. (2007b). A new thalamic pathway of vibrissal information modulated by the motor cortex. J. Neurosci. 27 12407-12412.

Valdés, J. L., Sánchez, C., Riveros, M. E., Blandina, P., Contreras, M. Farías, P., and Torrealba, F. (2010). The histaminergic tuberomammillary nucleus is critical for motivated arousal. Eur. J. Neurosci. 31, 2073-2085

Van der Loos, H. (1976). Barreloids in mouse somatosensory thalamus. Neurosci. Lett. 2, 1-6.

Van Horn, R. N. (1970). Vibrissae structure in the rhesus monkey. Folia Primatol. 13, 241-285. 
Veinante, P., and Deschênes, M. (1999). Single- and multi-whisker channels in the ascending projections from the principal trigeminal nucleus in the rat. J. Neurosci. 19, 5085-5095.

Veinante, P., and Deschênes, M. (2003). Single-cell study of motor cortex projections to the barrel field in rats. J. Comp. Neurol. 464, 98-103.

Veinante, P., Jacquin, M. F., and Deschênes, M. (2000a). Thalamic projections from the whiskersensitive regions of the spinal trigeminal complex in the rat. J. Comp. Neurol. 420, 233-243.

Veinante, P., Lavallée, P., and Deschênes, M. (2000b). Corticothalamic projections from layer 5 of the vibrissal barrel cortex in the rat. J. Comp. Neurol. 424, 197-204.

Verberne, A. J. M., and Struyker Boudier, H. A. J. (1991). Midbrain central grey: regional haemodynamic control and excitatory amino acidergic mechanisms. Brain Res. 550, 86-94.

Vianna, D. M. L., and Brandão, M. L. (2003). Anatomical connections of the periaqueductal gray: specific neural substrates for different kinds of fear. Braz. J. Med. Biol. Res. 36, 557-566.

Villanueva, L., Bouhassira, D., Bing, Z., and Le Bars, D. (1988). Convergence of heterotopic nociceptive information onto subnucleus reticularis dorsalis neurons in the rat medulla. $J$. Neurophysiol. 60, 980-1009.

Vincent, S. B. (1913). The tactile hair of the white rat. J. Comp. Neurol. 23, $1-36$.

von Heimendahl, M., Itskov, P. M., Arabzadeh, E., and Diamond, M. E. (2007). Neuronal activity in rat barrel cortex underlying texture discrimination. PLoS Biol. 5, e305. doi: 10.1371/journal.pbio.0050305

Voogd, J., and Glickstein, M. (1998). The anatomy of the cerebellum. Trends Neurosci. 21, 370-375.

Voorn, P., Vanderschuren, L. J. M. J., Groenewegen, H. J., Robbins, T. W., and Pennartz, C. M. A. (2004). Putting a spin on the dorsal-ventral divide of the striatum. Trends $\mathrm{Neu}$ rosci. 27, 468-474.

Waite, P. M. E., and Jacquin, M. F. (1992). Dual innervation of the rat vibrissa: responses of trigeminal ganglion cells projecting through deep or superficial nerves. J. Comp. Neurol. 322, 233-245.
Wanaverbecq, N., Bodor, A. L., Bokor, H., Slézia, A., Lüthi, A., and Acsády, L. (2008). Contrasting the functional properties of GABAergic axon terminals with single and multiple synapses in the thalamus. J. Neurosci. 28, 11848-11861.

Waterhouse, B. D., Devilbiss, D., Seiple, S., and Markowitz, R. (2004). Sensorimotor-related discharge of simultaneously recorded, single neurons in the dorsal raphe nucleus of the awake, unrestrained rat. Brain Res. 1000, 183-191.

Welker, C. (1971). Microelectrode delineation of fine grain somatotopic organization of $(\mathrm{SmI})$ cerebral neocortex in albino rat. Brain Res. 26, 259-275.

Welker, C., and Sinha, M. M. (1972). Somatotopic organization of Smll cerebral neocortex in albino rat. Brain Res. 37, 132-136.

Welker, C., and Woolsey, T. A. (1974). Structure of layer IV in the somatosensory neocortex of the rat: description and comparison with the mouse. J. Comp. Neurol. 158, 437-453.

Welker, E., Hoogland, P. V., and Van der Loos, H. (1988). Organization of feedback and feedforward projections of the barrel cortex: a PHA-L study in the mouse. Exp. Brain Res. 73, 411-435.

Welker, W. I. (1964). Analysis of sniffing of the albino rat. Behaviour 22, 223-244.

Wenk, G. L. (1997). The nucleus basalis magnocellularis cholinergic system: one hundred years of progress. $\mathrm{Neu}$ robiol. Learn. Mem. 67, 85-95.

Westby, G. W. M., Collinson, C., and Dean, P. (1993). Excitatory drive from deep cerebellar neurons to the superior colliculus in the rat: an electrophysiological mapping study. Eur. J. Neurosci. 5, 1378-1388.

White, E. L., and DeAmicis, R. A. (1977). Afferent and efferent projections of the region in mouse $\mathrm{SmL}$ cortex which contains the posteromedial barrel subfield. J. Comp. Neurol. 175, 455-481.

Williams, M. N., Zahm, D. S., and Jacquin, M. F. (1994). Differential foci and synaptic organization of the principal and spinal trigeminal projections to the thalamus in the rat. Eur. J. Neurosci. 6, 429-453.

Wimmer, V. C., Bruno, R. M., de Kock, C. P. J., Kuner, T., and Sakmann,
B. (2010). Dimensions of a projection column and architecture of VPM and POm axons in rat vibrissal cortex. Cereb. Cortex 20, 2265-2276.

Wineski, L. E. (1985). Facial morphology and vibrissal movement in the golden hamster. J. Morphol. 183, 199-217.

Wise, S. P., and Jones, E. G. (1977). Somatotopic and columnar organization in the corticotectal projection of the rat somatic sensory cortex. Brain Res. 133, 223-235.

Wolfe, J., Hill, D. N., Pahlavan, S., Drew, P. J., Kleinfeld, D., and Feldman, D. E. (2008). Texture coding in the rat whisker system: slipstick versus differential resonance. PLoS Biol. 6, e215. doi: 10.1371/journal.pbio.0060215

Woolf, N. J. (1991). Cholinergic systems in mammalian brain and spinal cord. Prog. Neurobiol. 37, 475-524.

Woolsey, T. A., and Van der Loos, H. (1970). The structural organization of layer IV in the somatosensory region (SI) of mouse cerebral cortex. The description of a cortical field composed of discrete cytoarchitectonic units. Brain Res. 17, 205-242.

Woolsey, T. A., Welker, C., and Schwartz, R. H. (1975). Comparative anatomical studies of the SmI face cortex with special reference to the occurrence of "barrels" in layer IV. J. Comp. Neurol. 164, 79-94.

Woolston, D. C., La Londe, J. R., and Gibson, J. M. (1983). Corticofugal influences in the rat on responses of neurons in the trigeminal nucleus interpolaris to mechanical stimulation. Neurosci. Lett. 36, 43-48.

Wouterlood, F. G., Sauren, Y. M. H. F., and Steinbusch, H. W. M. (1986). Histaminergic neurons in the rat brain: correlative immunocytochemistry, Golgi impregnation, and electron microscopy. J. Comp. Neurol. 252, 227-244.

Wright, A. K., Norrie, L., Ingham, C. A. Hutton, E. A. M., and Arbuthnott, G. W. (1999). Double anterograde tracing of outputs from adjacent "barrel columns" of rat somatosensory cortex. Neostriatal projection patterns and terminal ultrastructure. Neuroscience 88, 119-133.

Wright, A. K., Ramanathan, S., and Arbuthnott, G. W. (2001). Identification of the source of the bilateral projection system from cortex to somatosensory neostriatum and an exploration of its physiological actions. Neuroscience 103, 87-96.

Yatim, N., Billig, I., Compoint, C., Buisseret, P., and Buisseret-Delmas, C. (1996). Trigeminocerebellar and trigemino-olivary projections in rats. Neurosci. Res. 25, 267-283.

Yohro, T. (1977). Structure of the sinus hair follicle in the big-clawed shrew, Sorex unguiculatus. J. Morphol. 153, 333-353.

Yu, C., Derdikman, D., Haidarliu, S., and Ahissar, E. (2006). Parallel thalamic pathways for whisking and touch signals in the rat. PLoS Biol. 4, e124. doi: 10.1371/journal.pbio.0040124

Zagon, A., Terenzi, M. G., and Roberts, M. H. T. (1995). Direct projections from the anterior pretectal nucleus to the ventral medulla oblongata in rats. Neuroscience 65, 253-272.

Zerari-Mailly, F., Pinganaud, G., Dauvergne, C., Buisseret, P., and Buisseret-Delmas, C. (2001) Trigemino-reticulo-facial and trigemino-reticulo-hypoglossal pathways in the rat. J. Comp. Neurol. 429, 80-93.

Zucker, E., and Welker, W. I. (1969). Coding of somatic sensory input by vibrissae neurons in the rat's trigeminal ganglion. Brain Res. 12, 138-156.

Conflict of Interest Statement: The authors declare that the research was conducted in the absence of any commercial or financial relationships that could be construed as a potential conflict of interest.

Received: 08 July 2011; accepted: 26 August 2011; published online: 03 October 2011.

Citation: Bosman LWJ, Houweling AR, Owens CB, Tanke N, Shevchouk OT, Rahmati N, Teunissen WHT, Ju C, Gong W, Koekkoek SKE and De Zeeuw CI (2011) Anatomical pathways involved in generating and sensing rhythmic whisker movements. Front. Integr. Neurosci. 5:53. doi: 10.3389/fnint.2011.00053

Copyright (c) 2011 Bosman, Houweling, Owens, Tanke, Shevchouk, Rahmati, Teunissen, Ju, Gong, Koekkoek and De Zeeuw. This is an open-access article subject to a non-exclusive license between the authors and Frontiers Media $S A$, which permits use, distribution and reproduction in other forums, provided the original authors and source are credited and other Frontiers conditions are complied with. 